QK 。

495

G74H842

1911

BOT, H, - . 


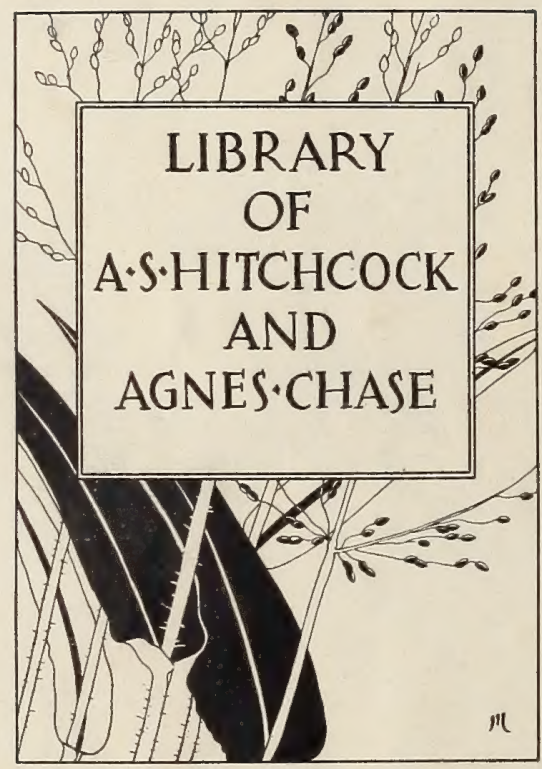





\section{ACTES}

Du

IIII" Congrès International de Botanique

BRUXELLES 1910

PUBLIES

AU NOM DE LA COMMISSION D'ORGANISATION DU CONGRES

PAR

\section{É. DE WILDEMAN}

SECRETAIRE OÉNERAL DE LA COMMISBION ET DU CONGRES

VOL. II

CONFÉRENCES ET MÉMOIRES


BRUXELLES

ALBERT DE BOECK, ÉDITEUR

265, Rue Royale, 265

Tept. Agr, card has Actes 3. Congrèr

Internat. Dot. Bruxelles 1910 .

$2: 185-234 .[1912]$.

Call no

451

C 766 A vol. 2 . 


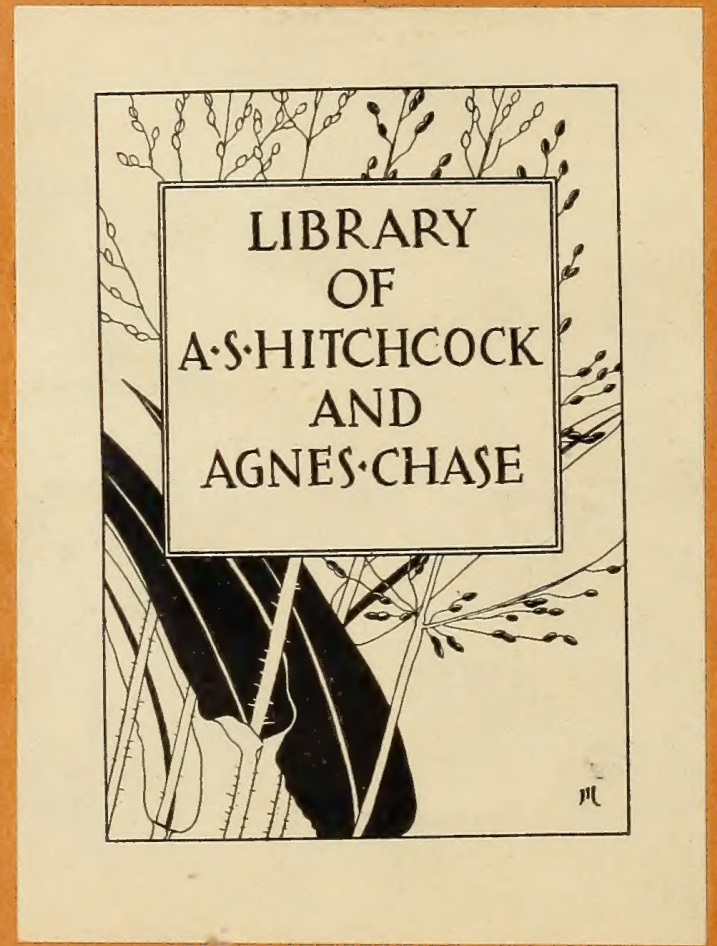




\title{
Notes sur la systématique des Bambusées
}

\author{
par J. Houzeau de Lehaie \\ (Ermitage, Mons-Belgique)
}

\section{SOMMAIRE}

I. Difficultés de la détermination spécifique et ses causes : rareté de la floraison, etc.

II. Insuffisance des caractères floraux. Tâtonnements et leurs conséquences.

- Remèdes. - Exemples.

III. Termes à employer dans les diagnoses; définition de quelques-uns d'entre eux.

IV. Caractères à choisir en dehors des organes floraux.

V. Application de la méthode préconisée à la diagnose et la description de quelques espèces.

Planches. 


\section{Sur la systématique des Bambusées}

Nous avons présenté au Congrès International de Botanique de Mai 1910 une proposition tendant à réglementer d'une façon nouvelle la systé-



Cliché Dr F. A. ForkL.

Fig. 1. - Touffe de Phyl. puberula (Miquel), Makino, en floraison. Division de la plante importée par le Dr Hénon (en l'honneur duquel elle fut alors dénommée Ph. Henoni). Photographie prise au parc public de Morges, Suisse, en 1905. Hauteur des plus grands chaumes 8 mètres environ. Après plusieurs années de floraison complète, la partie aérienne mourut entièrement; puis de petites repousses non florifères furent émises par les rhizomes et la reconstitution de la partie aérienne se poursuivit chaque année avec plus de vigueur. Si l'on a soin de couper tous les chaumes dès les premiers symptômes de floraison, la reconstitution est beaucoup plus rapide. 
matique des bambusées. C'est cette proposition que nous exposons ici plus en détail.

La détermination des Bambusées présente, en général, de très grandes difficultés. Elles proviennent de plusieurs causes:

10 Rareté de floraison de la très grande majorité des espèces;

$2^{\circ}$ Absence d'un travail d'ensemble sur la systématique,

3o Et surtout manque de méthode et, par suite, d'unité dans la façon de rédiger les diagnoses.

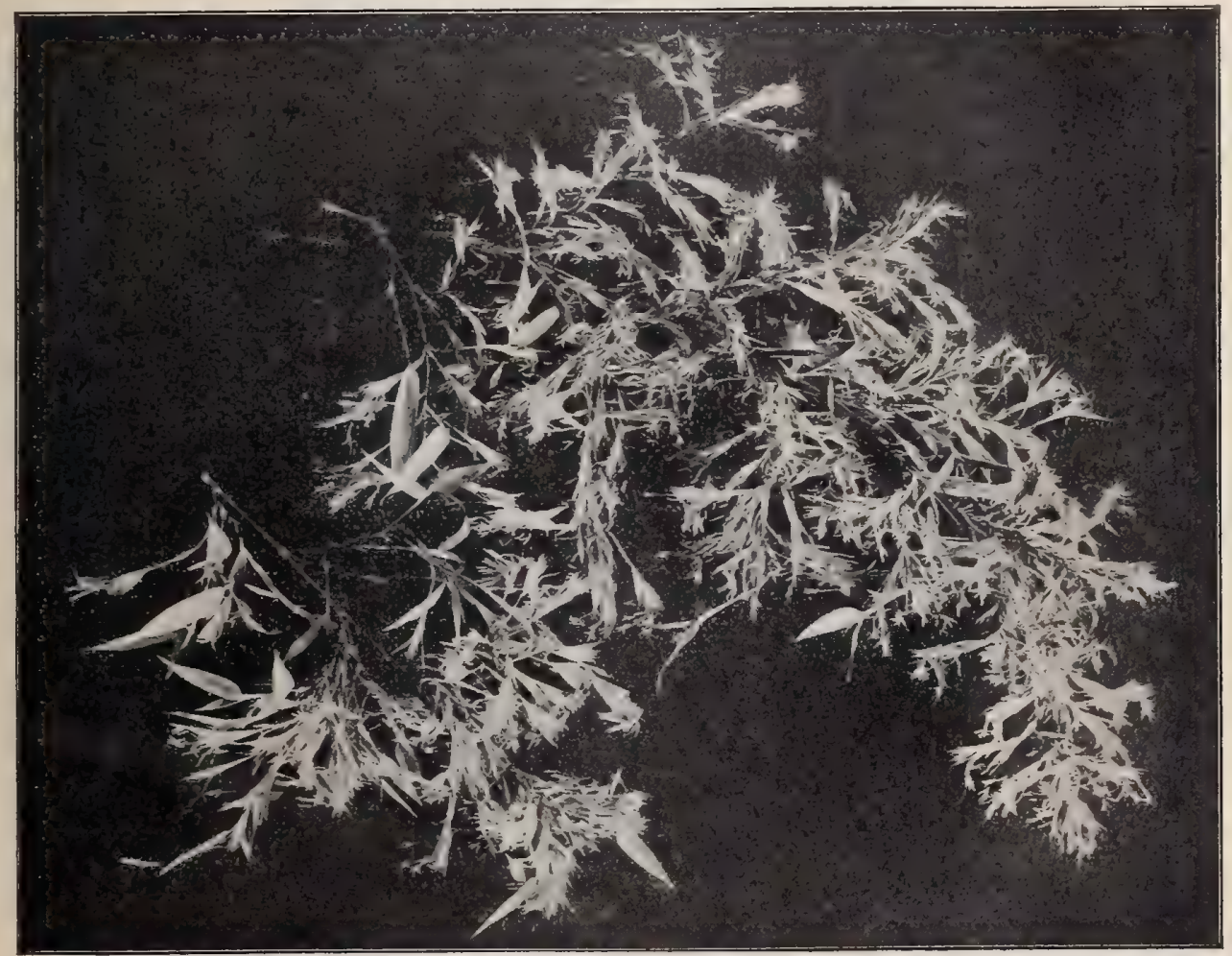

Cliché Dr F. A. Forel.

Fig. 2. - Phyl. puberula (Miquel), Makino. Rameaux en fleurs. Première année de floraison pendant laquelle la panicule est encore plus ou moins feuillée. A cette opulente floraison succéda une fructification d'une pauvreté extrême. Les rares caryopses recueillis donnèrent un très faible pourcentage de germination et les frêles individus qui en provinrent disparurent presque tous. Il nous en reste un seul issu d'un caryopse recueilli à Marlagne par M. Drion. Nous pensons que c'est la seule jeune plante née en Europe encore vivante. C'est peu quand on pense que toutes les plantes cultivées en France ont fleuri entre 1900 et 1910 et que les plantes reçues du Japon pendant la même période ont toutes fleuri également, sauf deux à notre connaissance. 
Les floraisons successives d'une même espèce étant généralement séparées par de longs intervalles (1), le botaniste ne rencontre que très exceptionnellement les espèces en fleurs.

Depuis vingt-huit ans (1883) que nous observons et étudions les bambous, nous en avons cultivé et examiné une centaine d'espèces vivantes; huit seulement nous ont montré leurs inflorescences.

Phyllostachys puberula var. nigra, introduit en 1827, n'a fleuri en Europe qu'en 1900. Avant cette date, aucun botaniste n'en avait décrit les

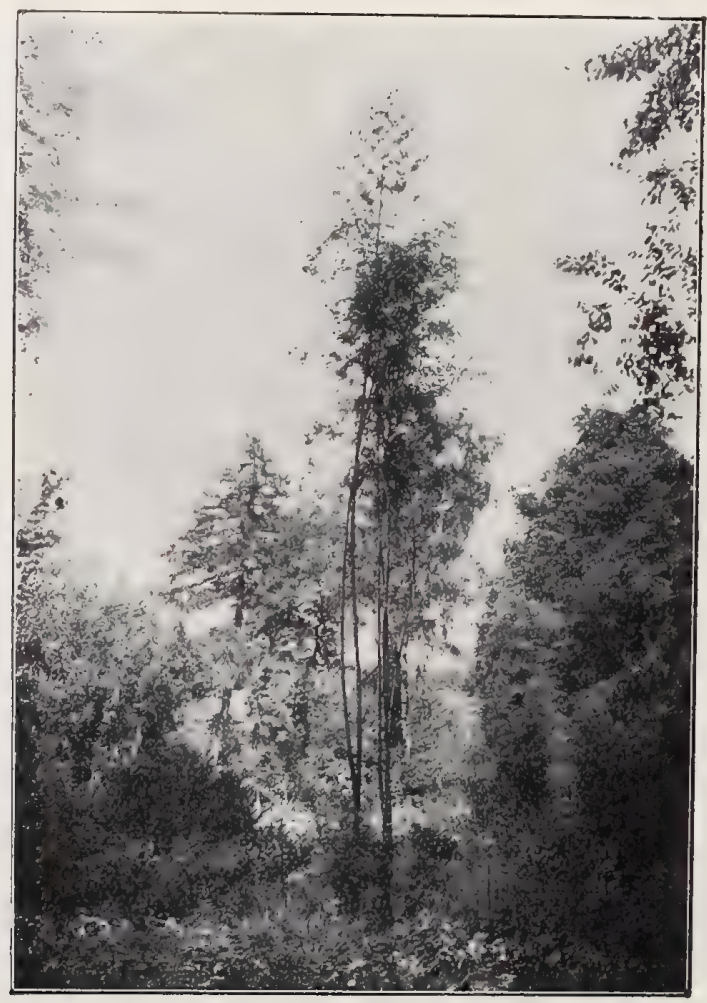

Cliche H. DE L.

Fig. 3. - Spécimen de Phyllostachys mitis, Rivière, planté à l'Ermitage, Mons, Belgique, en avril 1905, photographié en septembre 1907. Hauteur $13 \mathrm{~m} .50$, diamètre des grands chaumes $0 \mathrm{~m} .08$. Cette plante provient de Prafrance (Gard), France. On remarquera que les chaumes sont flexueux; ce n'est pas à cette espèce que l'on a donné le nom de Phyl. flexuosa. Ce dernier nom s'applique à un bambou dont les tiges sont cependant bien droites à l'état de développement complet de l'espèce.

(1) Pour certaines espèces, chaque floraison s'étend à tous les individus, à toute l'aire de dispersion de l'espèce, et aux individus introduits dans les cultures; pour d'autres à un district seulement. 
inflorescences (1). Une réintroduction de cette variété datant de 1846, largement répandue en Europe, n'y a jamais fleuri.

Phyl.mitis, Riv., introduit en 1856, a fleuri en faible exemplaire l'année suivante au Hamma d'Alger. On n'en a ni recueilli, ni décrit les organes floraux. Ils sont donc restés jusqu'à présent inconnus des botanistes, la floraison, en Chine, sa patrie, n'ayant jamais été signalée. La vigueur des plantes ne semble nullement influer sur la date de floraison, car depuis 1856 il a existé à Alger et dans un très grand nombre de localités d'Afrique et d'Europe des plantes faibles ou fortes, de plantation ancienne ou récente, qui se sont toujours montrées réfractaires à la floraison.

D'après G a mble et Brandis, les Arundinaria himalayens fleurissent à des intervalles variant de vingt à trente ans suivant les espèces. Les grandes bambusées de l'Inde anglaise tropicale fleurissent tous les trente, quarante ou même quarante-cinq ans, suivant les espèces, et les fleurs de beaucoup d'entre elles sont encore inconnues.

Deux espèces, introduites avant 1850, viennent de fleurir chez nous. C'est leur première floraison observée en Europe. Les fleurs en étaient inconnues jusqu'ici; nous nous proposons d'en donner prochainement les diagnoses.

Parmi les cent et quelques espèces de bambusées cultivées en Europe, dix-huit seulement ont fleuri, parmi lesquelles deux ou trois ont montré leurs fleurs deux fois, et une seule, pensons-nous, a fructifié trois fois.

Voici d'ailleurs la liste aussi complète que possible des floraisons de bambusées observées ou signalées par des botanistes:

Ar undinaria auricoma, Mitford. Fleurit chaque année à Kew.

aristata, Gamble. Fl. 1868-69. 1890 (Gamble, p. 19).

baviensis, Balansa. F1. 13 juillet 1886 (H. K.) (2).

callosa, Munro. F1. 1885 (Gamble, p. 12).

densiflora, Munro. F1. 1873. 1890 (Gamble, p. 9).

falcata, Nees ab Es. Fl. 1876-1881-1886, Inde. 1886, Kew. 1908, Europe.

falcata var. glomerata. Fl. 1879 (Gamble, p. 14). Fl. chaque année à Kew en serre.

Falconeri, Mitford. Fl. 1821. 1876 (Gamble, p. 21). 1846, Inde (Stapf). 1881 (Brandis). 1908-1909, Ermitage.

floribunda, Thwaites. Fl. 1853 (Gamble, p. 6).

gracilis, Blanchard. Fl. 1830-1860-1890, Europe.

(1) Munro, p. 38.

(2) $($ H. K. $)=$ Herbier de Kew. 
Arundinaria Griffithiana, Munro. Fl. 1835-1856-1872-1889 (Gamble, p. 11). 1910, Inde (notre introduction).

Hindsii, Munro. F1. 1877-1880-1886 (H. K.). 1910 Ermitage.

Hookeriana, Munro. Fl. 1848-1885-1892 (Gamble, p. 17). 1898, Kew.

humillima, Pilger. Fl. novembre 1902 (H. K.).

intermedia, Munro. F1. 1848. 1879 (Gamble, p. 26). 1868 (Anderson). 1889 (H. K.). 1910. Villa Thuret.

japonica, S. et Z. Fl. 1867-68, Algérie, France. 1877-80-86-98 Japon.

Khasiana, Munro. FI. 1850-1889 (Gamble, p. 15).

macrosperma, Michaux: F1. 1803. Amérique boréale.

Pantlingii, Gamble. F1. 1895 (Gamble, p. 129).

polystachya, Kurz. Fl. 1886-1876 (Gamble, p. 7).

Prainii, Gamble. Fl. 1886-1889-1891 (Gamble, p. 21).

racemosa, Munro. FI. 1857-1887-1890 (Gamble, p. 9).

sat, Balansa. FI. 1887.

Simoni, Rivière. Fl. 1876 (Rivière) 1903-10, Europe.

spathiflora, Trinius. F1. 1821 (Wallich). 1881 (Brandis). 1892-93 (Gamble, p. 18).

Trianae, Munro. Fl. 1856 (H. K.).

variabilis, Makino. Fl. 1897 (H. Z.) (1).

variabilis var. Fortunei. F1. 1906-10, Ermitage.

Walkeriana, Munro. Fl. 1861-1888 (Gamble, p. 4).

Wightiana, Nees. Fl. 1882 (Herbier Brandis à Hambourg).

Bambusa Arnhemica, Von Mueller. Fl. 1905, Australie.

arundinacea, Wildenow. FI. 1804-1812-1836-1864-1868-1874-1882-1885-1890 (Her-

bier Brandis). 1894-1907-1908 (Gamble, p. 54).

"balcooa, Roxburg. F1. 1849-1876-1889 (Gamble, p. 43).

Griffithiana, Munro. F1. 1837 (Gamble, p. 49).

khasiana, Munro. F1. 1850-1885 (Gamble, p. 40).

lineata, Munro. Fl. chaque année à Calcutta (Gamble, p. 47).

longispiculata, Gamble in Brandis. Fl. 1845 à Paris. 1910-11, Ermitage.

nana, Roxburg. FI. 1893, Japon et Kew.

nana var. Alphonse Karri. FI. 1908-10, France. Meillereie, Bureau (Dr Ed.)

nana var. gracillima. Fl. 1911, Ermitage.

nutans, Wallich. F1. 1840-1893-94 (Gamble, p. 33), 1886 (Herbier Brandis).

Oliveriana, Gamble. F1. 1893-94 (Gamble, p. 131).

pallida, Munro. FI. 1850-1890 (Gamble, p. 38).

polymorpha, Munro. Fl. 1859-1862-1871-1889 (Gamble, p. 37).

spinosa, Nees. F1. 1874, Hamma. 1910, Inde.

teres, Her. Hamilton. Fl. 1891 (Gamble, p. 34).

tulda, Roxburg. FI. 1859 (H. K.). 1867-68-1872-1876-1884-1886-1892 (Gamble, p. 31). 1880-1910 (Herbier Brandis).

vulgaris, Wendland. FI. 1851-1879-1863-1890-92 (Gamble, p. 44).

(1) $($ H. Z. $)=$ Herbier du Dr C. Schröter à Zurich. 
Cephal ostachyum capitatum, Munro. Fl. 1848-1866-1869-1874-1878-1892 Sikkim. 18301835-1850-1871-72 Khasia (Gamble, p. 105).

" Fuchsianum, Gamble. Fl. 1889-1892 (Gamble, p. 108).

latifolium, Munro. Fl. 1835-1879-1882 (Gamble, p. 107).

pallidum, Munro. FI. 1835-1872-1885-86-1878 (Gamble, p. 106).

" pergracile, Munro. Fl. 1862-1880-81-1890 (Gamble, p. 109). 1859-1861 (Brandis).

1907 Inde (notre introduction). Floraison partielle chaque année.

Chusquea abietifolia, Grisebach. F1. 1884, Kew.

» Mulleri, Munro. F1. 1853-1857 (H. K.).

» pallida, Munro. Fl. 1844 (H. K.).

Dendrocalamus Brandisii, Kurz. F1. 1862-71-1890-94 (Gamble, p. 91). 1880 (Herbier Brandis).

Dendrocalamus calostachyus, Kurz. Fl. 1868-1875 (Gamble, p. 89).

Colletianus, Gamble. F1. 1892 (Gamble, p. 94).

flagellifer, Munro. F1. 1899 (Gamble, p. 92).

giganteus, Munro. Fl. 1860-61-1888, Calcutta, 1897, Burma (Gamble, p. 88). 1899, (Herbier Brandis).

Hamiltonii, Nees et Arnot. Fl. $189+$ (Gamble, p. 86). 1907, Inde (notre introduction.)

Hookeri, Munro. FI. 1850-1881 (Gamble, p. 84).

latiflorus, Munro. Fl. 1894 (Gamble, p. 132).

longifimbriatus, Gamble. F1. 1891 (Gamble, p. 92).

longispathus, Kurz. Fl. 1876-1879-80K-1871-1891 (Gamble, p. 90).

macroculmis (Rivière), H. de L. F1. 1872, Hamma.

membranaceus, Munro. Fl. 1827-1857-1862-1879 (1871-1890), (Gamble, p. 82).

sericeus, Munro. F1. 1858-1871 (Gamble, p. 81).

Sikkimensis, Gamble. F1. 1885 (Gamble, p. 85).

strictus, Nees. F1. 1907-08 (notre réintroduction). Floraison partielle chaque année. 1865-1870-1887-1890-1891 (Brandis).

Dinochloa Tjankorreh. Buse. FI. 1858-1874-75 (Gamble, p. 112).

Gigantochloa Kurzii, Gamble. F1. 1878-1892 (Gamble, p. 65).

latispiculata, Gamble. FI. 1886 (Gamble, p. 68).

ligulata, Gamble. FI. 1891 (Gamble, p. 67).

macrostachya, Kurz. Fl. (1862-1880) (1869-71-1893) 1879-1889) (Gamble, p. 64).

Scortechini, Gamble. Fl. 1886 (Gamble, p. 63).

Wrayi, Gamble. F1. 1888 (Gamble, p. 65).

Glaziophyton mirabile, Franchet. FI. 1888.

Melocanna bambusoides, Trinius. F1. 1863-66-1892 (Gamble, p. 120). 1905 (Herbier Brandis). 1909-10, Calcutta (notre réintroduction).

compactiflorus, Bentham et Hoocker fils. F1. 1871-1878 (?). 1894 (?) (Gamb? ?, p. 95).

Merostachy's capitata, Hooker. Fl. 1867-1873-1878.

»Clausseni, Munro. F1. 1878.

» Fischeriana, Ruprecht. F1. 1842.

» petiolata, Denstedt. Fl. 1874. 
") racemiflora, Fournier. Fl. 1841.

》speciosa, Nees. Fl. 1840.

" Kunthiana, Poiret. F1. 1905 (Herbier Brandis).

Ochlandra Brandisii, Gamble. Fl. 1882 (Brandis), (Gamble, p. 127).

" Rheedii, Bentham et Hooker fils. Fleurit chaque année sans mourir (Bourdillon), (Gamble, p. 122).

"Redleyi, Gamble. Fl. 1892 (Gamble, p. 128).

* stridula, Thwaites. Fl. tous les ans en Trimen (Gamble, p. 123).

"Travancorica, Bentham. Fleurit tous les ans (Bourdillon), 1869 (Gamble, p. 126). 1875-1882 (Bourdillon), 1882 (Herbier Brandis).

Oxytenanthera abyssinica, Munro. F1. 1865 (H. Brandis).

) albo-ciliata, Munro. FI. 1857-1871-1880-1891-92 (Gamble, p. 71). 1909 (notre introduction).

» Borzii, Mattei. Fl. 1909 Erithrée. Introduction en Europe par l'Institut d'agronomie tropicale de Florence. M. Mattei en al fait (à tort, croyons-nous), le genre Houzeaubambus.

1) Bourdilloni, Gamble. Fl. 1889 (Gamble, p. 76).

1) monostygma, Beddome. Fl. 1852-1870-1891 (Gamble, p. 74). 1909 (notre introduct.).

》 nigro-ciliata, Munro. Fl. 1849-1875-1879 (Gamble, p. 69).

Oxytenanthera parviflora, Brandis. Fl. 1880 (Gamble, p. 72), (Herbier Brandis).

" sinuata, Gamble. Fl. 1885 (Gamble, p. 71).

v) Stocksii, Munro. F1. 1884-1889 (Gamble, p. 75).

"Thwaitesii, Munro. Fl. (1847-1871), (1870-1878), (1865-1871), (1883-1890) (Gamble, p. 73).

Phyllostachys aurea, Rivière. Angleterre (H. K.).

" bambusoides, Siebold et Zucc. FI. 1843 (?), (Siebold), (Herbier de Leyde), 19001904 (Makino). Japon (H. Z.).

congesta (?), Rendle. Fl. 1887 (H. K.).

Faberi (?), Rendle. Fl. 1888 (H. K.).

flexuosa, Rivière. Fl. 1876 (Rivière, p. 99).

mitis, Rivière. F1. 1856. Hamma d'Alger.

Nervinii, Hance. F1. 1876.

nidularia, Munro. Fl. 1874.

nidularis, Herb. Paris. Fl. 1887 à Florence (Fenzi).

puberula, (Miquel), Makino. Fl. 1889-1900. Japon 1900-06, Europe.

puberula var. Boryana (Mitford), H. de L. Fl. 1904-11, Europe.

var. fulva (Mitford), H. de L. F1. 1905, Kew.

var. nana (?) Rendle. Fl. 1887, Chine.

var. nigra (Munro), H. de L. Fl. 1904, Kew. 1901, Japon

var. nigra-punctata (Mitford), H. de L. Fl. 1903, Kew et toute l'Europe.

pubescens, H. de L. Fl. 1900, Japon (H. Z.).

Stauntonii, Munro. Fl. 1898 (Gamble).

Pseudosta chy um polymorphum, Munro. Fl.1857-1891 (Gamble, p. 119). 1898 (H. Brandis).

Sasa albo-marginata, Makino et Shibata. FI. 1886, Japon (H. Z.).

"borealis, Mak. et Shib. Fl. 1893-94, Japon (H. Z.). 
Schizostachyum aciculare, Gamble. Fl. 1885 (Gamble, p. 118).

" Brachycladum, Kurz. FI. 1898 (Herb. Brandis).

„Blumei, Nees. Fl. 1889 (Gamble, p. 117).

" latifolium, Gamble. Fl. 1891 (Gamble, p. 117).

» tenue, Gamble. Fl. 1891 (Gamble, p. 115).

Teinostachyum attenuatum, Munro. Fl. 1864-1890 (Gamble, p. 100).

»Dulloa, Munro: Fl. 1880-1889-1892-93 (Gamble, p. 101-02).

„ Griffithii, Munro. Fl. 1889 (Gamble, p. 98).

" Helferi, Gamble. Fl. vers 1888 (Gamble, p. 163).

»Wightii, Beddome. Fl. 1883-84-1887-89 (Gamble, p. 99-100).

Thyrsostachys Oliveri, Gamble. Fl. 1891 (Gamble, p. 59).

» siamensis, Gamble. Fl. 1892 (Gamble, p. 60).

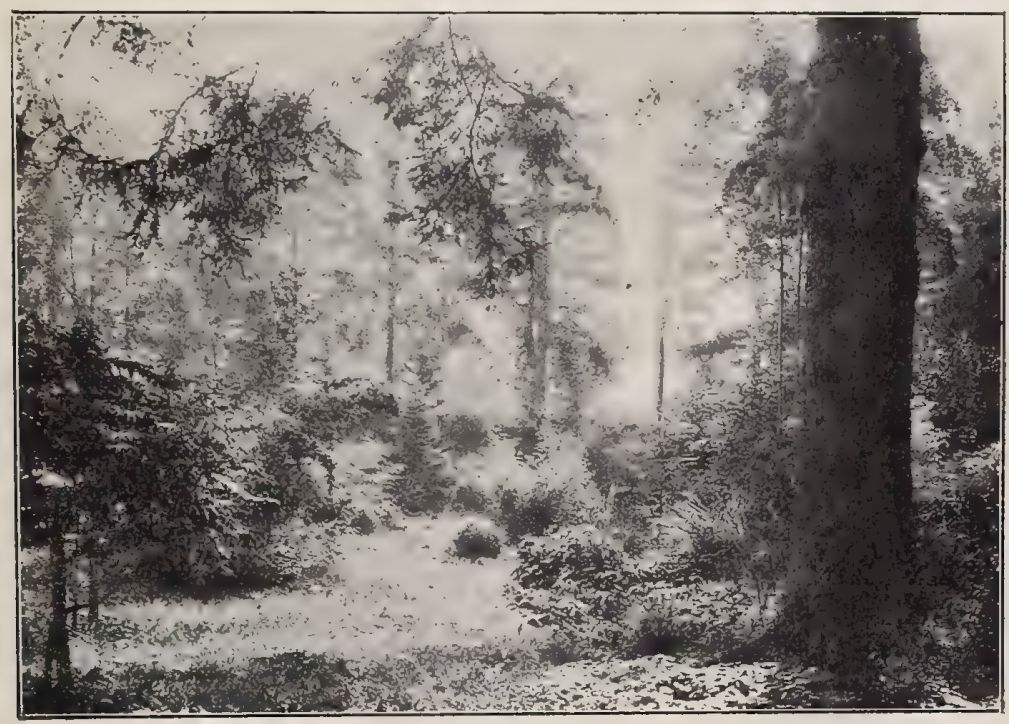

Cliché H. Drion.

Fig. 4.- Vue prise dans le parc de M.H. Drion, de Marlagne, Wépion, Belgique en juillet 1907. En regardant de gauche à droite: Phyl. puberula var. nigra, Ph. puberula. Ph. bam. var. Castilloni. Ph. puberula var. nigra-punctata, Ph. ruscifolia, Ph. pubescens. Ce parc contient 45 espèces et variétés de bambous cultivés en pleine terre.

On voit par ces exemples que beaucoup d'auteurs se sont préoccupés des dates de floraison, on voit aussi combien il est rare, on peut dire exceptionnel, de pouvoir examiner les inflorescences des bambusées que l'on étudie. Il en résulte que les diagnoses reposant uniquement sur les caractères des organes floraux - véritable base de toute systématique- sont pratiquement insuffisantes pour la détermination des plantes que l'on rencontre.

Par exemple, le Prof. T. Makino a donné comme diagnose une description absolument complète et d'une grande exactitude, de l'inflorescence 
de Phyl. pubescens, H. de L. sous le nom erroné de Phyl. mitis, Riv. (1), eh bien il est impossible qu'un botaniste puisse reconnaître la plante ainsi décrite, même en allant parcourir toute la Chine, patrie de cette plante, ou le Japon où elle est largement cultivée, si elle n'est pas en fleurs.

Il ne semble donc pas logique de reléguer les seuls caractères usuels de détermination dans la description, ou de laisser leur introduction dans la diagnose à l'arbitraire du botaniste.

Il faut en effet se rendre compte qu'un prodrome des bambusées, établi d'après les règles aujourd'hui admises, serait presque toujours inutilisable pour les déterminations.

Ces raisons et la pratique nous ont convaincu de la nécessité de comprendre toujours quelques caractères de certains organes végétatifs dans les diagnoses des bambusées. Ces caractères judicieusement choisis sont les seils pratiquement utilisables, nous y insistons, dans l'immense majorité des cas. II nous semble donc logique de les mettre en évidence et de ne plus admettre qu'ils puissent être omis.

La décision de principe que nous demandons de prendre n'est d'ailleurs pas une innovation: c'est la réglementation d'un état de choses existant, mais livré jusqu'ici à l'arbitraire.

La plupart des botanistes, en effet, ont déjà senti la nécessité, en décrivant les bambusées, de joindre certains caractères des organes végétatifs à ceux des organes floraux. Ruprecht, Munro, Makino, S.h ib a t a ont souvent dû insister sur quelques-uns des caractères; mais ils ont toujours semblé le faire avec quelque répugnance et uniquement pour suppléer au manque de caractères tirés des inflorescences.

Rivière, G a mble et Brandis ont montré plus de décision : ils ont toujours employé les caractères tirés de la nervation des feuilles et parfois d'autres, tirés de la feuille, de la gaîne et du chaume. Au moment où la mort l'a frappé, Brand is dressait un tableau de détermination basé uniquement sur les caractères cellulaires des feuilles.

Siebold, au contraire, n'ayant tenu aucun compte des organes végétatifs, certaines de ses diagnoses sont restées incomprises pendant plus de soixante ans. C'est notamment le cas pour la diagnose - accompagnée de figures exactes - de son Phyllostachys bambusoides qui a donné lieu à la confusion la plus inextricable et a fait naître la plus absurde synonymie.

(1) The Botanical Magasine edited by Tokyo botanical Society. Vol. XV, 1901, pp. 68-70. 
Chaque auteur, en effet, qui a fait un travail sur les bambusées, a cité et décrit Phyl. bambusoides S. et Z.; mais par une fatalité inexplicable, ce ne fut jamais celui de Siebold et Zuccarini, ni celui d'aucun de ses devanciers. Si bien que le Phyl. bambusoides de tel auteur n'est jamais celui d'un autre. Des plantes appartenant à trois genres ont été décorées de ce nom. Quand le vrai Ph. bambusoides fut introduit en 1866 par l'amiral du

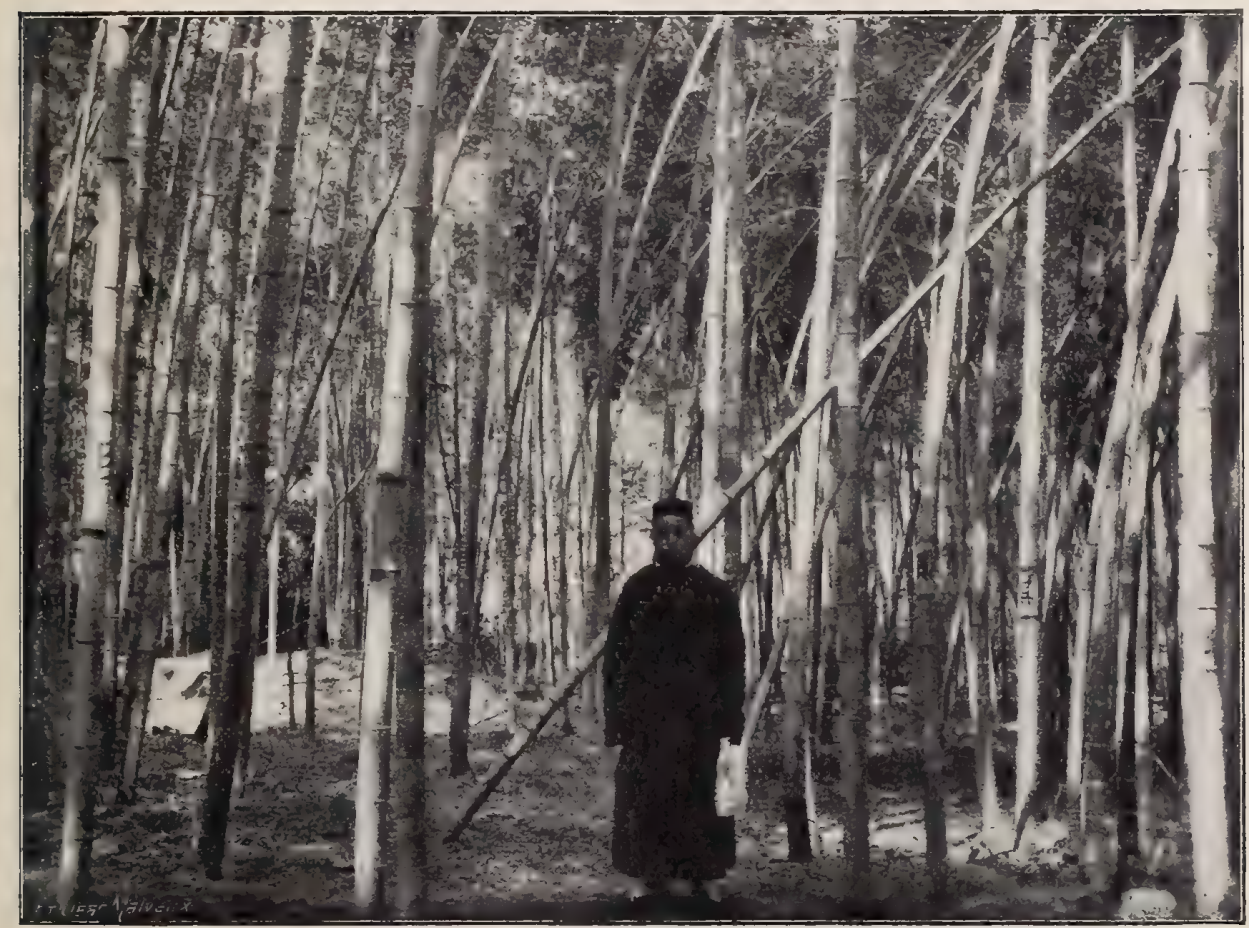

Cliché F. N. MEsER.

Fig. 5. - Forêt de Ph. bambusoides S. et Z. ( $P h$. Quilioi, Rivière) aménagée pour la production du bois d'œuvre. Cette plantation dont les chaumes sont de moyenne grandeur se trouve dans un sol favorable. Cependant les mérithalles sont un peu courts et le vent à déraciné quelques chaumes, ce qui indique qu'il a manqué un peu d'eau à l'époque de pousse des turions; et que le sol est un peu léger, ou qu'il manque à la plantation un abri contre la violence des tempêtes. Le millésime du développement des chaumes est peint sur chacun d'eux en rouge, pour savoir à quel moment il faudra les abattre (quand ils auront quatre ans). Cette plantation ne peut être donnée comme un modèle de culture, car les chaumes sont de grosseur rès variable. Photographí prise en Chine.

Quilio, Rivière ne pouvant l'identifier avec aucune des plantes décrites, le prit pour une plante nouvelle et le décrivit sous le nom de Phyl. Quilioi, Rivière. 
Tout cet imbroglio eût été évité si Sie bold avait décrit ou figuré quelques-uns des organes végétatifs de son Phyl. bambusoides.

Voici le résumé des tâtonnements auxquels divers auteurs se sont livrés dans leur recherche du vrai Phyl. bambusoides, S. et $Z$. La valeur scientifique des auteurs cités indique bien l'étendue et la nature des difficultés avec lesquelles ils se sont trouvés aux prises et montre clairement combien il importe d'épargner pareille tâche à l'avenir.

Dans le Synopsis pl. oec, univ. regni Japonici, auct. Dr de Siebold, nous trouvons p. 4, No 17, la mention suivante:

"No 17. - B. Matake, Japon (V. V.).

"Soboles suppeditant baculos quaesitos, ac culmi juniores victum; adulti ad aedifi"candum, fabricandumque vulgo adhibentur.

Tout ceci s'applique parfaitement à Phyl. bambusoides S. et Z. (Quiloi, Riv.) qui est sans aucun doute l'espèce connue au Japon sous le nom vulgaire de ma-dake. Elle est à tel point cultivée et utilisée au Japon qu'elle ne pouvait avoir échappé à l'observation de Siebold.

Dans les Abhandlungen des Math. Phys. Cl. der Koenige Bayerischen Acad. der Wis., Munich, Vol. III, p. 745 (1843), de Siebold (P. Fr.) et Zuccarini, s'expriment ainsi:

"Phyl. bambusoides, S. et Z. culmi inermes, ramis fistulosis firmis, colore stramineis, nodis prominentibus, ramulis semiverticillatis, basi squamis inanibus serius deciduis ) obtectis iterum ramosis ultimis in speciminibus nostris spiculas $3-5$ subcessiles ferentibus, summo in quovis verticillo apice foliifero; vaginae foliorum glabrae, ore setis (nervis " excurrentibus) deciduis fimbriatae; folia breviter petiolata lamina basi rotundata, lanceo- lata, acuminata, margine scabra, superne glabra, subtus praesertim basin versus subtiliter "pubescentia, firmula, utrinque e nervo medio 4-6 nerva.

》Spiculae primum cylindricae, demum lanceolatae, pollicares; laminae glumis aristae " loco insidentes e basi rotundata lanceolatae acutae, dense multinervae, scabrae, glumis " dimidio breviores; antherae elongatae 5-6" longae. "

N'est-il pas extrêmement remarquable que presque tous les caractères que cette diagnose renferme sont génériques et que par hasard aucun n'est spécifique? La difficulté était surtout grande pour ceux qui ont cherché à faire des identifications d'après les organes végétatifs. Les seuls caractères ne s'appliquant pas à la majorité des espèces du genre sont les suivants: "folia... margine scabra... utrinque e nervo medio 4-6 nervia ".

Dans la description de l'inflorescence il y a une indication plus sérieuse, mais cependant insuffisante: "laminae glumis aristae loco insidentes e basi rotundata lanceolatae, " acutea, dense multinervae, scabrae, glumis dimidio breviores ". Pour ceux qui ont vu les inflorescences des Phyllostachys, le choix se restreignait à deux espèces: bambusoides et pubescens et il fallait, ou bien consulter le Synopsis et identifier d'après le nom vernaculaire, ou bien consulter la planche des Abhandlungen qui représente un ovaire absolument caractéristique. Mais ce fil conducteur était si mince qu'il s'est brisé entre les mains de presque tous ceux qui ont essayé de le suivre, comme nous allons le montrer. 
Miquel dans son "Prolusio florae Japonicae, pars III 》, p. 285, s'exṕrime ainsi:

"Phyllostachys bambusoides, S. et Z... Folia spiciminum sterilium vulgo perspicue * majora quam ramulorum floridorum; illa usque pede longiora, 3 poll. lata, vel $3 / 4^{-1} / 3$ pedis longa, ovato - vel magis lanceolato-oblonga, nervis lateralibus utrinque usque 14 , minorum vero paucioribus 9-7, novella tenere ciliolata; omnia basi abrupta quasi in "petiolum constricta $\%$

Quand Miquel décrit une plante dont les feuilles ont un pied de long, trois pouces de largeur et jusque 14 paires de nervures secondaires, ce n'est pas Phyl. bambusoides qu'il a sous les yeux: c'est probablement Sasa paniculata, M. et Sh.

Voici donc une espèce, et une erreur.

Quand il dit "minorum vero paucioribus 9-7 " il est évident qu'il a sous les yeux des matériaux appartenant à une autre espèce, car chez aucun bambou on ne trouve un écart allant de 7 à 14 dans le nombre des paires de nervures secondaires.

Voici donc une seconde espèce, et une erreur.

Le paragraphe relatif à l'inflorescence: "Palea inferior... jusque: racemos longe "pedunculatos exhibent " se rapporte à une plante appartenant au genre Phyllostachys: soit bambusoides, soit pubescens, il est impossible de dire laquelle.

Voici donc une troisième espèce.

Puis vient un petit paragraphe ainsi conçu: «SAlbo-marginata, foliis lato-albo-mar"ginatis". Voici le Sasa albo-marginata, M. et Sh. décrit comme une variété de Phyl. bambusoides. C'est encore une erreur, d'autant plus complète qu'il n'est pas une variété de l'une des plantes décrites dans la même diagnose.

En résumé, la diagnose de $M i q u e l$ couvre quatre espèces appartenant à deux genres et il n'est même pas certain que l'une soit la bonne. Il était bien difficile, si non impossible, qu'il en fût autrement sans une connaissance approfondie des espèces d'Extrême-Orient. Nous allons voir que bien d'autres auteurs, parmi les plus érudits, s'y sont laissé prendre.

Franchet et Savatier dans leur "Enumeratio plant. in Japonia sponte cresc., 》 hucusque rite cognit. (179), Vol. II, p. 182, s'exprime ainsi:

Phyl. bambusoides, S. et Z......

"Observation. Le Dr Savatier a observé fréquemment cette espèce autour d'Yo"koska, où elle paraît bien spontanée; elle doit fleurir rarement dans cette station....... "Les feuilles sont très souvent bordées d'une large bande jaune; on les trouve dans cet " état mélangées à d'autres tout à fait vertes sur les mêmes rameaux; la var. $\beta$. albo" marginata, Miq. ne paraît donc pas devoir être conservée."

En écrivant ces détails il est évident que les auteurs n'avaient pas sous les yeux des échantillons de Phyl. bambusoides, $\mathrm{S}$. et $\mathrm{Z}$. Tout porte à croire qu'ils avaient en vue le Sasa paniculata, M. et Sh., sans qu'on puisse émettre une certitude. 
Munro voulant concilier les écrits de ses devanciers a synthétisé le gâchis. Consultez les "Transactions of the Linnean Society, vol. XXVII (1886) I. A monograph of the bambuseae p. p. 36-37 \%. Sa diagnose fait des emprunts à Siebold, Griffith et Miquel. Il en résulte qu'il y a une part de vérité: les citations de Siebold et une part d'erreurs, celles des autres. Il est impossible de citer ici son article qui est trop long, ce serait d'ailleurs répéter en partie les textes de Siebold et de Miquel qui précèdent. Il résulte de l'examen du texte de Munro que sa diagnose couvre plusieurs espèces: Ph. bambusoides, le vrai, Sasa albo-marginata et d'autres encore, sans doute. On en trouve une autre preuve dans les échantillons de l'herbier de Kew, étiquetés Ph. bambusoides de la main de Munro, qui appartiennent à plusieurs espèces.

Freeman Mitford s'exprime ainsi dans «The bamboo garden, p. p. 155-157 »:

"Phyllostachys bambusoides. Many and various are the impostors that have laid claim to this title, Arundinaria Simoni especially being a pretender to this or any other name. From Japan under this designation 1 received Ya-dake, the "Arrow Bambos", which turned ont to be nothing but Métaké (1) under another name; and for a long time Phyllostachys viridi-glaucescens (2) was made to do duty for this species, even in Botanic gardens. But at last the real "Simon pure" has been brought over from HongKong, and the cheats are all send out of court discredited and put to shame.

"In some essential feature Phyllostachys bambusoides differs from all the members of the Phyllostachys group which have reached us. "

Nous avons cité toute cette première partie pour montrer que Mitford avait pressenti combien cette question était épineuse. Toutefois, la suite indique que Mitford n'avait pas sous les yeux le vrai Phyl. bambusoides, S. et Z.; en voici un passage caractéristique: "The branches are borne in triplets, the longest as I have alredy said, being in the middle ». Ce caractère exclut la plante en question du Genre Phyllostachys. D'ailleurs, nous avons été examiner la plante de Mitford à Batsford Park, à Kew, à la Meilleraie, et nous en possédons un exemplaire; nous pensons que c'est un Arundinaria, voisin de A. fastuosa (Mitford), H. de L.

(1) Lors d'une ancienne importation qui comprenait à la fois $Y a$ et Mé-daké, les étiquettes de ces deux espèces furent détachées pendant le voyage et interverties par le destinataire. Depuis lors, quand on recevait l'un ou l'autre du Japon, on le prétendait ici en Europe mal dénommé. En un mot, les Européens prétendaient savoir mieux que les Japonais les noms vernaculaires de ces deux espèces. $\mathrm{Ce}$ n'est que tout récemment que l'erreur fut reconnue et que les deux vraies dénominations vernaculaires commencèrent à être appliquées en Europe: Ya-daké à Arundinaria Japonica et Me-dàke à Arundinaria Simoni.

(2) Malheureusement, Mitford ne nous dit pas qui a tenté d'identifier Arundinaria Simoni, puis $P h$, viridi-Glaucescus avec $P h$. bambusoides. 
Sir Ernest Satow. Voyez le texte de cet auteur à la page 46, et la planche en couleur qu'il donne. Il n'y a aucun doute possible, sous le nom de Ph. bambusoides $\mathrm{S}$. et $\mathbf{Z}$. (fig. 5) il décrit et figure Arundinaria japonica, le $Y a$-dake des Japonais.



Cliché H. Drion,

Fig. 6. - Groupe d'Arundinaria japonica, S. et Z. planté à l'Ermitage, Mons, Belgique, en 1898, en sol très humide. Les plus grands chaumes atteignent 5 mètres. Photographie prise en septembre 1907. Division de notre première plante de bambou acquise en 1883 .

Gamble. "Annals of the Royal botanic garden, Calcutta. Vol. VII. The bambuseae of british India, by J. S. Gamble M. A. F. L. S. 1896 ». Pour exposer complètement la façon dont cet auteur a traité la question de Phyl. bambusoides, il faut remonter, p. 26, à sa diagnose du genre. On peut y lire ce qui suit: "Shrubby coespitose bamboos ». (Toutes les espèces connues sont traçantes) "Culms smooth ». (Certaines espèces ont le chaume rugueux, d'autres tomenteux), "flattened on one side " (cela n'est exact que pour la partie du chaume qui porte des branches; certains Phyl. y sont flattened on two sides); "nodes prominent », (en général, le nœud n'est proéminent que dans la portion portant des branches), "internodes rather short" (le contraire serait plus exact); "branches fasciculate at the nodes» (en général, il n'y a que deux branches à chaque noud). Le reste de la diagnose comprend quelques bons caractères génériques, beaucoup de caractères communs à toutes les triglossées et quelques-uns s'appliquant à toute la sous-famille. Il semble donc inutile de pousser plus loin la citation. Cette diagnose d'un genre très peu représenté dans l'Inde anglaise paraît avoir été établie surtout pour couvrir la plante dont nous allons examiner la diagnose spécifique. 
Gamble, p. 27, s'exprime ainsi:

"Phyllostachys bambusoides, S. et Z. A coespitose shrub». (Phyl. bamb. est l'un des plus longuement traçants du genre); "Culms graceful " (c'est l'un des plus rigides, droits, érigés qui existent); "Yellow smooth » (il est peut-être le plus vert du genre); " 10 to $12 \mathrm{ft}$. high, about 5 to $7 \mathrm{in}$. in diameter or less 》 (il atteint 60 à 80 pieds et $0 \mathrm{~m} 20$ de diamètre; mais les individus nains n'en sont pas moins raides, traçants et verts dans un bon climat) "Culm sheaths 6 to $10 \mathrm{in}$. long, 1 to $2 \mathrm{in}$. broad, tin, papery, striate, roun-



Cliché F, N. MEYrR.

Fig. 7. - Les enfants d'un résident européen rapportent les jets de bambous que l'on préparera comme légume. Au milieu un jet de Mosso-chiku (Ph. pubescens). de moyenne grosseur, pesant 2 kilos. A droite deux petits jets de $P h$. puberula. Le $P h$. pubescens produit un légume excellent et de grande consommation: un hectare de Mosso peut donner, si le climat est chaud, le sol léger et bien engraissé, 25,000 kilos de jets frais par an. Dans les régions de grande culture de cette espèce, on sèche une partie de la récolte qui est exportée (en ballots comme la morue séchée de Terre-Neuve) jusqu'en Mandchourie. Phyl. puberula donne moins de produit, Photographie prise en Chine.

det above into a short neck and truncate, the margins produced to meet the ligule and furnished with a few long stiff ciliae" (La gaîne de Phyl. bamb. est bien plus large pour sa hauteur, assez coriace et épaisse, abondamment tachée de brun et de noir, et n'a pas de " neck ». Ce n'est que dans les exemplaires énormes qu'elle est ciliée à la bouche; or Gamble n’a certes pas vu de grandes gaînes, puisqu'il décrit une petite plante). "Leaves 
roundet at the base into a " 1 to '2 in. long, black, hairy petiole » (La feuille de Phyl. bamb. est arrondie à la base en un court pétiole vert, glabre).

Il ne semble donc pouvoir rester aucun doute: Gamble avait sous les yeux une plante qui n'était pas le Phyl. bambusoides S. et Z., qui n'était sans doute pas un Phyllostachys, quand il a rédigé la diagnose des organes végétatifs. Si nous passons à l'examen de la diagnose des organes floraux, dont nous ne citerons pas entièrement le texte, il devient évident que Gamble décrit cette fois un vrai Phyllostachys. Lequel? il est facile de le dire avec certitude: c'est le vrai Phyl. bambusoides, S. et Z, voici pourquoi: "Ovary depressed, ovoid, glabrous, stalked at the base... ». Tous les autres caractères énoncés sont communs aux deux Phyl bambusoides, S. et Z., et pubescens H. de L...

Si à présent on examine la planche 27 de Gamble en tenant compte de la partie suivante de son texte: "Munro has identified Griffith's plant with the well-known China " and Japan species, but apparently no flowers have been seen. I have consequently Taken "my plate from a Hong-Kong specimen in the Calcutta Herbarium ", on ne peut se défendre d'une vive surprise. Gamble a donc réuni sous un même nom, dans une même diagnose:

10 Un échantillon non fleuri récolté aux Mishmi-Hills par Griffith;

20 Un échantillon fleuri envoyé de Hong-Kong.

En résumé, la première partie de la diagnose décrit une petite plante cespiteuse qui nous est inconnue; la seconde décrit le vrai Phyl. bambusoides, S, et Z.

La synonymie demande un sérieux examen:

"Munro 1. c. ». Nous avons vu qu'il faudrait dire "partim »,

"Franch et Sav, 1. c. ». Nous avons montré que c’est une erreur.

"Phyl. megastachya Steudel, Syn. 339 ». Nous avons examiné les échantillons de Steudel et nous les attribuons à Phyl. pubescens.

"B. reticulata, Rupr. Bamb. 58 ». Rien dans la diagnose de Ruprecht ne justifie cette identification qui est tout au moins hasardée.

"Bambusa bifolia, Siebold M. S. (Teste Munro) ». Nous avons vu les échantillons de Siebold, et nous les rapportons à Phyl. pubescens. Il est d'ailleurs bien étonnant que l'on accuse, sans en donner aucune preuve, Siebold d'avoir donné à la même plante les noms de Phyl. bambusoides et de Bambusa bifolia."

Il faut d'ailleurs reconnaître qu'après la publication de son grand ouvrage, Gamble a eu des doutes sur son identification; car à l'article du Phyl. assamica, Sir D. Brandis (1) s'exprime ainsi: "Following Munro, Gamble in Bambuseae united this with Phyl. bam》busoides, S. et Z.; Gamble, t. 27, but he has since informed me that in his opinion the "Indian plant is distinct, "

Voilà donc où conduit le mauvais choix des caractères, le manque de précision et de détails dans leur expression, la concision trop grande et souvent voulue. Eh bien, ce que nous demandons, c'est qu'il n'en soit plus ainsi à l'avenir.

(1) S. D. Brandis. Indian Trees, p. 667, London 1906.

(1) Munro, 1. c. p. 31. 
Il ne faut cependant pas croire que cela soit du passé, et qu'aujourd'hui, les descriptions sont suffisantes sous tous les rapports. Il suffit pour s'en convaincre, d'examiner l'une de celles qui ont le plus récemment paru.

Dans le numéro de janvier 1911 de "Hooker's icones plantarum, Vol. X, part. II, t. 2930 ", le Dr O. Stapf donne la diagnose, accompagnée d'une planche, de Arundinaria tessellata, Munro «...; culmi basi ultra $8 \mathrm{~m} / \mathrm{m}$. diametro, fistulosi (uti rami foliati) graciles... » fistuleux comme les rameaux feuillés. Chez toutes les espèces que nous avons examinées, le rameau feuillé (pas la branche, il faut distinguer) est solide. S'il est fistuleux dans l'espèce décrite, c'est un caractèrè de première importance, à mettre en relief, sans doute suffisant à lui seul pour spécifier la plante. "Foliorum vaginae ad ramorum bases ortae laminis destitutae ». Ceci est un caractère générique. Suivent sept lignes décrivant "laminae perfectae »; il manque le nombre de paires de nervures secondaires; les nombres de nervures tertiaires, de tesselles et de dents marginales au $1 / 4$ de pouce. Les indications au sujet des gaînes du chaume manquent. Si l'échantillon n'en porte pas, l'examen attentif indique toujours si les gaînes sont caduques ou persistantes: caractère indispensable à donner. La planche elle-même est indistincte à ce sujet. Elle donne aussi un profil des nœuds si différents de tout ce que l'on connaît chez les autres bambusées, qu'il y a là un caractère de tout premier ordre. La planche ne mentionne pas le grossissement des numéros 1 à 7 ; c'est regrettable, car quelques chiffres placés auprès de ces dessins eussent donné avec précision des caractères excellents. Le numéro 2 montre une tessellation tantôt en carrés, tantôt en rectangles de $2 \times 1$. C'est là un écart énorme qui constitue un caractère très important. La description devrait nous fixer à ce sujet, car Munro (1) dit: "areolis depressis subquadratis". Se serait-il exprimé ainsi pour décrire des aréoles rectangulaires de $2 \times 1$ ? Au sujet de la ligule, le texte des Hooker's Icones ne dit rien, tandis que la planche figure une ligule entière et glabre. Munro dit: "ligula elongata fimbriata ». Plus loin, il répète "ligula plerumque elongata (brevi fide Nees), troncata et ciliata ». Il y a une autre anomalie: Munro dit "internodiis $1 \frac{1}{2}$ poll. longis ». La planche des Icones nous montre sur un chaume très mince (fide Munro) un entre-nœud de 7 centimètres.

Conclusions. - 10 La planche et la description demandent à être revues, précisées, amendées au point de vue des organes végétatifs; 2 o Est-ce bien Ar. tessellata Munro?; 3o Il y a lieu de rechercher si Munro a eu raison d'identifier le Nastus tessallatus, Nees, avec son Ar. tessallata.

Quant à la description de l'inflorescence, elle est excellente; nous rentrons ici dans le domaine connu où l'on ne tâtonne plus: la diagnose est claire, nette, précise, concise et complète. Il y a cependant encore quelques caractères génériques: "Lodiculae 3.... portica paulo minor».

En voici un second exemple empunté à «R. Pilger in A. Engler, Botanische Jahr»bücher für systematik, Pflanzengeschichte und Pflanzengeographie, t. 39, p. 601, Leipzig 1907."

"Oxytenanthera Braunii, Pilger n. sp.; frutescens, ramuli floriferi inferne foliati " (ceci est un caractère générique), foliorum approximatorum lamina chartacea, oblongo" lanceolata, basi rotundata, superne sensim angustata (tous caractères génériques ou plus 
généraux encore), longius setoso-acutata (ceci est spécifique) glabra (idem), margine scaberrima (margine désigne-t-il tout le tour ou un seul bord? il y a manque de précision); nervi supra vix conspicui, medianus subtus parum prominulus (caractère générique), nervi laterales 7-8 parum conspicui (ceci est spécifique), ligula brevis, truncata (caractère générique). »

En résumé, voici ce qui subsiste de cette description qui, à première vue, paraît assez détaillée et complète: "Frutescens, (folia) longius setoso-acutata, glabra, nervi laterales "7-8 parum conspicui ». Cela est insuffisant pour identifier la plante d'après les organes végétatifs.

La description de l'inflorescence est, comme toujours, beaucoup meilleure, cependant, des caractères génériques s’y sont glissés. Il faut d'ailleurs reconnaître que cet écueil est bien difficile à éviter.

Cette description est donc aussi à refaire.

Le lecteur se demandera peut-être à quoi servait l'herbier de Siebold et Zuccarini conservé à Leyde. En vérité à peu de chose au sujet de Phyl. bambusoides, car il ne contient que des inflorescences et des feuilles, et les pièces de détermination les plus probantes, les gaînes manquaient pour cette espèce.

On constate donc que si les plus anciens auteurs ont négligé. les organes végétatifs, la plupart des botanistes qui ont récemment étudié les bambusées d'une manière approfondie sont entrés dans une voie nouvelle: les uns choisissant certains caractères, que d'autres ont négligés.

Il semble utile qu'il n'en soit plus ainsi à l'avenir; il importe qu'il y ait accord sur le choix. C'est pourquoi il faut préciser quels sont les organes végétatifs et les caractères qui devront être mentionnés dans les diagnoses des bambusées.

A ceux qui objecteraient que nous énumérons des caractères en trop grand nombre, on peut répondre que l'on atteindra ainsi deux résultats précieux :

10 Rendre impossibles les confusions avec les espèces nouvelles que l'on décrira dans la suite;

2o Faciliter le contrôle assurant la détermination, lors même que l'un ou l'autre des organes végétatifs choisis manquerait à l'échantillon examiné.

Nous dirons enfin qu'une planche doit accompagner la diagnose. Certains caractères pourront y être notés avec assez de précision pour que le texte y trouve un complément d'explication et de précision. 


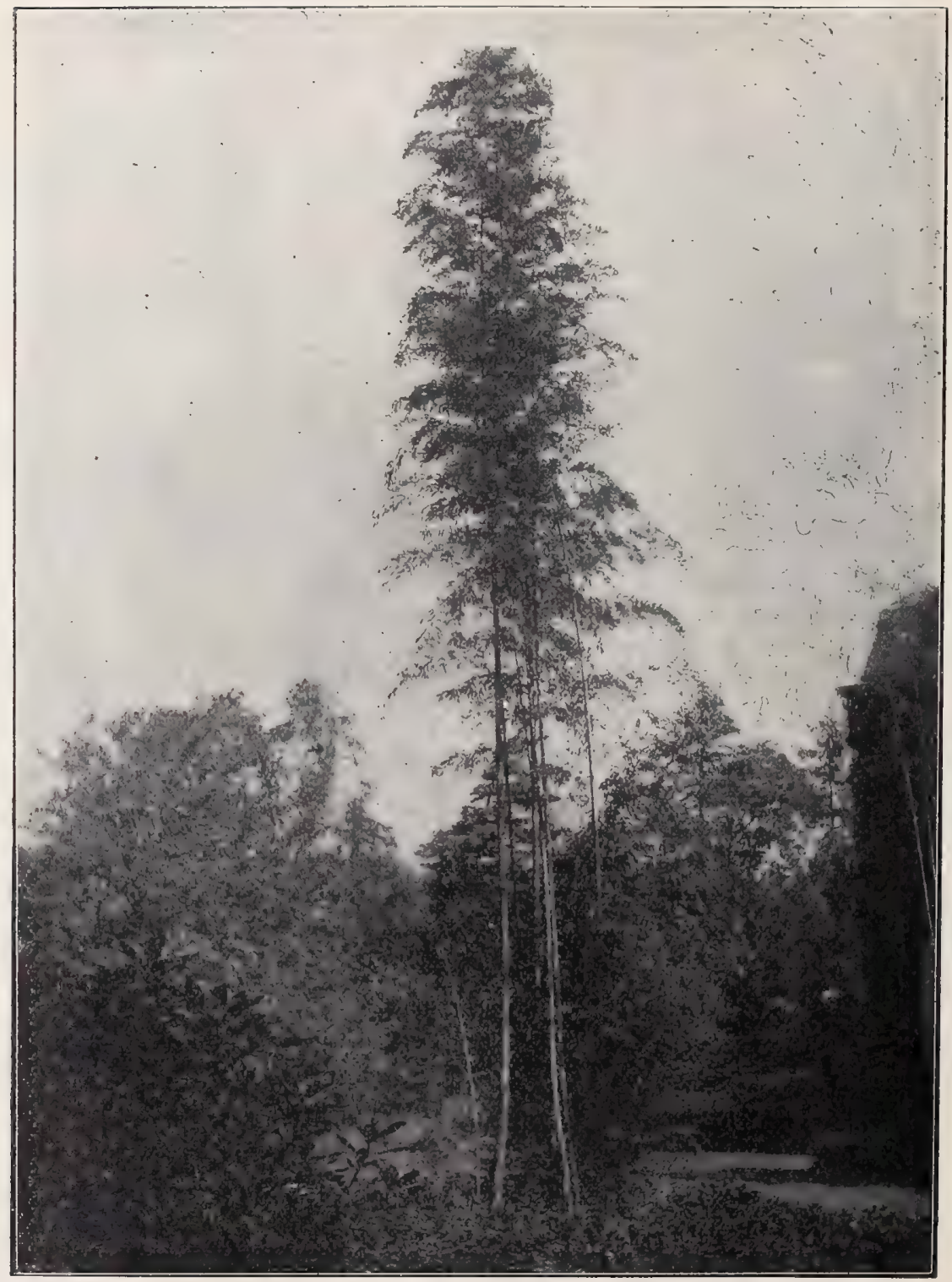

Cliché H. DB L.

Fig. 9. - Spécimen de Ph. pubescens H. de L., planté à l'Ermitage, Mons, Belgique, en avril 1905. Hauteur $16 \mathrm{~m} 50$, circonférence du plus gros chaume 0m33 à 1 mètre de hauteur. Photographie prise en septembre 1907. L'extraordinaire abondance du feuillage menu contraste avec ce que l'on observe dans certaines parties au moins de la Chine. 


\section{Enumeration des caractères choisis.}

La GAINE du chaume prise vers la partie moyenne du chaume. On reconnait qu'une

I. gaine est prise dans la partie moyenne du chaume quand ses appendices sont bien développés sans que le pseudophylle ait pris le caractère d'un limbe de feuille
1. forme,

2. dimensions (par rapport au mérithalle),

3. couleur, maculature,

4. vestiture (externe et interne),

5. aspect des surfaces,

6. appendices (pseudophylle, auricules, ligule),

7. nervation,

8. caducité ou persistance,

9. épaisseur et consistance.

1. terminal du rhizome (bambou cespiteux) ou latéral (bambou traçant),

2. couleur,

3. vestiture,

4. mode de ramification,

5. forme (en section transversale) : cylindrique ou canaliculé,

6. forme du noud (ou profil longitudinal).

III. L'ÉCAILLE BICARÉNÉE, organe ca-

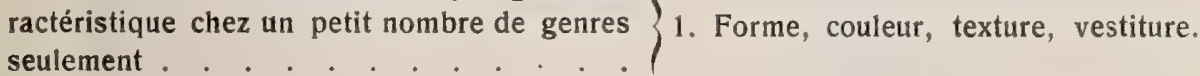

1. Dimensions,

2. forme,

3. couleur,

4. vestiture,

5. dentelure,

6. nervation (nervures secondaires, tertiaires, tesselles),

7. gaînette et ses appendices ligule, auricules, soies) (1).

Un autre point qu'il importe de fixer et préciser, ce sont les termes à employer dans les diagnoses et descriptions pour la désignation des organes des bambusées.

(1) Les soies de la gaînette sont souvent détruites par les intempéries sans être caduques. Ces organes devront donc être étudiés souvent sur de très jeunes feuilles. 


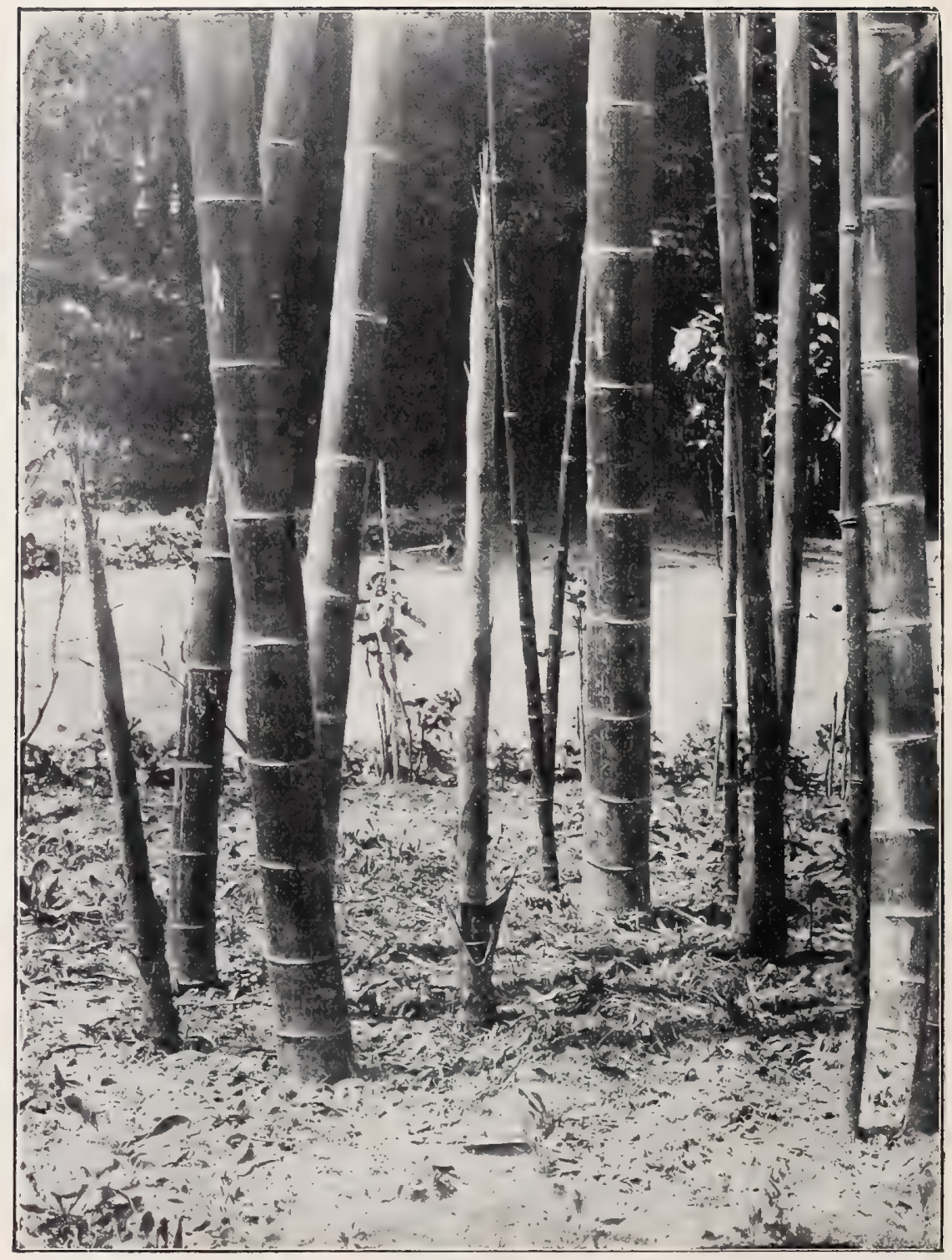

Cliché H. de L.

Fig. 10. - Base de la plante figurée Fig. 9. Photographie prise en juillet 1905. montrant le développement de deux chaumes faibles. 
Parties des bambous enumérées d'après l'ordre de description.

LATIN.

Coespes,
Rhizoma,
Radix,
Radicella,
Caulo-bulbus,

Turio

Culmus,

Sulcus,

Stria,

Merithallium,

Lignum,

Canalis medullaris,

Medulla,

Nodus,

Septum,

Inferior pulvillus,

Cicatrix vaginae,

Superior pulvillus,

Prominentia,

Radix adventiva,

Spino radix,

Gemma,

Ramus,

Spina,

Ramulus,

Vagina,

Pseudophyllum,

Auricula,

Cilium,

Ligula,

Os,

Squama bicarinata,

Vagina rami,

Vaginella,

Folium,

Petiolus,

Limbus, lamina,

Dens,

ANGLAIS.

FrANÇAIS.

Allemand.

Partie souterraine.

stump,
rhizome,
root,
rootlet,
culm-bulb,

souche,

rhizome,

racine,

radicelle,

caulo-bulbe,

\section{Partie aérienne.}

culm-bud,

culm,

groove,

channeling,

internode,

wood,

hollow,

pith,

node,

partition,

inferior projection,

sheath's scar,

superior projection,

protuberance,

advantive root,

root-spine,

bud,

branche,

spine,

branchlet,

culm-sheath,

imperfect blad,

auricle,

bristle,

ligule,

opening,

binerved scale,

branche sheath,

leafe sheath,

leafe,

petiole,

blad,

dent, turion,

chaume,

sillon,

cannelure,

mérithalle,

bois,

canal médullaire,

(étui médullaire), moelle,

nœud,

diaphragme,

bourrelet inférieur,

cicatrice vaginale,

bourrelet supérieur,

protubérance,

racine adventive,

spino-racine,

bourgeon,

branche,

épine,

rameau,

gaîne,

pseudophylle,

auricule,

cil,

ligule,

bouche,

écaille bicarénée,

gaîne secondaire, gaînette,

feuille,

pétiole,

limbe,

dent,
Rasen.

Rhizom, Würzelstock.

Würzel.

Würzelchen.

Stam-bulb.

Stockknospe.

Halm, Stam.

Furche.

Rinne.

\{ Merithallium,

Internodium.

Holz.

Markröhre.

Mark.

Knoten.

Scheidewand.

Unterer Ring.

Oberer Ring.

Hervorragung.

Beiwurzel.

Wurzeldom.

Knospe.

Zweig.

Dorn.

Zweigchen.

Scheide.

Pseudophyllum.

Oehrchen.

Borste.

Blatthauschen.

Offnung, Mund.

Vorblatt.

Zweigscheide.

Schiedchen.

Blatt.

Blattstiel.

Blattfläche.

Zahn. 


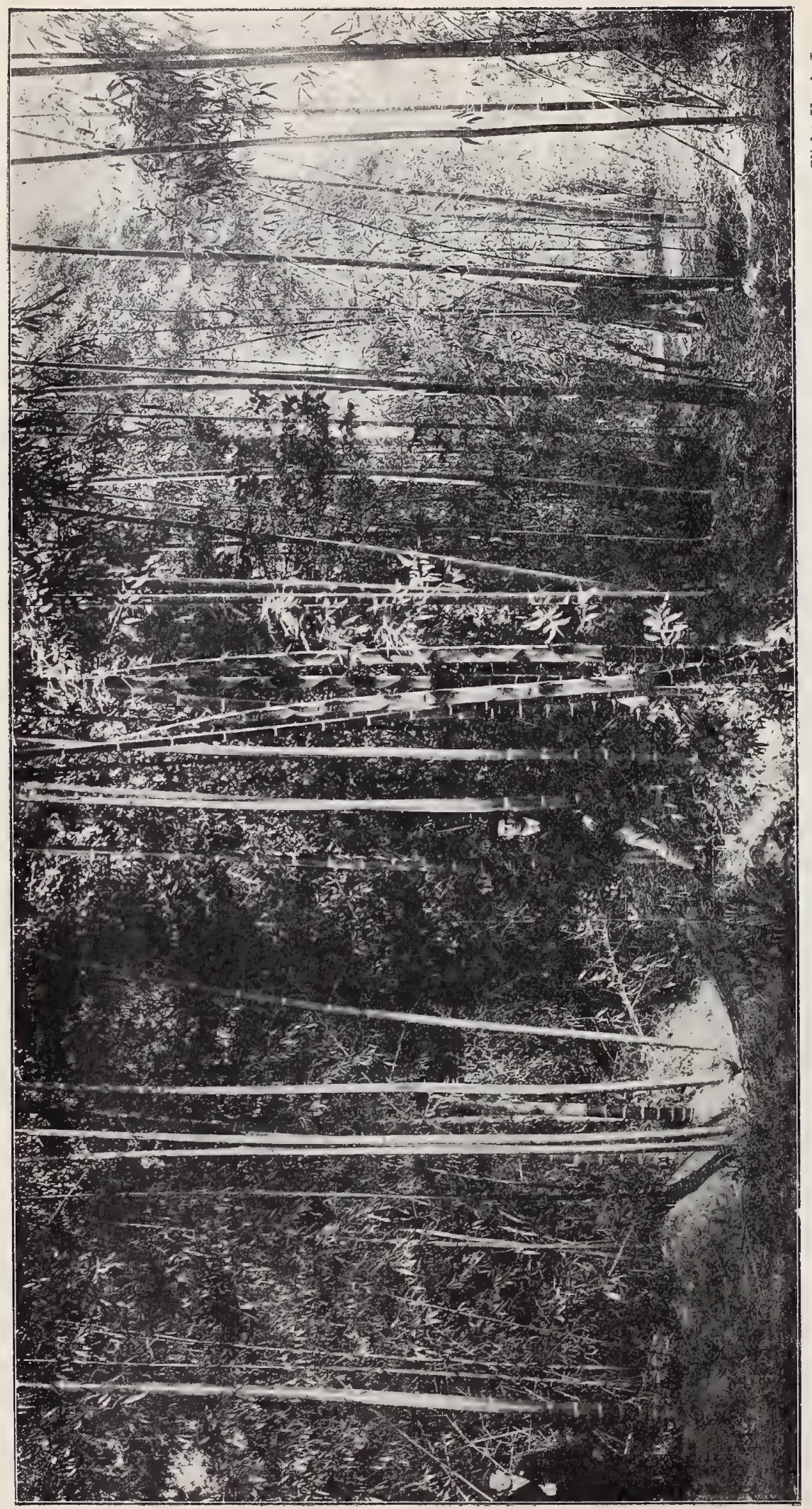

它

ह

ज०

\&.

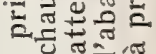

$\stackrel{\circ}{2}$

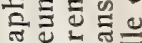

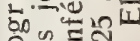

눙엉.

믈

츨 틀 준

-

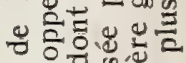

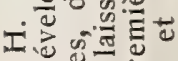

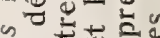

里空范要

范

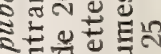

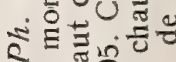

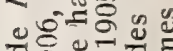

ชิ

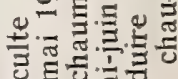

此

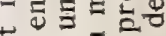

范

I

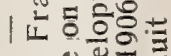

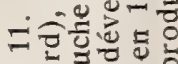

성

II

$8.0 \%$

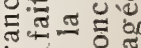

州为要 


\section{Partie aérienne (suite).}

$\begin{array}{llll}\text { Pilus, } & \text { hair, } & \text { poil, } & \text { Haar. } \\ \text { Seta, } & \text { bristle, } & \text { soie, } & \text { Borste. } \\ \text { Nervus medius, } & \text { midrip, } & \text { nervure médiane, } & \text { Mittelrippe. } \\ \text { „secundarius, } & \text { secondary vein, } & \text { secondaire, } & \text { Seiterrippe. } \\ \text { intermediate vein, } & \text { tertiaire, } & \text { Verbindungsnerv. } \\ \text { Tessella, } & \text { transverse vein, } & \text { tésselle, } & \\ \text { Tessellatus, } & \text { tesselate, } & \text { téssellé, } & \text { Schachtressartig. } \\ \text { Area, } & \text { areola, } & \text { aréole, } & \text { Hof. } \\ \text { Punctum. } & \text { pellucid gland, } & \text { point pellucide, } & \text { Punkt. }\end{array}$

\section{Fructification.}

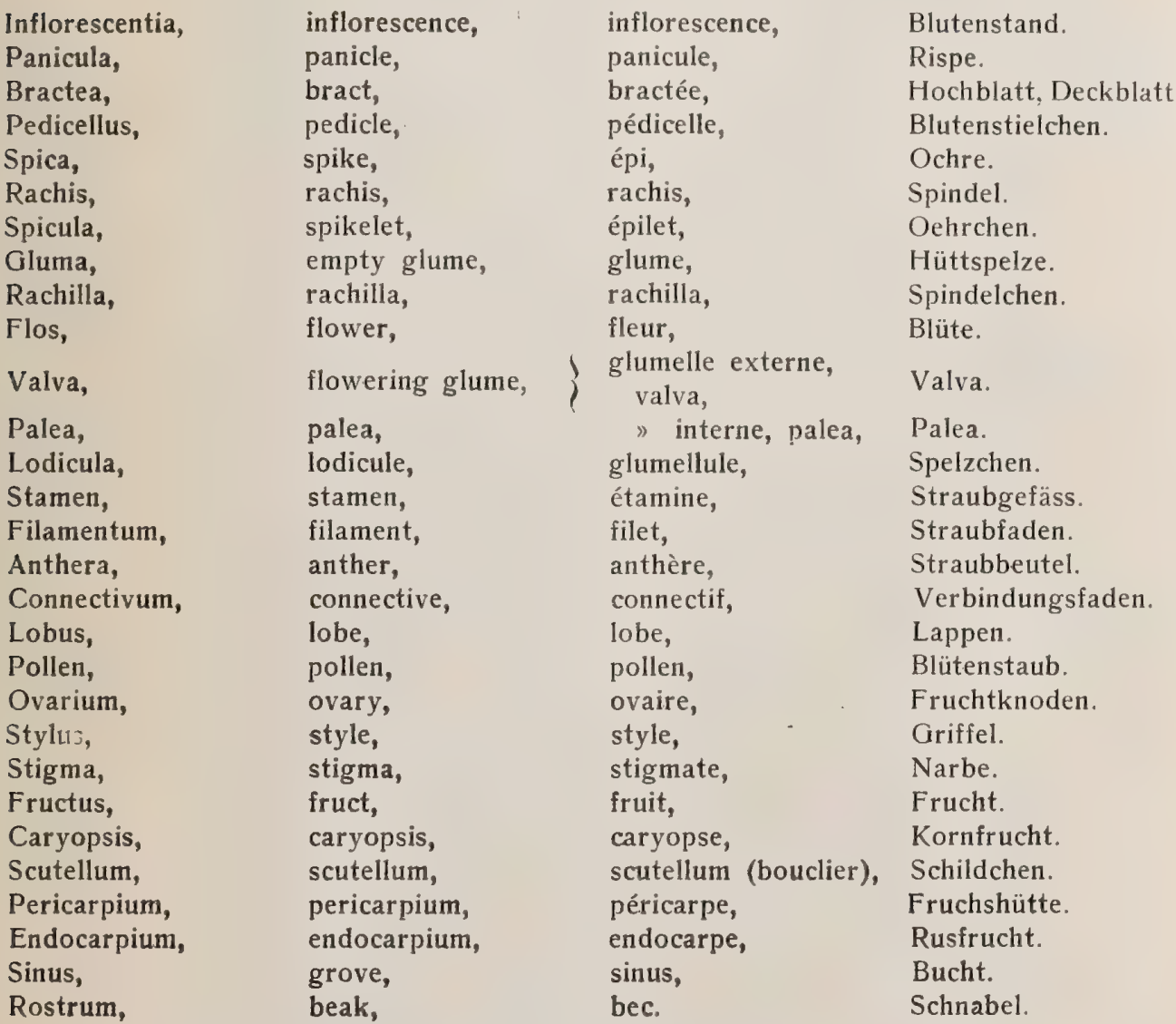

Les dénominations allemandes sont dues à l'obligeance de feu Geh. Pfitzer, d'Heidelberg. 


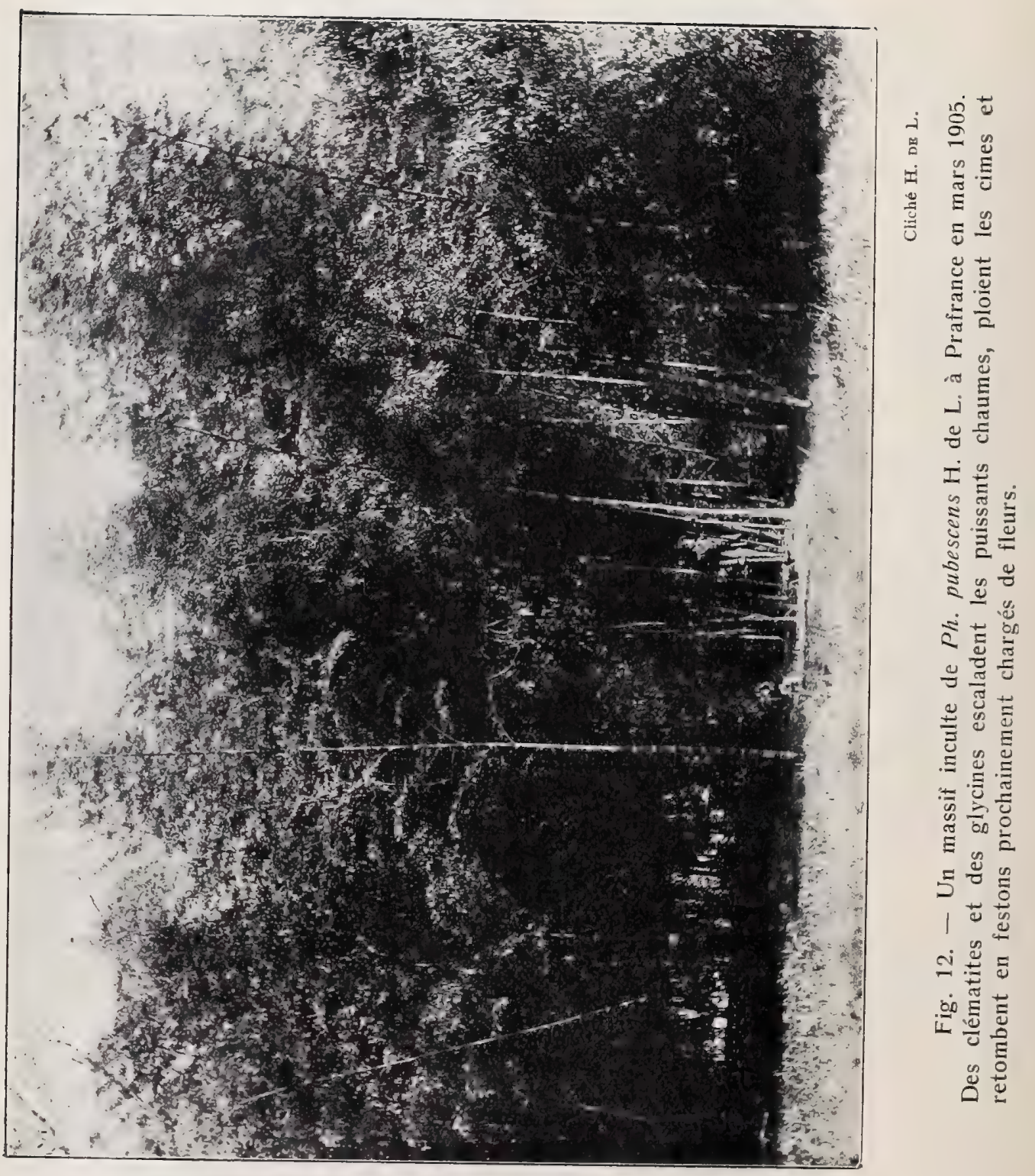




\section{Définitions de quelques termes.}

Caulo bulbe, partie du chaume souterraine, solide, renflée, sur laquelle les racines sont insérées.

Turion, le jeune chaume déjà sorti de terre, encore couvert de ses gaînes vivantes, mais ne portant pas encore de feuilles.

Cannelure, la dépression longtudinale du chaume dans laquelle étaient logées les branches pendant leur développement sous la gaîne, dans quelques genres.

Bourrelet inférieur... supérieur, du nceud, sur le chaume et les branches.

Cicatrice vaginale, point d'insertion de la gaine entre les deux bourrelets sur le chaume, les branches et les rameaux.

Spino racine, racines avortées spinescentes qui se développent au nœud en verticille.

Ex.: Bambusa quadrangularis, Arundinaria armata (1).

Branche, la branche porte des gaînes surmontées d'un pseudophylle.

Rameau, le rameau porte des gaînettes soit dépourvues de pseudophylles, soit portant des feuilles.

Ecaille bicarénée, elle est insérée à la base et autour des branches chez quelques genres.

Tesselles, nervures transversales, placées ordinairement à angle droit des autres nervures de la feuille, du pseudophylle ou de la gaîne.

Bractée, gaînette enveloppant un groupe d'épilets, surmontée d'un limbe réduit.

\section{Exemples de diagnoses et descriptions.}

\section{Diagnose de la sous-famille des bambusées.}

B a mbusées. - Graminée vivace, ligneuse, buissonnante, arborescente ou grimpante, distique; souche rhizomateuse, solide, cespiteuse ou traçante; turion couvert de gaînes; chaume de $1 / 2$ à 45 mètres (plus même chez certaines grimpantes) de longueur, fistuleux ou parfois solide, portant des branches; gaînes qui l'enveloppent caduques, marcescentes ou persistantes, extrêmement caractéristiques de chaque espèce; feuille généralement petite, articulée (excepté chez les Platonia), pétiolée, caduque, parfois tessellée.

Inflorescence ordinairement grande, paniculée, d'abord feuillée, enfin souvent aphylle, composée, soit d'épis terminaux nombreux, soit de 1 à quelques épilets portés sur des rameaux axillaires ordinairement aphylles; épilet 1 à $\infty$ fleurs, ordinairement la sủérieure imparfaite; glume 1 à $\infty$, manquant parfois, la supérieure la plus grande; glumelles 1 ou

(1) Il ne laut pas les confondre avec les épines, du B. spinosa, par exemple, qui sont des rameaux transformés. 
plus souvent 2, valva cuspidée, plurinervée, palea bicuspidée, bicarénée, ne manquant jamais; glumellules ordinairement 3, manquant parfois; étamines 3 à 6 ou $\infty$ libres ou monadelphes, excertes, souvent pendantes; anthères biloculaires; styles connés; stigmates 1 à 3 plumeux; caryopse très variable, généralement petit sillonné à scutellum visible, parfois très volumineux, charnu, à scutellum caché.

Bambuseae. - Gramina perennia, lignosa, fruticosa, arborescentia vel scandentes, alternatim disticha; coespes rhizomata, solida, coespitosa vel stolonifera; turio vaginatus;

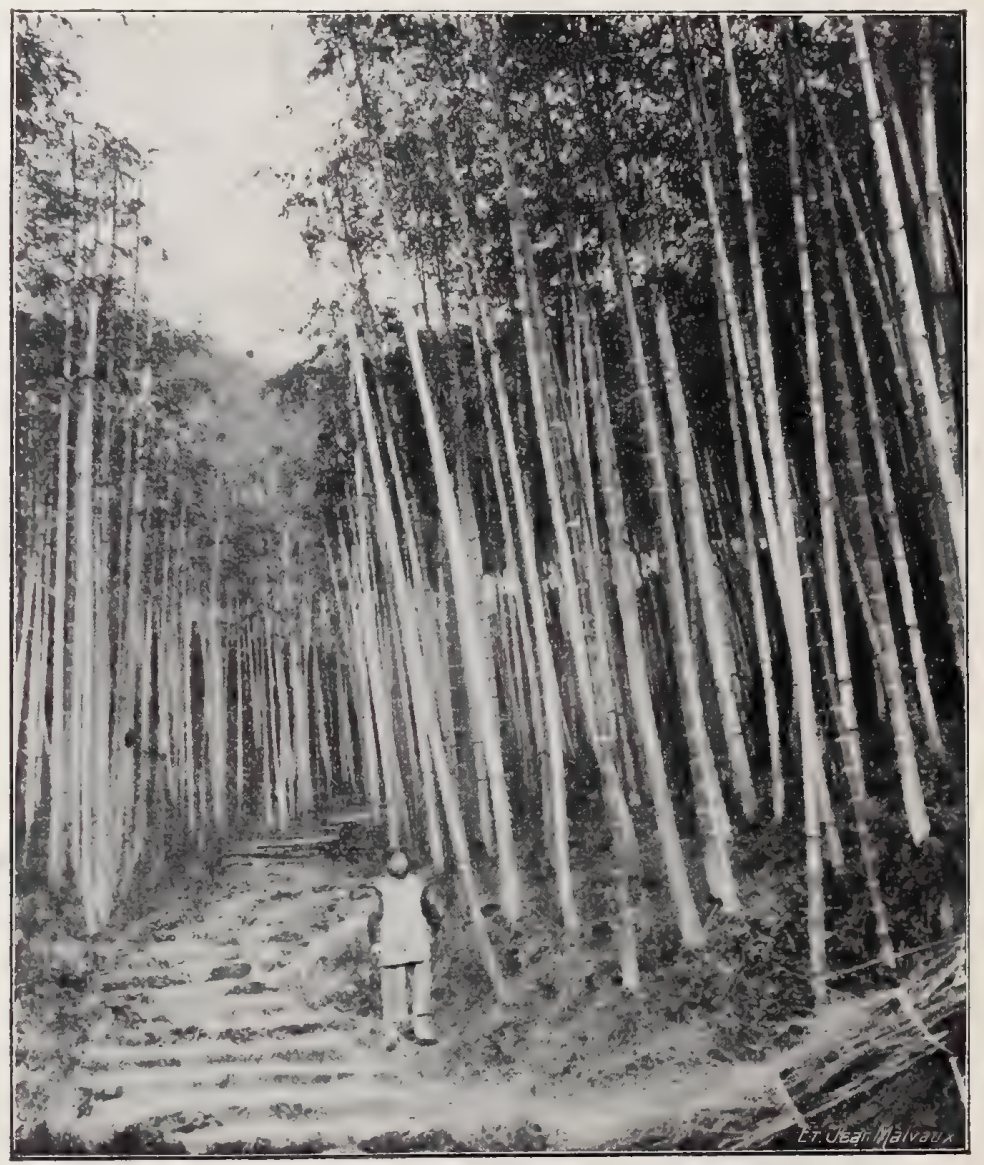

Cliché F. N. MEYrR.

Fig. 8. - Une forêt aménagée de Phyl. pubescens H. de L., en Chine. L'espèce cultivée sur le fertile limon rouge est presque arrivée à son maximum de taille. On remarquera le développement énorme de bois par rapport au feuillage. La culture de cette puissante espèce nous semble tout indiquée pour faire de la pâte à papier partout où les étés sont longs et chauds et où l'hiver est rarement marqué par des minima inférieurs à $10^{\circ}$ centigrades. C'est aussi une merveilleuse plante d'ornement pour de vastes parcs. En Belgique sa culture en plein air n'est'à conseiller que dans les endroits exceptionnellement chauds et abrités. Elle y atteint 5 à 6 mètres et gèle jusqu'au sol vers - 150 à -170 . Photographie prise en Chine. 
culmus 1/2-45 m. longus (scandentium aliquando major), fistulosus vel rare solidus, ramosus, vaginis deciduis, marcescentibus vel persistentibus vestitus; vagina maxime characteristica in omnibus speciebus; folia saepius parva articulata (nisi in Platonia), petiolata, decidua, nunc tessellata.

Inflorescentia saepius magna, paniculata, primo foliosa, dein saepe aphylla, composita vel, numerosis terminalibus spicis, vel 1- aliquibus spicibus in ramis axillaribus saepissime

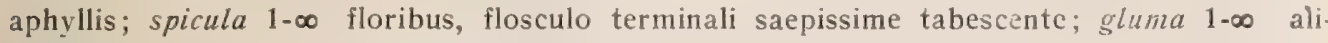
quando deficiens, superior maxima; glumellae 1 aut saepius 2, valva cuspidata, plurinerva, palea bicuspidata, bicarinata, nunquam deficiens; glumellae praecipue 3, aliquando defi-

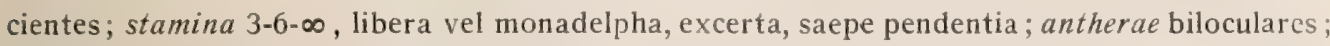
styli connati; stigmata 1-3 plumosa; caryopsis maxime variabilis, praecipue parva, sulcaia, scutello ronspicuo, aliquando maxima carnosa, scutello tecto.

\title{
La sous-famille comprend quatre sections:
}

\author{
I. les Arundinariae, \\ II. les Bambuseae verae, \\ III. les Dendrocalameae, \\ IV. les Bacciferae ou Melocanneae.
}

Nous ne nous occuperons ici que des Arundinariae.

\section{Diagnose de la section des Arundinariae.}

Ar undinariée, plante souvent traçante, turion pointu ou obtus; chaume ordinairement glabre; gaîne du chaume généralement peu densément pubescente au dos ou glabre, souvent lisse ou vernissée en dedans, à bouche étroite, à pseudophylle caduque, étroitement lancéolé, aigu, un peu rétréci à la base, allongé ou réduit; feuille toujours très distinctement tessellée chez les espèces traçantes, rarement, peu ou pas chez les cespiteuses.

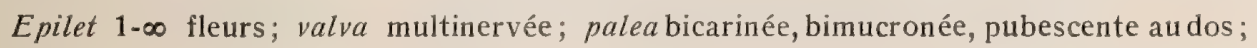
étamines 3-6 à filets libres, souvent pendantes; stigmates 2-3 plumeux; caryopse moyen ou petit, à péricarpe mince, membraneux, soudé à la graine, à scutellum visible. Asie, Amérique, Afrique.

Arundinariae, saepe stoloniferae; turio acutus vel obtusus; culmus erectus vel ascendens, aliquando scandens, praecipue glaber, rare spinosus; vagina culmi praecipue laeviter pubescens, aliquando maxime pubescens, aliquando glabra, intus saepe laevis vel vernicorsa, ore stricta, pseudophyllo deciduo, stricte lanceolato acuto, basin paulo constricto, elongato, parvo vel parvulo; folia distincte tessellata apud omnes stoloniferas et aliquot coespitosas.

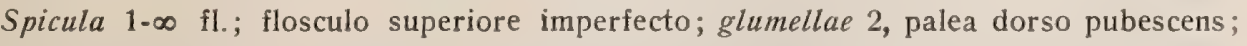
stamina B-6; stigmata 2-3; caryopsis pericarpio tenui, membranaceo, adherente semini, scutello conspicuo. Asia, America, Africa. 
La section des Arundinariae comprend trois genres qui se différencient par les caractères suivants:

A. Plante ne dépassant pas 5 mètres, souche longuement traçante, à mérithalles relativement longs, chaume fistuleux, glabre, non canaliculé, dressé ou ascendant; gaîne persistante, unicolore, glabre ou un peu pubescente, bientôt sèche et grise; feuille grande, tessellée, épaissement papiracée, glabre, brillante en dessus.

Inflorescence en panicule latérale, ordinairement aphylle; glumes très petites; étamines 6 à filets très courts; caryopse ovoïde, acuminé, inclus.

I. Genre $\mathbf{S}$ a s a.

Nord-est de l'Asie, Chine, Japon; sous bois, montagnes et plaines.

B. Plante ne dépassant pas 15 mètres, généralement moins de 10 , parfois très petite: $1 / 2$ mètre; souche capiteuse chez les espèces de l'Hymalaya, des montagnes centre-asiatiques, de l'Amérique tropicale et quelques-unes de l'Afrique, longuement traçante chez les autres d'Asie, de l'Amérique du Nord et de l'Afrique; chaume dressé ou arqué, rarement grimpant; gaîne généralement unicolore ou chinée, brillante en dedans, restant étalée après sa chute quand elle est caduque; feuille petite ou moyenne; étamines 3 (parfois 4), 6 chez les espèces grimpantes, à filets courts ou assez courts; caryopse petit et dur, inclus, ou moyen et mou, excert.

II. Genre Arundinaria.

Asie, Amérique, Afrique.

C. Plante de 10 (rarement moins) à 35 mètres; souche longuement traçante à mérithalles assez courts; chaume branchu seulement vers le haut, canaliculé dans cette partie; branches 1-3, ordinairement 2 à chaque nœud, inégales, gaîne presque toujours maculée, caduque, souvent glabre ou lâchement pubescente; écaille bicarénée grande, bifide; feuille ordinairement petite, tessellée; inflorescence comprenant tout le chaume; épi terminal comprenant des groupes d'épilets enveloppés chacun par une bractée; étamines 3 à filet très long, pendantes; caryopse petit, cylindrique, dur mucroné, inclus entre les glumelles, rare.

III. Genre Phyllostach ys.

Chine, Inde (Japon, 1 espèce?).

\section{Diagnose des genres appartenant aux Arundinariae.}

Genre Sas a, Makino et Shibata 1901. - On Sasa a new genus of Arundinariae and its affinities, T. Makino and K. Shibata; Botanical Magazine, Tokyo, Vol. XV, No 168, 1901.

Plante buissonnante, "gregarious"; souche mince, -3 à $10 \mathrm{~m}$. $\mathrm{m}$. de diamètre - branchue, longuement traçante, à mérithalles de 5 à 10 centimètres; turion non maculé; chaıme ascendant ou dressé, terminant le rhizome ou latéral, rigide, mince, poli, fistuleux, non canaliculé, à nœuds peu proéminents, branchu dans sa partie isupérieure, portant une seule branche à chaque nœud, couvert de gaînes persistantes, fortement enroulées, se desséchant rapidement, alors grisâtres, quittant le chaume pour s'enrouler à la branche lors de son apparition, 
puis se détruisant sur place; rameau solitaire, gros, bisannuel, à sommet persistant; feuille grande, souvent large, glabre au-dessus, à disposition palmée au sommet du rameau, nervure médiane très proéminente en dessous, nervures secondaires 6 à 14 paires, feuilles tessellées.

Inflorescence paniculée, lâchement rameuse, une, plusieurs ou parfois nombreuses sur un chaume, ordinairement dépassant les feuilles, portée sur un pédoncule latéral, dressé, couvert de gaînes, aphylle (ou rarement et anormalement feuillé) ; épilet 3-13 fleurs, souvent pourpré, étroit, plus ou moins comprimé; fleurs serrées ou lâches sur le rachilla, lancéolées; glumes 2 petites, membraneuses, très rapprochées ou un peu écartées, l'inférieure souvent très petite; valva beaucoup plus grande que les glumes, dépourvue de carènes, multinervée tessellée; palea ordinairement très visiblement plus courte, ou rarement plus longue que valva, distinctement bicarénée, hispide sur les carènes, multinervée intra et extra les carènes, ordinairement bifide; glumellules 3 multinervées, pubérulentes au bord; étamines 6 (rarement moins), à filets courts, plus ou moins dressées pendant l'anthèse; ovaire glabre; styles courts, connés; stigmates 3, plus longs que les styles, dressés écartés; caryopse oblong parfois un peu arqué, souvent sillonné, courtement excert entre les glumelles, libre.

Genus Sasa, frutescens, coespes 3-10 m. m., ramosa, longerepens, merithallio 15-10 cent.; turio immaculatus; culmus erectus vei ascendens, terminalis vel lateralis, rigidus, tenuis, laevis, fistulosus, non canaliculatus, supra ramosus, ramo unico, crasso ad nodum paulo prominentem, indutus vaginis persistantibus, arcte involustis rapide excicatis, tum cinereis; vagina ramum vix nascentem involvens, postea in situ periens; ramuli solitarii, crassi, vertice bienno, sicio marcescente; folia magna, saepe laxa, vertice ramuli fere fasciculata, superne glabra, nervus medius infra valde prominens nervi secundarii 6-14 paria, tessellata.

Inflorescentia paniculata, laxe ramosa, insita pedunculo laterali, an plures, vel aliquando multæ in eodem culmo, plerumque superantes folia, pedunculi erecti, vaginati, aphylli; spicula 3-13 fl. saepe stricta, plus minus compressa, flores in rachilla approximatae vel laxae lanceolatae; glumae 2 membraceae, approximatissimae, vel paulo remotae, parvae, praecipue inferior; valva major ecarinata, glumis multo major, multinervia, tessellata, palea plerumque brevior, raro longior, bicarinata, carenis, hispidis, multinervia intra extraque carinas, saepissime bifida; glumellulae 3, multinerviae, margine puberulentes; stamina 6 (raro minus), filamentis brevibus, plus minus erecta per anthesim; ovarium glabrum; stili breves connati; stigmata 3 , stilis longiora, erecta, patentia; caryopsis oblonga, aliquando subarcuata, saepe sulcata, breviter intra valvam paleamque exserta.

8 espèces et 4 variétés décrites.

Asie de l'est, continentale et insulaire, jusqu'à la latitude moyenne de Shakaline: Japon, Chine du nord, Mandchourie, Mongolie, (Turkestan chinois?). IPlantes surtout de sous-bois et de montagne.

Le genre Arundin aria est beaucoup plus complexe et nous serons amené à le diviser en plusieurs sections pour en faciliter l'étude.

II. Arundinaria, Michaux, Fl. Bor. Amer. I. 74 (1803); Miegia, Pers. Syn. Pl. I. 101 (1805); Ludolfia, Willd. in Berl. Verh. (1808), 320; Triglossum, Fisch. in Catal. Hort. Gorenk. (1812); Macronax, Rafin. in N. Y. Med. Rep. V. 350; Ruprecht, Act. Acad. Caes. 
Petrop. Ser. VI. Tom. V. 2e part. p. 21 (1839); Munro, A Monog. of the Bambusaceae, Trans, of the Linn. Soc. Vol. XXVIl. p. 30 (1866); Gamble, Bamb. of Brit. India, in Bull. Gar. of Calc. (1896) p. 3; Brandis, Indian trees p. 664 (1906).

Arundinaria, plante buissonnante, arborescente ou grimpante, souche cespiteuse ou traçante, émettant des chaumes terminaux dans le premier cas, latéraux dans le second; turion rarement maculé, quelquefois chiné; chaume fistuleux ou solide, parfois épineux, rond ou canaliculé; branches $1-\infty$ au nœud, généralement la centrale la plus grande, parfois en demi-verticille, ou, exceptionnellement en verticille complet; rameau à sommet bisannuel, marcescent ou persistant, terminé par 4-12 feuilles (parfois plus); feuille petite, mince, papiracée, ou moyenne et subcoriace, glabre ou pubescente sur 1 ou 2 faces, presque toujours tessellée chez les espèces traçantes, et presque toujours non tessellées chez les autres; gaine persistante, semi-persistante, semi-caduque ou caduque, ordinairement unicolore, lisse, unie et brillante en dedans, pubérulente au dos; écaille bicarénée petite, entière ou bimucronée, membraneuse, ou coriace, manquant parfois.

Inflorescence ou paniculée comprenant tout le chaume, d'abord feuillée, ensuite aphylle, ou bien en épi, soit terminal, soit porté sur des rameaux aphylles égalant environ la hauteur des rameaux feuillés du chaume; épilet pédonculé ou longuement pédonculé, comprenant $1-\infty$ fleurs (jusque 75 !) complètes; glumes ordinairement 2 ; valva plurinervée acuminée; palea bicarénée, hispide, bicuspidée; glumellules lancéolées, ciliées au bord; étamines 3 à 6 excertes, pendantes, à fillets courts (1 à 2 fois l'anthère); ovaire cessile, obové ou acuminé; styles courts, terminés par 2-3 stigmates légèrement saillants; caryopse petit, cylindrique, droit, sillonné, dur, caché entre valva et palea chez les espèces cespiteuses; gros arqué, peu ou pas sillonné, mou, excert chez les espèces traçantes.

Asie, Amérique, Afrique. Environ 120 espèces.

Arundinaria, frutescens, arborescens vel scandens; coespes vel coespitosa culmis terminalibus, vel repens culmis lateralibus; turio raro maculatus vel punctatus;culmus fistulosus vel solidus, raro spinosus, cylindricus vel sulcatus, supra ramosus, rami ad nodum 1 $\infty$ aliquando semi-verticallati, rarissime verticillati, centralis saepe majore; ramuli vertice biennio, etiam sicco marcescente, vel persistente, plerumque 4-12 foliis terminalibus; folia parva, tenuia, papiracea; aut media et subcoriacea glabra vel pubescentia praecipue apud species stoloniferas tessellata, raro apud alteras; vagina marcescens, persistens aut decidua, vulgo unicolor, laevis, intus nitens, dorso puberula; squama bicarinata parva, integra vel bimucronata, membranacea vel coriacea, aliquando deficiens.

Inflorescentia, sive totus culmus paniculatus primo foliosus deinde aphyllus, sive spicae vel terminales, vel in ramis aphyllis fere culmi ramis foliosis aequalibus incitae; spicula $1-\infty$ (usque 75 !) fl.; plus minus longe pedunculata; glumea plerumque 2 , valva p'urinervia, acuminata, palea bicarinata, hispida, bicuspidata; glumellulae lanceolatae, margine puberulae; stamina 3-6, exserta, pendentia, filamentis brevibus; ovarium sessile, obovatum vel acuminatum; styli brevi connati, 2-3 stigmatibus breviter excertis; caryopsis vel, in coespitosis parva, cylindrica, recta, sulcata, dura, inter glumellas abscondita, vel, in repentes crassa, parum aut non sulcata, mollis, excerta. 


\section{SECTIONS DU GENRE ARUNDINARIA}

1. Plantes presque toutes asiatiques, de montagne; souche cespiteuse; chanme fistuleux, arqué, cylindrique; branches nombreuses, la centrale ordinairement très prépondérante; gaîne caduque ou semi-caduque; feuille plane ou un peu en gouttière, petite ou moyenne, généralement molle, rarement tessellée; épilet 1-5 fleurs; étamines 3, caryopse petit, dur.

Thamnocal a m us.

Environ 30 espèces.

II. Plante américaine; souche cespiteuse, chaume plein, rond ou canaliculé; branches nombreuses au nœud, parfois en verticille complet, la centrale ordinairement très prépondérante; gaîne caduque; feuille petite; épilet pauciflore, souvent une seule fleur complète; étamines 3.

Verticilatae.

Environ 15 espèces.

III. Plante asiatique ou américaine; souche cespiteuse; chanme grimpant, solide; épilet 5-10 fleurs; étamines 6.

Scandentes.

Environ 10 espèces.

IV. Plante d'Asie, d'Amérique ou d'Afrique; souche longuement traçante, chaume fistuleux, canaliculé; branches 1 ou peu nombreuses au nœud; gaîne persistante; épilet à fleurs nombreuses (10-75); étamines 3, exceptionnellement plus; caryopse gros.

Euarundinaria $\mathrm{e}$.

Environ 30 espèces.

V. Plante d'Asie; souche longuement traçante; chaume fistuleux, canaliculé, atteignant 10 à 15 mètres; gaîne semi-caduque unicolore, plus ou moins vernissée en dedans, feaille moyenne, tessellée; fleur inconnue.

Fastuos a e.

Au moins 2 espèces.

L'ordre dans lequel ces cinq sections sont placées n'est évidemment pas satisfaisant, attendu que les Euarundinariae doivent se placer auprès des Sasa et que les Fastuosae doivent prendre rang auprès des Phyllostachys, qui vont suivre. Mais comme, d'autre part, il est logique de juxtaposer les deux sections précitées du genre Arundinaria, nous nous trouvons en présence d'une impossibilité d'établir une série linéaire, et il faut avoir recours à une série à deux dimensions. Voici comment il semble assez logique de la comprendre: 


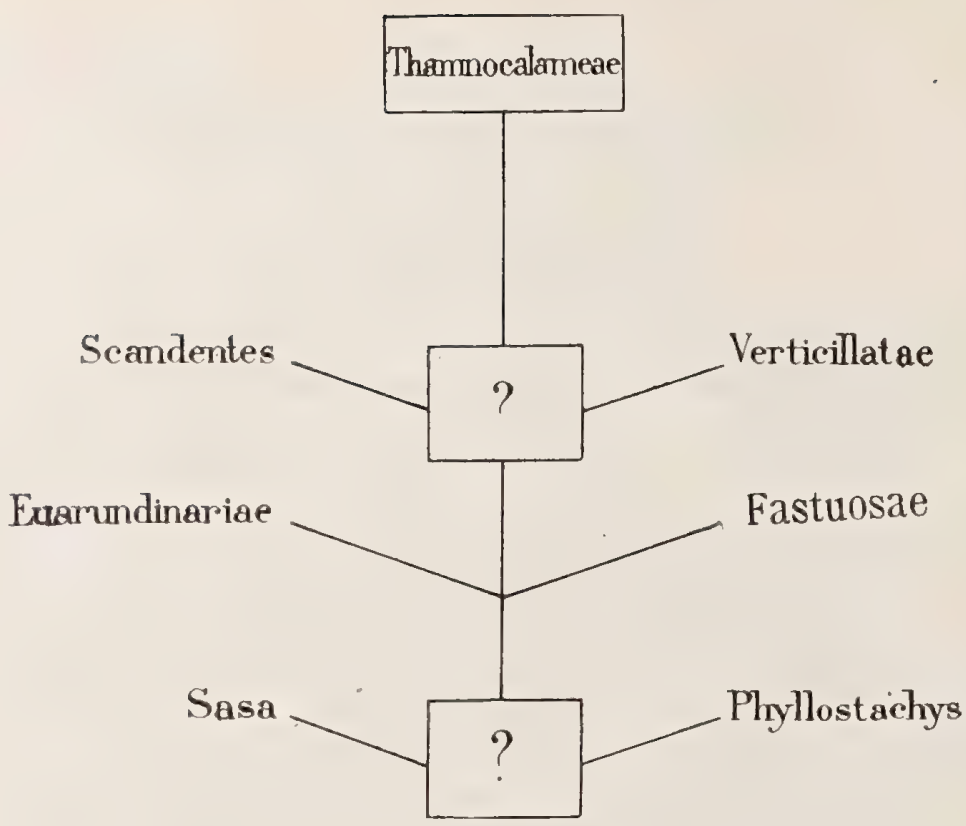

Phyllostachys. Siebold et Zuccarini, Abh. Akad. der Wiss. Münch. (Math. Phys. Clas.) III. 745, t. 5, fig. 3 (1843); Endl.Gen. Pl. III. 58 (1843); Munro, A. Monog. of the Bambusaceae, Trans. of the Lin. Soc. Vol. XXVII. p. 35. (1866); Rivière, Les Bambous, Paris, ex Bull. Société d'Acclim. pp. 231 -286, 1878. Gamble, Bambuseae of Brit India, in Bull. Jar. Bot. of Calc. (1896); p. 26. Brandis, Indian Trees, p. 667 (1906).

Plante buissonnante, ou plus souvent arborescente; souche longuement traçante; rhizome de 1-4 cent. de diamètre, sillonné, à inérithalles courts, renflés aux nœuds, portant chacun un bourgeon et un seul verticille de racines courtes sinueuses, émettant au printemps des chaumes (branches axillaires aériennes et feuillées) d'abord couverts de gaines imbriquées, dressés, élevés de $2 \frac{1}{2}$ à 35 mètres, latéraux (terminaux chez les sujets jeunes ou faibles) à base hypogée solide, renflée, incurvée, s'insérant sur le rhizome par un pédicelle très mince, composée de mérithalles nombreux (pouvant dépasser le nombre de 30), courts, portant chacun ordinairement (quand le chaume est vigoureux) plusieurs verticilles de racines longues, droites, divergentes indivises, garnies sur toute leur longueur de minces radicelles; ce chaume est fistuleux dans toute sa partie aérienne, bagué sous chaque nœud d'un anneau cireux plus ou moins persistant, rond et à nœuds peu proéminents dans la partie inférieure du chaume qui est dépourvue de bourgeons actifs et par conséquent de branches, plus haut à nœuds proéminents, sillonné d'un côté (parfois de 2 côtés), (semi-cylindrique à son extrême-cime), portant ordinairement deux branches inégales à chaque nœud, dans un ordre alterne, distique et symétrique, issues d'un seul bourgeon; gaîne couvrant ordinairement le $1 / 2$ ou les $2 / 3$ du mérithalle, presque toujours grande, souvent coriace, caduque, à sommet ogival, presque toujours maculée, à nervures apparentes sur les deux faces (surtout après dessication), tessellées; écaille bicarénée bifide parfois jusqu’à la base, marcescente, généralement translucide, rarement glabre sur les carènes; branches ordinairement deux à chaque nœud, inégales, fistuleuses, subsolides ou solides, à section polygonale, sillonnées, à nœuds proéminents, plusieurs fois divisés (excepté chez $P h$. ruscifolia), divergentes à angles souvent 
d'environ $80^{\circ}$; portant des rameaux cylindriques, solides à nouds peu ou non proéminents, chacun des mérithalles de la base du rameau portant un bourgeon dormant; à sommet annuel, dépourvu de bourgeons axillaires, caduc, terminé par 3-5 (parfois plus) feuilles petites ou moyennes, minces ou papiracées, glabres et vert brillant au-dessus, glauques audessous, pubérulentes le long de la base de la nervure médiane, tessellées, dentées au bord externe.

Inflorescence paniculée, comprenant le chaume entier, dont tous les bourgeons des rameaux (le terminal, puis les axillaires) se développent successivement en épis, ordinairement d'abord feuillée (pendant la floraison du bourgeon terminal du rameau), enfin aphylle (pendant la floraison des bourgeons axillaires du rameau); épi lancéolé ou subglobuleux, composé de groupes d'épilets sessiles enveloppés chacun de l'une des bractées feuillées de l'épi (cette disposition est si caractéristique chez beaucoup d'espèces que Siebold en a tiré le nom du genre); épilet 1-4 fleurs complètes, étroit, cylindrique ou comprimé latéralement; glumes ordinairement 2, l'inférieure plus petite, multinervée, tessellée; glumelles: valva plurinervée, acuminée, tessellée, palea bicarénée, hispide, bicupidée, multinervée souvent tessellée; glumellules ordinairement 3, ciliées au bord et au dos vers le haut, souvent plurinervées; étamines pendantes, à filets 3-4 fois aussi longs que l'anthère; ovaire longuement stipité ou obové, prolongé en styles connés, divisés en trois stigmates révolutés, plumeux, longuement saillants; caryopse rare, petit, cylindrique, droit, sillonné, caché entre les glumelles, surmonté des styles formant un long bec dur et acéré.

Asie de l'est, Inde, Chine surtout, (Japon?).

Genus Phyllostachys frutescens vel saepius arborescens; coespes longe repens; rhizoma 1-4 cent. crassum, sulcatum, merithalliis brevibus inflatis ad nodum, cuique alternatim unigemmatum et verticillatim breve radicellatum, culmi vernales, primo vaginis imbricatis tecti, erecti, $2 \frac{1}{2}-35 \mathrm{~m}$. alti, laterales (terminales vero apud juniores vel debiles plantas), quorum basis hypogea, caulo-bulbus dicta, solida, inflata, incurva, in rhizomate pedunculo tenuissimo incerta, merithallis plurimis (usque ad triginta) brevibus, plerumque gerentibus (in robustis) plura verticilla radicum, radices quae longae, rectae, divaricatae, indivisae, radiculis instructae sunt; culmus in parte epigea fistulosus, cylindricus in parte inferiore ramis destituta, nodis non prominentibus, superne alternatim sulcatus (aliquando utroque latere).(apice semi cylindricus) nodis prominentibus fere semper 2-ramis ad nodum, una gemma ortis, ordine alterno, disticho, symetrico; vagina magna, apice ovato-acuta, decidua, saepissime maculata, tessallata; squama bicarinata bifida aliquandousque ad basim, marcescens, rami 2 ad nodum inaequales, pluries partiti ( $P h$. ruscifolio excepto); ramuli cylindrici, solidi, ad basim gemmati cuique nodo, apice annuo deciduo, 3-5 foliis (vel pluribus) terminalibus; folia parva, tenuia vel papiracea, superne glabra, tessellata margine externa dentata vel serrulata.

Inflorescentia, totus culmus paniculatus, plerumque primo foliosus, demum aphyllus; spica lanceolata vel subglobosa, spicularum glomeris cessilibus, indutis bractea foliosa; spicula 1-4 fl., stricta; glumae persaepe 2, inferior minor, palea bicarinata, hispida, bicuspidata, multinervia saepe tessellata; glumellulae saepissime 3, ciliata margine et dorso; stamina pendentia, filamentis 3-4 antheris longiora; ovarium stipitatum vel obovatum; styli connati; stigmata 3 plumosa, revoluta, longe excerta; caryopsis rara, parva, cylindrica, recta, sulcata, mucronata, inter glumellas abscondita. 
Le genre Phyllostachys est bien plus serré que le précédent et, par conséquent, a moins besoin d'être divisé. Toutefois, nous y ferons deux sections, faisant remarquer que jusqu'à l'examen des fleurs de l'unique espèce placée dans la seconde section, nous conservons des doutes sur le genre auquel elle appartient.

I. Chaume élevé; branches ordinairement deux à chaque nœud; feuille lancéolée, linéaire, plante chinoise.

Euphyllostachys.

Environ 12 espèces et de très nombreuses variétés.

II. Chaume petit, ne dépassant pas $2 \mathrm{~m}, 1 / 2$; branches ordinairement 3 ou plus (la plus grande au milieu) à chaque nœud; feuille petite, courte, ovale lancéolée, plante japonaise.

Une seule espèce connue.

Rus cifoliae.

\section{Quelques diagnoses d'espèces, accompagnées de planches, rédigées en tenant compte des principes énoncés.}

Phyllostachys puberula (Miquel) Makino. - Miquel, Prol.fl. Jap., p. 173 (1865), Makino M. S. S. in herbario Zuricence (1894); Makino in Bot. Mag. of Tokyo, p. 64 (1900); tab. LII, LIII et LIV.

Frutescens vel arborescens, $3-25 \mathrm{~m}$. altus; coespes 1-3 cent. crassa; turio pubescens, griseus vel fuscatus; culmus praecipue bilateraliter sulcatus; vagina subcoriacea, parum maculata, apice obscurior, dorso dense puberula, adjunctis longis sparsis, nigrescentibus, caducis pilis; pseudophyllus vaginae $100-150 \times 10-15 \mathrm{~m}$. m. erectus, lateraliter undatus puberulus utraque pagina, canaliculatus, lanceolato-acutus, gerens ad basim saepius 1-2 auriculas spatulatas, longe ciliatas postice, caducas, et ligulam breviusculam, parum fimbriatam; squama bicarinata usque ad basim inaequaliter bifida, dorso carinisque puberula; rami solidi; ramuli tenuissimi, $2-3$ fol., folia $60-100 \times 10-15 \mathbf{m}$. $\mathbf{m}$. stricte lanceolata, subgibbosa, arcuata; nervi secundarii 4-5 paria, nervuli 5-9 inter secundariis, $45-50$ in $5 \mathrm{~m}$. $\mathrm{m}$.; tessellae $30-35$ in $5 \mathrm{~m}$. $\mathrm{m}$.; dentes laterales $15-20$ in $5 \mathrm{~m}$. $\mathrm{m}$.

Inflorescentia paniculata, composita spicis primo lanceolatis, deinde subglobosis, pubescentibus $20-40 \times 15-25 \mathrm{~m}$. m. multispiculatis; bractea spicae limbo $5-15 \times 1-$ $4 \mathrm{~m}$. m. lanceolato-acuminato, fasciculum 2-5 spicularum involvente; spicula (1-4) praecipue $2 \mathrm{fl}$, flosculo terminali imperfecto magno; glumae unquam deficientes, dorso et apice puberulentes, basim glabrae, inferior $5-7 \times 1-2 \mathrm{~m}$. $\mathrm{m}$., superior $9-11 \times 2-3 \mathrm{~m}$. $\mathrm{m}$.; valva scabra super et inter nervos marginibusque, minus ad basim quam sommo cetaceo, apice subglabro, laxe et obscure tessellata $12-16 \times 4-6 \mathrm{~m}$. m.; palea sulbifida, carinis breviter cetaceis, dorso, carinis et marginibus, maxime medio, puberula, indistincter nervosa intra et extra carinas; glumellulae obscure 3-5 nervae, $11 / 2-2 \mathrm{~m}$. m. longae, ovato-lanceolatae; stamina filamentis $25-30 \mathrm{~m}$. m.; antherae $8-10 \mathrm{~m}$. m.; ovarium ovato-acuminatum; styli fere glumellas aequantes; stigmata hyalina vel violacea, $8-10 \mathrm{~m}$. m.; caryopsis rarissima $5-7 \times 1 \frac{1}{2}-2 \mathrm{~m}$. m., obscura, cylindrica longe mucronata $4-6 \mathrm{~m}$. $\mathrm{m}$. 
Phyllostachys puberula (Miquel) Makino, plante buissonnante ou arborescente de 3 à $25 \mathrm{~m}$. de hauteur; souche de 1 à 3 cent. de diamètre; turion gris ou roussâtre: chaume ordinairement sillonné de deux côtés (à deux extrémités d'un diamc̀tre) montrant dans sa partie branchue d'un côté un sillon double ou triple très accusé, et à l'opposé un sillon simple peu accusé, semi-cylindrique à l'extrême cime; gaine coriace ou subcoriace, très variable, couvrant la moitié ou plus du mérithalle, pouvant atteindre jusque $0 \mathrm{~m} 50 \times 0 \mathrm{~m} 30$, généralement plus foncée vers le sommet, peu maculée, couverte au dos d'une fine pubescence semée de grands poils épars foncés, caducs; à pseudophyle pouvant atteindre $100-150 \times 10-15 \mathrm{~m}$. m., dressé, ondulé en forme de lame de cris malais, de même couleur que le sommet de la gaîne, mais généralement de teinte plus foncée, finement pubérulent sur les deux faces, en gouttière, laucéolé-aigu, accompagné à la base de deux auricules (parfois absentes) spatulées, longuement ciliées au bord postérieur, cadu. ques, et d'une ligule assez courte un peu fimbriée; écaille bicarénée bifide jusqu'à la base, c'est-à-dire séparée en ses deux éléments d'inégales longueurs, longs, étroits, obtus, translucides, un peu jaunâtres, mous, un peu pubérulents sur les carènes, au dos et sur les bords; branche solide, polygonale, à 3 ou 4 faces bombées, planes ou sillonnées; rameau très mince, ordinairement moins de $1 \mathrm{~m}$. m. de diamètre, portant ordinairement 2-3 feuilles, portion persistante de 1-3 cent., portion caduque de 5 à 8 cent., y compris les gaînettes; feuille de $60-100 \times 10-15 \mathrm{~m}$. m., parfois bien plus sur de jeunes plantes ou de faibics chaumes, étroitement lancéolée-acuminée, souvent plus ou moins bordée, arquée et gauche, à pointe décombante, vert vif et uniforme au- dessus; nervure médiane très visible, proéminente au-dessous (la pubérulence accompagnant la base de cette nervure a donné, dit-on, l'idée à Miquel d'appliquer le nom de Bambusa puberula à cette plante. Ce ne fut pas un choix heureux, car ce caractère n'est ni spécifique ni même générique, attendu que les bambusées chez lesquelles ce caractère manque sont relativement peu nombreuses); nervures secondaires 4-5 paires; nervures tertiaires 5-9 entre les secondaires, $45-50$ au $1 / 2$ centimitre; tesselles 30-35 et dentelure, 15-20 au 1/2 centimètre, généralement une grande, puis une petite dent alternant; gainette glabre, striée, un peu pubérulente au bord, coussinet mince, appliqué, un peu fimbrié, formant colerette derrière l'insertion du pétiole; poils auriculaires apprimés, dressés, caducs; ligule 1-2 m. m., un peu fimbriée, glabre ou légèrement pubérulente, un peu plus foncée que la gaînette; pétiole mince, court 2-4 m.m.

Inflorescence paniculée, ample, composée d'épis d'abord lancéolés, puis subglobuleux de 20-40 $\times 15-25 \mathrm{~m}$. m. comprenant de nombreux épilets; bractée de l'épi à limbe réduit 5-15 $\times 1-4 \mathrm{~m}$. m. lancéolé acuminé, enveloppant un groupe de 2-5 épilets; épilet (1-4) généralement 2 fleurs complètes, fleur incomplète grande; glumes manquant parfois, un peu pubérulentes au dos et au sommet, glabres vers la base, l'inférieure 5-7 $\times 1-2 \mathrm{~m}$. m., la supérieure $9-11 \times 2-3 \mathrm{~m}$. m., nervure médiane proéminente, 2-3 paires de secondaires; valva à nervure médiane proéminente, 4-5 paires de secondaires, scabre sur et entre les nervures et sur les bords, moins vers la base qu'au sommet cétacé (dont l'extrême pointe est presque glabre), lâchement et obscurément tessellée, de couleur variable, de 12-16 ×4-6 m. m.; palea légèrement bifide, les deux carènes terminées chacune par une pointe acérée courte, un peu scabre sur le dos, les carènes et les bords, surtout vers le milieu de sa hauteur, translucide, verdâtre sur les carènes, nervures peu distinctes 2-3 entre les carènes, 1-2 paires plus visibles au dehors, non tessellée; glumellules jaunâtres vaguement $3-5$ nervées, $11 / q^{-2} \mathrm{~m}$. m. de 
longueur; étamines à filets 3 fois aussi longs que l'anthère de $8-10 \mathrm{~m}$. m.; ovaire ovale acuminé; styles presque aussi longs que les glumelles; stigmates hyalins ou violâtre, de 6-8 m. m.; caryopse jaune, brunâtre ou noirâtre (2 ou 3 fertiles dans une grosse poignée d'épis) cylindrique $5-7 \times 1-1 \frac{1}{2} \mathrm{~m} . \mathrm{m}$., brusquement rétréci à la base et au sommet, brillant, un peu chagriné à sinus peu profond, dont les bords sont parfois indistincts, surmonté d'un bec de 4-6 m. m.

Chine moyenne, vallée du Yank-tse-Kiang où il est largement cultivé; introduit au Japon, en Europe, dans l'Amérique du Nord.

Cette plante est extrêmement variable et l'on en trouve, soit à l'état spontané, soit dans les cultures en Chine et au Japon, une quantité de formes et de variétés portant des noms vernaculaires distincts. Un certain nombre sont parvenues en Europe. Voici la spécification de quelques-unes pour montrer l'étendue et le sens de ces variations.

1. Phyllostachys puberula var. typica (Miquel), chaume atteignant 25 mètres de hauteur, très droit, rude au toucher la première année, devenant ensuite lisse et doux, vert d'abord, virant au vert glaucescent ou grisâtre; vert grisâtre ou gris jaunâtre, quand il est sec; turion comestible, gris souris hérissé de poils noirs épars; gaîne du chaume verte abondamment couverte d'un enduit cireux pulvérulent blanc grisâtre, masquant la teinte verte pubérulente, quand elle est vivante; jaune brunâtre uniforme ou très peu maculée et plus foncée vers le haut quand elle se dessèche; épi de fleurs vert, verdâtre ou très légèrement violâtre; bois de première qualité, résistant, dur, serré, élastique. Nom vern. japonais: Hachiku, Tauchiku.

II. Phyl. puberula var. flavescens, plante moitié ou ${ }^{2} / 3$ du No I ; chaume jaune brillant, irrégulièrement strié de vert dans sa portion dépourvue de branches, jaune à sillon vert dans sa portion ramifiée, cette disposition des couleurs se retrouve sur toutes les ramifications sillonnées; turion comme le No 1, mais vert strié de jaune sous l'enduit cireux; gaîne panachée striée de jaune sur fond vert (la proportion des couleurs y est inverse de ce qu'elle est sur le chaume); feuille verte parfois striée-panachée de jaune; épi vert comme le No I.

III. Phyl. puberula var. flavescens inversa, plante comme le No II, mais dont toutes les couleurs du turion et du chaume sont disposées à l'inverse de celles du No II; feuille comme le No II.

IV. Phyl puberula var. Boryana, plante un peu moins grande que le No I; chaume d'abord vert, se couvrant ensuite de macules plus ou moins grandes et nombreuses, nuageuses, pochées ou définies, vermiculées, zonées, confluentes ou non, diversement nuancées de jaune, brun, brun rougeâtre ou noir, parfois certains mérithalles sont complètement envahis par ces taches, les chaumes ayant moins de $15 \mathrm{~m}$. $\mathrm{m}$. de diamètre à la base ne portent généralement aucune tache caractéristique de la variété; turion brun violâtre; gaîne de même couleur; épi vert brunâtre ou violâtre. Nom vern. japonais: Madaradake. 
V. Phyl. puberula var. fulva, plante de même taille environ que le No III; chaume d'abord jaune ou jaune olivâtre, se parsemant ensuite de larges taches irrégulières, parfois confluentes, brun très foncé ou noir ; turion, gaîne et épi comme le No IV.

VI. Phyl. puberula var. Han-chiku, plante de même taille que le No IV; chaume jaune pâle olivâtre ou jaune brunâtre finement et densément (surtout au haut du mérithalle) pointillé de brun foncé ou de noir; feuille moins arquée, bodée et gauche que chez le No 1 ; turion, gaîne et épi comme le No IV. Nom vern. japonais : Han-chiku.

VII. Phyl, puberula Muchisasa, plante haute de 3 à $4 \mathrm{~m}$. seulement, courtement et à peine traçante (sans doute variété naine de culture); chaume ayant sous des dimensions réduites tous les caractères du No VIII; feuille comme le No VI; turion, épi, fleur comme le No IV. Nom vern. japonais: Muchisasa.

VIII Phyl. puberula var, nigra, plante de même taille que le No IV; chaume d'abord vert passant bientôt au noir plus ou moins foncé et brillant, en général les petits chaumes sont moins uniformément foncés que les grands, parfois même chez ceux-ci la teinte foncée n'envahit pas toute la surface du chaume; feuille comme le No VI; turion, épi, fleur comme le No IV. Nom vern. japonais: Kurodake.

IX. Phyl. puberula var. nigra-punctata plante aussi vigoureuse et grande que le No 1; chaume généralement moins foncé que chez le No VIII, souvent pointillé de noir sur fond sombre, presque noir; feuille comme le No VI, turion, épi, fleur comme le No IV. Nom vern. japonais: Gomadake.

D'autres variétés nous sont uniquement connues par leur nom vernaculaire; mais nous n'avons jusqu'ici aucune notion de l'existence d'intermédiaire entre ces diverses formes. Toutes les variétés introduites ont successivement fleuri en Europe, excepté Muchisasa et une partie de Kuro-dake. Les semis signalés sont fort peu nombreux.

Phyllolsta chys pubescens, H. de L. Le Bambou p. p. 7-14 (1906). - Makino, Phyl. mitis, Bot. Mag. of Tokyo. Vol. XIV, pp. $64-69$ (1900); tab. LV, LVI et'LVII.

Arborescens 10-35 m.; coespes longissime repens, $2-4$ (vel plus) cent. crassa, parum compressa; turio dense pubescens, rufus; culmus sulcatus vel bilateraliter sulcatus, usque 30 cent. crassus, ad basim brevissimis internodiis, caetera parte brevibus, omnino breve dense hyaline tomestosus (sed minimi, maximique culmi saepe glabri) initio, dein glaber, primo micante virescens, deinde latere insolato flavescens, ansula cerea infra nodum evidens et persistens; vagina coriacea, merithallo paulo. longior, dense pubescens pilis erectis, micantibus, fuscis vel fulvis, $3-5 \mathrm{~m}$. m. longis, subcaducis, epidermo vario colore; pseudophyllum usque $100 \times 15 \mathrm{~m}$. m. coriaceum, subundatum, subcanaliculatum, puberulum, fuscato-violascens, primo erectum, dein reflexum ; auriculis paliidis, omnino laciniato-fimbriatis, longe in marginibus vaginae decurrentibus; ligula laciniato-fimbriata, pallida; squama bicarinnata usque ad ${ }^{1 / 3}$ vel plus inaequaliter acute bifida, fuscato-pallida, puberula; rami solidi vel fistulosi, primo virescentes, demun vitellini ab aetate et sole; ramuli tenuissimi, folia vere caduca ante novarum exitum, 80-100×8-10 m. m., stricte lanceolato-acuminata, marginibus in 
medio fere parallelis; nervi secundarii -4-paria,nervuli7-9 inter secundarias, 40-45 in $5 \mathrm{~m}$. $\mathrm{m}$., tessellae 32-36 in $5 \mathrm{~m}$. m., dentes $17-18$ in $5 \mathrm{~m}$. $\mathrm{m}$.

Inflorescentia paniculata, spicis lanceolatis $50-70 \times 8-12 \mathrm{~m} . \mathrm{m}$. , multospiculatis; bractea spicae limbo usque $25 \times 10 \mathrm{~m}$. m., superiores minores, fasciculum 3 spicularum involvente; spicula 25-27 m. m., 1 fl. perfecto, flosculo.terminali tabescente; flora subviridis, 22 26 m.m., gluma unica, glumellis minor, limbo minimo, ciliata, ad margines puberula, plurinervia; valva apice hispido-spinosa, rigide papyracea, subviridis, piloso-pubescens, circiter 10-11 nervia, laxe et minute tessellata; palea paulo minor quam valva, carinis proximis, circiter 11 nervia, laxe et minute tessellata; glumellulae lanceolato-acuminatae $61_{1}-7 \mathrm{~m}$. marginibus ciliatae, laxe dorso pubescentes, ad basim crebre nervatae; stamina filamentis $40 \mathrm{~m}$. m.; styli connati glabri, ad basim crassi, apice attenuati, stigmata stylis longiora laxe plumosa; caryopsis ignota.

China media et meridionalis. N. V. J. Môsô-chiku.

Phyllostachys pubescens, H. de L., plante arborescente de 10-35 mètres de hauteur; souche très longuement traçante à rhizome de 2-4 (parfois plus) cent. de diamètre, un peu aplati; turion densément pubescent roussâtre ou brun foncé; chaume d'abord vert brillant, à sillon simple (parfois deux opposés), pouvant dépasser $0 \mathrm{~m}, 30$ de diamètre, (très conique à la base, dont les mérithalles sont très courts), à mérithalles courts — ne dépassant guère $0 \mathrm{~m}, 35$, - complètement couvert d'un tomentum court, serré, hyalin, quand il est de moyenne grosseur - les chaumes très minces ou très gros sont glabres - tomentum qui disparaît généralement avant la fin de la première année et laisse à nu le chaume dont la couleur verte primitive se nuance de jaune et d'oranger surtout aux endroits qui sont exposés au soleil, à anneau cireux sous le nœud très accusé et persistant, d'abord blanc pur, passant au gris; gaîne épaisse, coriace, très variable, pouvant atteindre à l'état frais un mètre de largeur à la base, sur une hauteur beaucoup moindre, alors triangulaire; diminuant de largeur non de hauteur pendant la dessiccation, un peu plus longue que le mérithalle qu'elle recouvre, plus ou moins triangulaire, d'autant plus lancéolée-ogivale qu'on l'examine sur un chaume plus mince, ou vers le haut d'un chaume fort, complètement couverte d'une pubescence serrée formée de poils dressés, .brillants, roux, brunâtres ou fauves de $3-5 \mathrm{~m}$. m., assez caducs qui laissent cependant apercevoir l'épiderme de la gaîne nuancé de vert, olive, jaune, ocre, violet ou même rose, l'ensemble semé de taches noires plus ou moins nombreuses, parfois confluentes, toujours plus rapprochées vers le sommet de la gaîne, taches qui se présentent comme des éminenoes applaties sur la gaîne desséchée, dont le fond est devenu grisâtre, bleuâtre ou jaunâtre; le tout parfois plus ou moins couvert d'une pruinosité cireuse modifiant les couleurs de façons diverses, pouvant même faire paraître le jeune chaume gris-bleu; à pseudophylle coriace, un peu ondulé, en gouttière, finement pubérulent sur les deux faces, brun foncé violâtre, d'abord dressé, puis réfléchi, pouvant dépasser $100 \times 15 \mathrm{~m}$. m., à auricules blanchâtres, jaunâtres, complètement fimbrées-laciniées, longuement décurrentes sur les côtés de la gaîne; à ligule fimbriée, laciniée, blanchâtre; écaille bicarénée bifide sur un tiers ou plus de sa hauteur, à lobes d'inégale longueur, étroits, subaigus ou aigus, brunâtres, papiracés, courtement pubérulents sur les deux faces et les bords; branche triangulaire ou quadrangulaire 
à faces planes ou un peu sillonnées; d'abord vertes, virant au jaune brillant en prenant de l'âge et sous l'influence de l'insolation directe; rameau très mince, ordiportion caduque 5-8 cent., y compris les gaînettes. L'ensemble de la ramure présente un aspect très caractéristique: les deux branches partant de chaque nœud sont presque horizontales, un peu ascendantes; il en est de même de toutes leurs subdivisions qui sont d'autant plus courtes qu'elles sont insérées plus loin de la base des branches, chaque mérithalle est arqué, la convelxité vers le haut, et chaque nœud forme un angle obtus ouvert vers le haut, les feuilles se tiennent el'es-mêmes presque horizontales, la pointe un peu relevée, il résulte de cette disposition que tout le feuillage porté par les branches de chaque nœud du chaume se présente dans un plan presque horizontal et que le chaume porte une série d'étages régulièrement espacés, décroissant en importance du bas de la ramure vers le haut; cette ramure occupe le $1 / 3$ ou le $1 / 4$ environ supérieur d'un grand chaume, le reste formant un puissant fût nu décrivant une très légère courbe en $s$ qui se continue et s'achève à la cime légèrement inclinée; ce caractère étagé est encore accentué par la petites se et le nombre des feuilles: celles-ci pouvant être au nombre de bien plus de cent mille sur un seul chaume; feuilles de $80-110 \times 8-10 \mathrm{~m} . \mathrm{m}$., vert clair, jaunâtre au printemps, époque où elles tombent avant le développement des nouvelles, étroitement lancéolées acuminées, à bords presque parallèles sur une partie de leur longueur, en gouttière; nervures secondaires 4 paires, nervures tertiaires 7-9 entre les secondaires $40-45$ au $1 / 2$ cent., tesselles $32-36$, dents 17-19 au 1/2 centimètre; gaînette glabre ou plus ou moins pubérulente en haut, striée, poils auriculaires écartés, étalés, caducs; ligule allongée, ovale, ciliée au sommet, plus ou moins pubérulente au dos.

Inflorescence composée d'épis lancéolés de 50-70×8-12 m. m., comprenant de nombreux épilets; bractée de l'épi à limbe développé, lancéolé pouvant atteindre $25 \times 10 \mathrm{~m}$.m., plus petit vers le sommet de l'épi, enveloppant chacune un fascicule de trois épilets; épilet long de 25-27 m. m., composé d'une fleur complète et d'une imparfaite; fleur verdâtre longue de 22-26 m. m.; glume une seule placée un peu au-dessous de la valva, plus courte que les glumelles, portant un pseudophylle petit et rudimentaire, ciliée et plus ou moins pubérulente vers le bord, plurinervée; valva à sommet hispide épineux, rigidement papiracée, verdâtre, piloso-pubérulente à environ 10-11 nervures, à tesselles très délicates et lâches; palea légèrement plus courte que la valva, linéaire lancéolée, atténuée au sommet, bifide, à lobules du sommet scabres hispides et spinescents, papiracée, verdâtre, clairement pubescente au dos, les deux carènes plus ou moins rapprochées ou obtuses, formant un sillon peu profond ct étroit entre les carènes, environ 11 nervures, délicatement et lâchement tessellées; glumellules lancéolées-acuminées longues de $6^{1 / 2}-7 \mathrm{~m}$. m., mincement menbraneuses, finement ciliées aux bords à pubescence très claire au dos, à nervures longitudinales nombreuses à la base; étamines à filets quatre fois aussi longs que l'anthère; pistil long d'environ 2 cent. ; styles connés, glabres, à base très épaisse, brusquement atténués en haut; stigmates beaucoup plus longs que les styles, lâchement plumeux; caryopse inconnu.

Var. heterocycla. T. Makino in Bot. Mag. Tokyo XIII 1899, p. 267 ; XIV p. 04 et in 1. c. Paris 1900 , p. 39.

Chaume plus petit que dans le type; mais pouvant atteindre $0.45 \mathrm{~m}$. de tour, les nœuds inférieurs sont alternativement obliques d'une manière très particulière et les mérithalles 
sont très raccourcis et ordinairement plus ou moins renflés. Le reste comme le type, mais les fleurs en sont encore inconnues.

Bambusa heterocycla Carr. in Rev. Hortic. 1878, p. 354; Bean in Gard. Chron. 3e Ser. XV, p. 368; Phyl. heterocycla Fr. Mitford, Bamb. Gard. p. 160, cum icon.; E. Satow in Trans. Asiat. Soc. Jap. XXVII 3 p. 59, Phyl, pubescens var, heterocycla H. de L. Le Bambou, p. 39 (1906).

Nom Jap.: Kikko-chiku.

Ce Phyllostachys au port majestueux est remarquable entre tous les bambous de sa région par la ressemblance de ses tiges avec d'immenses plumes d'autruche. La disposition régulière de la ramure dorée, du feuillage menu, mobile à la moindre brise, la courbe gracieuse, à peine visible, la grosseur des chaumes, le rapprochement des nœuds, les bagues blanches qui les soulignent, permettent de le reconnaître à première vue quand il a une fois attiré l'attention. Rien n'égale la grâce, la beauté, la force, l'utilité de cette plante. Elle sera un jour l'orgueil de tous les grands parcs dans la région où les étés sont chauds et où la température hivernale descend rarement au-dessous de $-10^{\circ}$ centigrades. Les jeunes turions, parfois énormes, cueillis au moment où ils sortent de terre, constituent un légume fort apprécié qui donne lieu à un très important commerce soit à l'état frais, soit à l'état sec. Les chaumes servent à faire divers ustensiles de ménage et surtout à préparer d'excellente pâte à papier.

Phyllostachys bambusoides Siebold et Zuccarini. Abhand. des Math. Phyl. Cl. der Koenige Bayerischen Acad. der Wis., Munich, Vol. III, p. 745 (1843); Munro, I. A Monograph of the Bambusaceae, Trans. of the Linnean Society, Vol. XXVII, p. 36 (1866), partim; Rivière, sub. Phyl. Quilioi. LesBambous et Bull. Soc. d'Acclimatation, pp. 241-45 (1878); tab. XLVIII, XLIX, L et LI.

Arborescens, 10-25 m., coespes longe repens, 1-3 cent. cressa, brevibus internodiis; culmus rectus, crasso-virens, uno latere sulcatus, raro usque $0 \mathrm{~m} .20$ crassus, ad bacim cylindricus vel subcompressus, aliquando parum crassior altius, merithallis longis, glaber, laevis, vernicosus, insolatione aliquando flavescens, ansula cerea infra nodum te zuis et decrescens; vagina papyracea, mirabile variabilis, in magnis culmis, maximá superne obscura, dorso laxe pilosa pilis fuscis $3-5 \mathrm{~m}$. m. primo adpressis, mox erectis, caducis; pseudophyllo papyraceo, primo erecto, citius decombente et convoluto, medio atro-viride, marginibus subroseis, auriculis saepissime carentibus; ligula laciniata, parva; squama bicarinata papyracea, bifida ad 1/3 vel $1 / 4$, lobis acutis, rufo-maculata, glabra vel carinis ciliata; rami effusi, cylindrici, canaliculati, fistulosi, micante virides; ramuli 1-2 m. m. crassi; folia 110-115 $\times 12-16 \mathrm{~m}$. m., arcuata; nervi secundarii 5-7 paria, nervuli $8-9$ inter secundarios, $30-37$ in $5 \mathrm{~m}$. $\mathrm{m}$.; tessellae $30-35$ in 5 m. m.; dentes 9-10. 
Inflorescentia spicis multispiculatis, lanceolatis, $40-60 \times 10-15 \mathrm{~m}$. m., bractea spici oris marginibus ciliata, limbo foliaceo amplo, ovato-lanceolato, cordato, $35 \times 20 \mathrm{~m}$. $\mathrm{m}$. minore in fasciculis superioribus, involvens 2-4 spicularum fasciculum; spicula 20-25 m. $\mathrm{m}$. 3-5 fl. fertiles, flosculo terminali tabescente magno; flos virescens vel rufescens 20-24 m. m longa; gluma una, saepe pseudophyllo parvo et atropho terminali 6-7 m. m., obliqux, carinata, carinis ciliata, subnervia, longior et obliquior in spiculis superioribus, aliquando deficiens in terminabilus; valva ovato-acuminata $15-17 \times 5-7 \mathrm{~m}$. m.; nervis secundariis 5-6 paria; palea valvam aequans, puberulo-scabra, carinis ciliata; glumellulae ovato-lanceolatae, emarginatae vel bifidae, ciliatae, 3-7 nerviae; stamina filamentis $30-40 \mathrm{~m}$. m.; ovarium stipitatum ovoideum; styli 25-30 m. m., connati; stigmata laxe plumosa; caryopsis ignota.

China media. Nom vern. japonais: Ma-dake.

Phyllostachys bambusoides $\mathrm{S}$. et $\mathrm{Z}$. Plante arborescente de 10 à 25 mètres de hauteur, souche longuement traçante de 1 à 3 centimètres de diamètre, à entrencuds courts, turion fort, noir mat ; chaume érigé, vert brillant, sillonné d'un seul côté, atteignant rarement $0 \mathrm{~m} .20$ de diamètre, parfois un peu plus gros à quelques mètres de hauteur qu'à la base, à mérithalles longs, glabre, poli, brillant, jaunissant parfois au soleil, anneau cireux sous le nœud, mince et disparaissant avec l'âge; gaîne papiracée extrêmement variable: chez les plus grands chaumes foncée surtout en haut, lâchement couverte au dos de poils noirs de 3-5 m. m. d'abord apprimés, bientôt érigés, caducs; pseudophylle papiracé, d'abord dressé, bientôt décombant et contourné, à bande médiane vert foncé, à bords vieux-rose; auricules souvent manquantes; ligule laciniée petite; écaille bicarénée papiracée, bifide sur $1 / 3$ ou $1 / 4$ de sa hauteur, à lobes aigus, maculée de brun, glabre, ciliée sur les carènes; branches éparses, cylindriques, canaliculées, vert-brillant; rameau de 1 à $2 \mathrm{~m}$. m. de diamètre; feuille en moyenne de 110-115 $\times 12-16 \mathrm{~m}$. m. gondolée; nervures secondaires 5-7 paires, tertiaires 8-9 entre les secondaires, 30-37 par $5 \mathrm{~m}$. m., tesselles $30-35 \mathrm{au} 1 / 2$ cent; dents $9-10$ au $1 / 2$ cent.

Inflorescence. Epis composé d'épilets multiples, lancéolés, de 40-60×10-15 m. m.; bractée de l'épi ciliée aux côtés de la bouche, à limbe foliacé grand, ovale-lancéolé, cordé de $35 \times 20 \mathrm{~m}$. m. plus petit dans les fascicules supérieurs de l'épi; épilet de 20 à $25 \mathrm{~m}$. $\mathrm{m}$. de longueur, à 3-5 fleurs fertiles, fleur terminale imparfaite grande; fleur verdâtre ou brunâtre de 20 à $24 \mathrm{~m}$. m. de long; glume une seule, souvent terminée par un pseudophylle petit et atrophié de 6-7 m. m. de long, oblique, carénée, à carènes ciliées, subnervée, plus longue et oblique dans les épilets supérieurs, manquant parfois dans les terminaux; valva ovale-acuminée, 15-17 $\times 5-7 \mathrm{~m}$. m., nervures secondaires 5-6 paires; palea égale à valva, scabre pubescente, ciliée sur les carènes; glumellules ovale-lancéolées, émarginées ou bifides, ciliées, 3-7 nervées; étamines à filament long de $30-40 \mathrm{~m}$. m.; ovaire stipité, ovoïde; styles 25-30 m. m., connés; stigmates lâchement plumeux; caryopse inconnu. Chine moyenne.

\section{L'espèce a des variétés dont quelques-unes nous sont connues:}

I. Phyl. bambusoides var. Castilloni Marliac, diffère du type par une taille moitié moins haute, turion strié de jaune et de vert, chaume jaune vif strié irrégulièrement de vert dans sa partie non canaliculée, partout ailleurs le sillon est vert et le reste du chaume est jaune brillant; sur les rameaux feuillés, on rtrouve la même disposition des couleurs que 
sur la partie du chaume dépourvue de sillon, mais les stries vertes sont rares; feuille un peu panachée de jaune pâle, moins gondolée que chez le type, et souvent en gouttière. N. V. J. : Kimmei-Chiku.

II. Phyl. bambusoides var. Castilloni inversa. Cette variété diffère de la précédente en ce que le vert $y$ domine sur le bois et n'est jamais la couleur du sillon : celui-ci est toujours jaune. La feuille n'est pas plus panachée que chez le No 1.

III. Phyl. bambusoides var. Castilloni holocrysa Pfitzer. Même taille que le No I, turion jaunâtre strié de verdâtre, chaume jaune vif lavé d'oranger ou d'oranger rougeâtre, surtout du côté exposé au soleil; feuille un peu panachée de jaune ou de rose.

IV. Phyl. bambusoides var. Marliacea (fide Kew). Hauteur 10 à 12 mètres. Nous regardons jusqu'à nouvel ordre cette plante comme une variété du Ma-dake. En examinant le turion on approuve entièrement la manière de voir admise à Kew, quoique les gaînes portent des oreillettes souvent très développées. En examinant le reste de la plante, on est au contraire tenté de rejeter cette opinion. Phyl. Marliacea diffère du Ma-dake par ses chaumes très coniques à la base, cannelés sur tout le pourtour, par ses branches très grosses, souvent solitaires au nœud, très longues; par l'abondance extraordinaire de son feuillage presque pleureur, par ses rameaux plus minces que chez le type. Il en diffère aussi par son mode de défoliaison, par l'époque de sortie de ses turions, et par sa moindre résistance au froid. Chez le Ma-dake comme chez tous les autres Phyllostachys, les feuilles tombent isolément, puis la portion caduque du rameau se détache, portant encore les gaînettes, mais déjà dépouillée de toutes ses feuilles. Chez la plante qui nous occupe, au contraire, la portion caduque du rameau meurt, reste quelque temps adhérente, puis enfin se détache encore chargée de ses feuilles fortement adhérentes. Les jeunes chaumes se montrent en juillet-août seulement, c'est-à-dire un mois au moins plus tard que ceux de Ma-dake. C'est l'une des causes de son défaut de résistance à la gelée: son bois n'est pas bien aoûté. Inflorescence inconnue. N. V. J.: Shibo-Chiku. Tab. L.

Le Phyl. bambusoides, Ma-dake, est l'une des plantes à bois les plus utiles au Japon et en Chine. Les chaumes en sont extrêmement réguliers et droits et le bois, d'excellente qualité se prête à de multiples usages. D'une croissance rapide, il est tout indiqué pour la production de la pâte à papier dans les climats à été chaud, dont les hivers ont rarement des minima de $-15^{\circ}$ centigrades.

\section{CONCLUSION}

Après 28 années d'étude assidue des bambusées, nous avons acquis la conviction qu'il est nécessaire, dans la description de ces plantes, de se conformer strictement aux règles énoncées précédemment. Une plus grande expérience pourra les modifier dans la suite; mais nous estimons qu'il y aurait péril à les restreindre, dans l'état de nos connaissances.

Ermitage, Mons (Belgique) Novembre 1911. 


\section{Explication des planches.}

\section{PLANCHE XLVIII}

- Phyllostachys bambusoides, Sieb. et Zucc.

1) Chaume dans sa partie moyenne dépourvue de branches, montrant le profil du nœud; le mérithalle est plus court que la moyenne. - en bas: coupe du même. Grandeur naturelle.

2) Chaume dans sa partie supérieure branchue, montrant le profil du nœud, le mode d'insertion des branches; l'écaille bicarénée translucide. Comme c'est sa face ventrale qui est figurée, nous n'avons pu montrer ni les carènes, ni les poils qu'elles portent, ni les taches brunes dont elle est souvent parsemée. En bas, coupe du chaume montrant les sillons. Grandeur naturelle.

3) Turion de moyenne grosseur, peu de jours après sa sortie de terre. Les gaînes d'un turion de cette grosseur sont déjà très densément maculées dans leur partie supérieure (1); mais il est rare qu'elles portent des poils au dos; les pseudophylles sont courbés ou révolutés; quand le turion est beaucoup plus fort, les pseudophylles sont, le plus souvent, décombants et presque droits. Le turion est parfaitement régulier et lisse, ogival à cette taille, plus il s'élève et plus il devient aigu au sommet. - Grandeur naturelle.

4) Gaîne de grandeur plutôt au-dessous de la moyenne, montrant la disposition des macules, leur forme et les poils dorsaux. La gaîne peut atteindre $0 \mathrm{~m} .60 \mathrm{au}$ moins de hauteur. Le pseudophylle est déjà bien développé sur une gaîne de cette taille, et la ligule bien visible et, fait rare, il y a un poil tenant lieu d'auricule à gauche de la bouche. -- Grandeur naturelle.

Tous les matériaux ayant servi de modèles pour dessiner cette planche ont été recueillis en plein air en Europe.

\section{PLANCHE XLIX}

Phyllostachys bambusoides, Sieb. et Zucc.

1) Branche portant quelques rameaux feuillés, montrant la disposition des poils auriculaires à la bouche des gaînettes. Ces poils sont assez caducs et tombent généra. lement au cours de l'automne et de l'hiver; un rameau examiné au printemps a donc perdu ce caractère. On remarquera le profil caractéristique du nœud. Nous n'avons pas pu représenter le gondelage caractéristique des feuilles pour ne pas charger le dessin. Grandeur naturelle.

(1) Plus le turion est petit, moins les gaînes sont maculées et moins les macules sont foncées. 
2) Nervation secondaire, tertiaire, tessellation et dentelure du bord externe. 4 diamètres.

3) Détails du sommet de la gaînette, montrant l'insertion de la feuille, les poils auriculaires caducs et la ligule pubérulente. - 10 diamètres.

Tous matériaux recueillis en plein air en Europe.

\section{PLANCHE L}

Phyllostachys bambusoides, var.? Marliacea.

1) Une branche montrant l'abondance de feuillage qui est l'une des caractéristiques de cette plante considérée - fide Kew - comme une variété; montrant aussi les cannelures de la branche. Ce caractère est encore plus apparent sur le chaume. On remarquera que la branche est représentée comme solitaire au noud. Ce caractère est presque aussi fréquent que la présence de deux branches à chaque nœud. - Réduit de $1 / 4$.

Matériaux récoltés, en serre, à l'Ermitage.

\section{PLANCHE LI}

Phyllostachys bambusoides, Sieb. et Zucc.

1) Rameaux fleuris. Tout le feuillage est déjà tombé. Nous avons supprimé presque toutes les étamines et les stigmates qui auraient chargé inutilement le dessin. Les deux épis de gauche - séparés - font partie de l'échantillon authentique de Siebold - herbier de Leyde -; les sept autres font partie de l'échantillon recueilli par T. Makino. appartenant au Dr C. Schröter, qui a eu l'obligeance de nous les communiquer. - Grandeur naturelle.

2) Un épi de l'échantillon de Makino, en double grandeur, montrant les bractées et leur limbe relativement très développés, engaînant chacune un groupe d'épilets.

3) Coupe schématique d'une fleur. - 10 diamètres.

4) Ovaire stipité surmonté des longs styles connés, brusquement amincis, et des stigmates plumeux, à gauche de l'ovaire une étamine, derrière l'ovaire une glumellule. 8 diamètres.

Les figures 3 et 4 sont données d'après la planche de Siebold dans les Abhandlungen, 1. $c$.

Nous n'avons pas osé demander l'autorisation de briser un épi (ils sont trop rares dans les herbiers); il en résulte qu'il manque à notre planche la représentation de pièces que nous considérons comme indispensables, telles que la glumelle bicarénée, qui est trop peu distinctement figurée par Siebold pour la reproduire ici. Il semble qu'elle soit profondément bifide, mais nous n'avons pu faire aucune vérification à ce sujet.

Tous les éléments de cette planche ont été recueillis au Japon en 1843 et 1900. 


\title{
PLANCHE LII
}

\author{
Phyllostachys puberula, (Miquel) Makino.
}

1) Jeune turion quelques jours après sa sortie de terre, montrant la disposition des pseudophylles flabelliformes et des oreillettes qui en accompagnent la base. Nous n'avons pas pu faire figurer la fine pubescence blanchâtre, nil'abondante pruinosité qui recouvrent le dos des gaînes. Turion de grosseur moyenne. - Grandeur naturelle.

2) Gaîne de grandeur au-dessous de la moyenne, montrant à la base l'abondante pubescence rousse; sur toute l'étendue les grands poils noirs caducs; en haut la fine pubescence qui aurait dû être figurée sur presque toute l'étendue. Pour représenter au sommet les détails de la bouche, nous avons dû abaisser le pseudophylle. Celui-ci ne se présente pas dans cette position: normalement il est dressé à l'état naturel, comme on le voit par le dessin d'ensemble du turion. La position adoptée permet de montrer la ligule un peu déchiquetée, à droite une oreillette complètement développée et, à gauche, les cils décurrents le long du bord de la gaîne. Tous ces organes existent normalement des deux côtés đe la bouche; nous en avons supprimé une partie pour la clarté du dessin. Ils n'existent que sur les turions vigoureux; plus le turion est faible et mince, moins il $y$ a de vestiture et d'appendices. - Grandeur naturelle.

3) Portion d'un chaume moyen prise vers la base, dans la partie dépourvue de branches, montrant la forme du nœud. En coupe, vers la base, le même figurant les deux sillons opposés souvent accusés même dans cette partie du chaume. Plus haut sur le chaume les mérithalles sont plus longs pour leur grosseur. - Grandeur naturelle.

4) Portion d'un chaume dans sa partie branchue, montrant la forme du nœud, l'insertion des branches, l'écaille bicarénée bifide, divisée en ses deux éléments. C'est la face ventrale qui est figurée, nous n'avons donc pas pu montrer les carènes ni la pubescence de cet organe. Cette figure montre aussi le sillon triple du côté où les branches sont insérées et simple du côté opposé; enfin on remarquera, en bas, la coupe précisant la forme et la valeur relative de ces deux sillons opposés, et la forme du canal médullaire. - Grandeur naturelle.

Tous les matériaux représentés ont été recueillis en plein air en Europe.

\section{PLANCHE LIII}

Phyllostachys puberula, (Miquel) Makino.

1) Feuillage sur chaume de l'année. - Grandeur naturelle.

2) Détails de l'insertion d'une feuille au sommet de la gânette, montrant la vestiture du pétiole, les poils auriculaires caducs et la ligule finement pubérulente. -8 Diamètres.

3) Nervation secondaire et tertiaire. -4 diamètres.

4) Nervation tertiaire, les tesselles et la dentelure du bord externe ('autre bord n'est pas dentelé). -8 diamètres.

Tous les matériaux représentés ont été recueillis en plein air en Belgique. 


\section{PLANCHE LIV}

Phyllostachys puberula, (Miquel) Makino.

1 et 2) Premières phases de la floraison accompagnées de feuilles. - Grandeur naturelle.

1) Début de la floraison sur un rameau du chaume de l'année.

2) Début de la floraison sur un rameau d'un vieux chaume.

3 et 4) Seconde période de floraison dépourvue de feuilles. - Grandeur naturelle.

3) La floraison de seconde année va commencer sur un chaume qui a fleuri l'année même de son développement (suppression de la plus grande partie des étamines pour la clarté du dessin).

4) La floraison de seconde année est commencée sur un chaume qui était âgé de 3 ans au moment où il a commencé à fleurir (suppression aussi d’une grande partie des étamines). On remarquera même ici l'abondance et la prépondérance des gaînettes surmontées d'un limbe réduit, dont chacune enveloppe la base d'un groupe d'épilets.

5) Un épilet complet comprenant, ce qui est fréquent, une seule glume, deux fleurs complètes, une fleur incomplète. -4 diamètres.

6) Coupe schématique d'une fleur. - 10 diamètres.

7) Glumelle externe. - 5 diamètres.

8) Glumelle interne. -5 diamètres.

9) Glumellules translucides, ovaire, styles et stigmates. - 5 diamètres.

10) Caryopse, dos, côté, ventre et coupe, montrant le scutellum gonflé déjà par la radicule, le sillon et le long bec dur et acéré formés par les styles durcis et desséchés. 4 diamètres.

Tous les matériaux figurés sur cette planche ont été recueillis en plein air en Belgique.

\section{PLANCHE LV}

Phyllostachys pubescens, H. de L.

1) Sommet d'un turion de moyenne grosseur, haut déjà de plusieurs mètres, il n'est déjà presque plus ogival, montrant les pseudophylles coriaces, robustes, un peu flabelliformes, dont la base est accompagnée d'oreillettes entièrement fimbriées, décurrentes sur les bords de la gaîne et d'une ligule laciniée jusqu'à la base. Le dos des gaînes, dont le haut seul est visible ici, est densément pubescent. Nous n'avons pas pu figurer les taches arrondies, confluentes, noirâtres qui se voient au travers de la pubescence rousse. - Grandeur naturelle.

2) Gaîne prise dans la partie moyenne du chaume, montrant la ligule fimbriée, nous avons supprimé les oreillettes qui la masquent en partie. Montrant aussi la vestiture du dos 
dense en haut et en bas, claire du côté externe (externe du dos, c'est-à-dire recouvrant l'autre quand la gaîne, qui fait plus que le tour du chaume, est enroulée. Il ne faut pas confondre les termes externe et interne par rapport à l'enroulement, soit pour les feuilles, soit pour les gaînes, avec les termes dorsal ou ventral pour ces organes); nulle sur près de 1 /4 de la largeur du dos, du côté interne (le côté interne du dos est donc celui qui est recouvert par le côté externe du dos quand la gaîne est enroulée sur le chaume). Le pseudophylle est figuré réfléchi; ce qui n’est pas une règle générale, il est parfois dressé au moment de la dessiccation et de la chute de la gaîne. Nous n'avons pas pu figurer les abondantes taches noires arrondies (saillantes à l'état sec) dont le dos de la gaîne est truité. La fréquence de ces taches sur les diverses parties du dos est en rapport avec l'abondance de la pubescence; elles ne sont souvent même pas absentes sur la marge interne où la pubescence manque. Plus la gaîne est petite et moins il y a de taches, moins aussi la pubescence est dense. $-1 / 3$ de grandeur naturelle.

3) Partie basale d'un chaume de grosseur moyenne, montrant l'amas de racines qui fixe ces puissants chaumes, les mérithalles raccourcis, la conicité du chaume, la forme des nœuds, l'anneau cireux blanc qui les souligne. Nous n'avons pas pu figurer la fine et serrée pubérulence composée de poils hyalins qui revêt entièrement les chaumes de moyenne grosseur, mais est assez souvent absente sur les chaumes très forts ou très faibles. $1 / 4$ de grandeur naturelle.

4) Portion de chaume dans la partie qui porte des branches, montrant la forme du ncud, l'insertion des branches, le double sillon du chaume et l'écaille bicarénée bifide qui est très grande et opaque dans presque toute son étendue. Nous avons dû figurer sa face ventrale, nous ne pouvons pas montrer les carènes pubescentes, ni la fine pubérulence fauve d'une grande partie du dos. On voit seulement la pubescence du bord des deux lobes aigus. - Grandeur naturelle.

Tous les matériaux de cette planche ont été recueillis en Europe.

\section{PLANCHE LVI}

Phyllostachys pubescens, H. de L.

1) Branche d'un chaume de trois ans chargée de feuilles (nous avons dû en supprimer une bonne partie, afin de ne pas encombrer le dessin), montrant chaque mérithalle arqué, tous les rameaux ascendants et le feuillage presque entièrement au-dessus de la partie ligneuse. - Grandeur naturelle. Échantillon recueilli en Belgique.

\section{PLANCHE LVII}

Phyllostachys pubescens, H. de L.

1) Branche fleurie, portant encore exceptionnellement, pendant la seconde année de floraison, quelques rameaux feuillés. On remarquera que chaque mérithalle des branches est arqué, la convexité en haut. Cette inflexion constante n'est pas causée par le poids, elle est spécifique et existe dès le développement de la branche. Celle-ci pousse très arquée (contrairement à ce qui se passe chezles autres espèces du genre), puis, au moment 
de la chute des gaînes, chaque noud se gonfle par en dessous, redressant la portion qui le suit; à la fin du développement, la branche pointe vers le ciel et a une direction générale presque droite, quoique composée d’une suite d'arcs de cercle essez accentués; puis, au cours du développement du feuillage, elle se place presque horizontalement sous l'influence du poids. Les branches de second, de troisième ordre, etc... se développent de la même façon. Puis les rameaux apparaissent; ceux-ci sont droits, pointent vers le haut et portent les feuilles érigées comme nous les montrons.

Lors de la floraison, le poids des épis infléchit toute la ramure dont toutes les extrémités deviennent décombantes et la masse des épis pend au-dessous des branches, prenant une position fort différente de celle du feuillage. Les épis de fleurs sont arqués. On remarquera les gaînettes, surmontées de limbes réduits, imbriquées, couvrant la base des groupes d'épilets dont les glumelles p'us ou moins redressées vers le haut dépassent les gaînettes; les étamines, très longues, et les styles pendent en masse sous les épis; nous en avons supprimé une grande partie, ainsi que les pistils pour la clarté du dessin. Grandeur naturelle.

2) Epi double grandeur provenant de la floraison de première année, recouvert à sa base des gaînettes qui ont porté des feuilles. Nous avons supprimé pistils et étamines pour montrer plus clairement la disposition des bractées qui enveloppent la base des groupes d'épilets dont les glumelles enroulées sont visibles, tendant à se redresser vers le haut. - Double grandeur.

3) Une bractée de l'épi composée d'une gaînette et d'un limbe réduit, montrant la nervation et la vestiture. - Double grandeur.

4) Portion de feuille, la nervation secondaire et tertiaire. - 4 diamètres.

5) Portion de feuille, la nervation tertiaire, les tesselles et la dentelure. -8 diamètres.

6) Détails du sommet de la gaînette et de l'insertion du pétiole. - 10 diamètres.

Les matériaux relatifs au feuillage ont été recueillis en plein air en Belgique; ceux qui ont servi à représenter les fleurs proviennent de l'herbier de Zurich et ont été récoltés à Tokio, en 1900, par T. Makino. Les détails internes de la fleur manquent pour la même raison que sur la planche représentant $\mathrm{Ph}$. bambusoides, $\mathrm{S}$. et $\mathrm{Z}$. 
6 



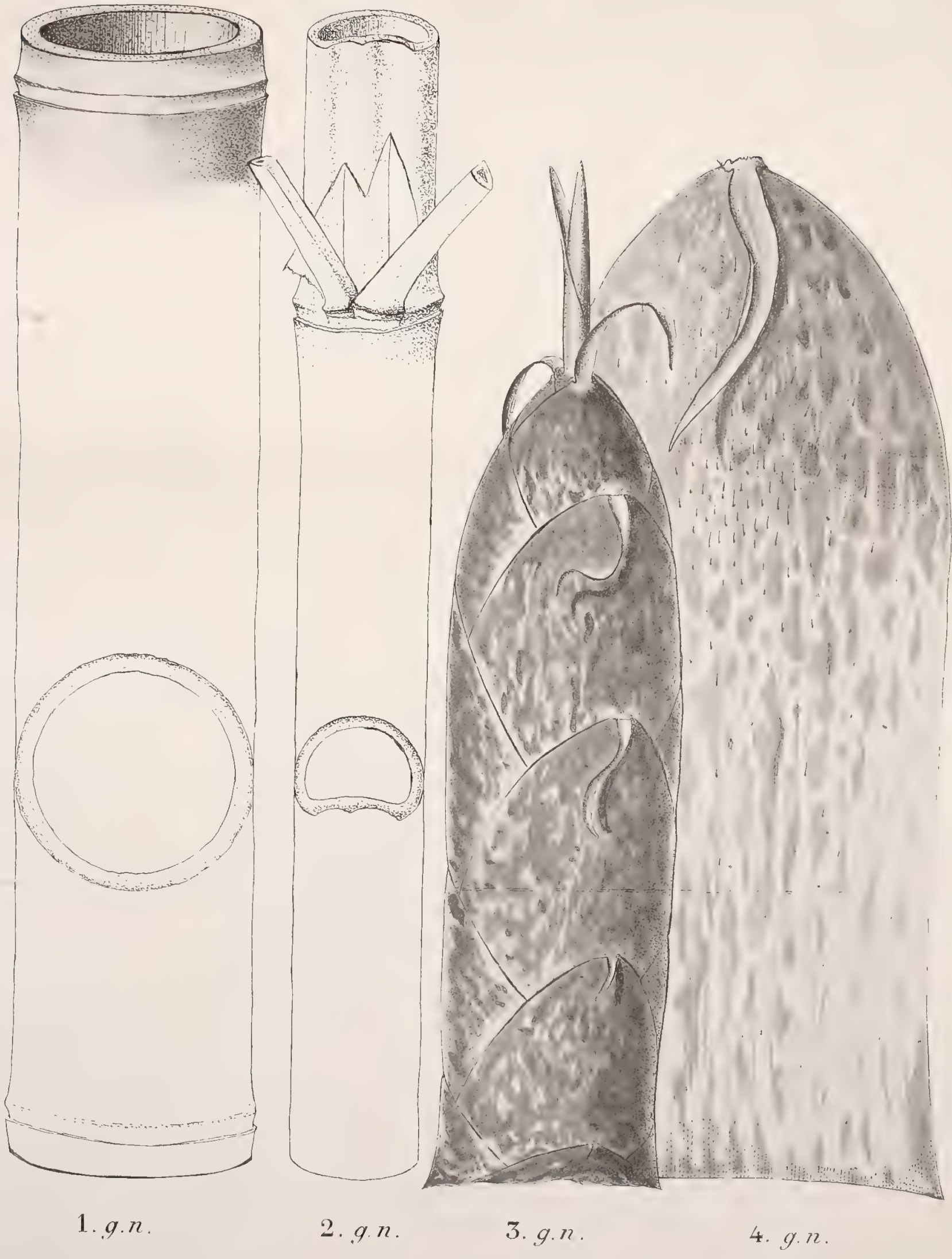






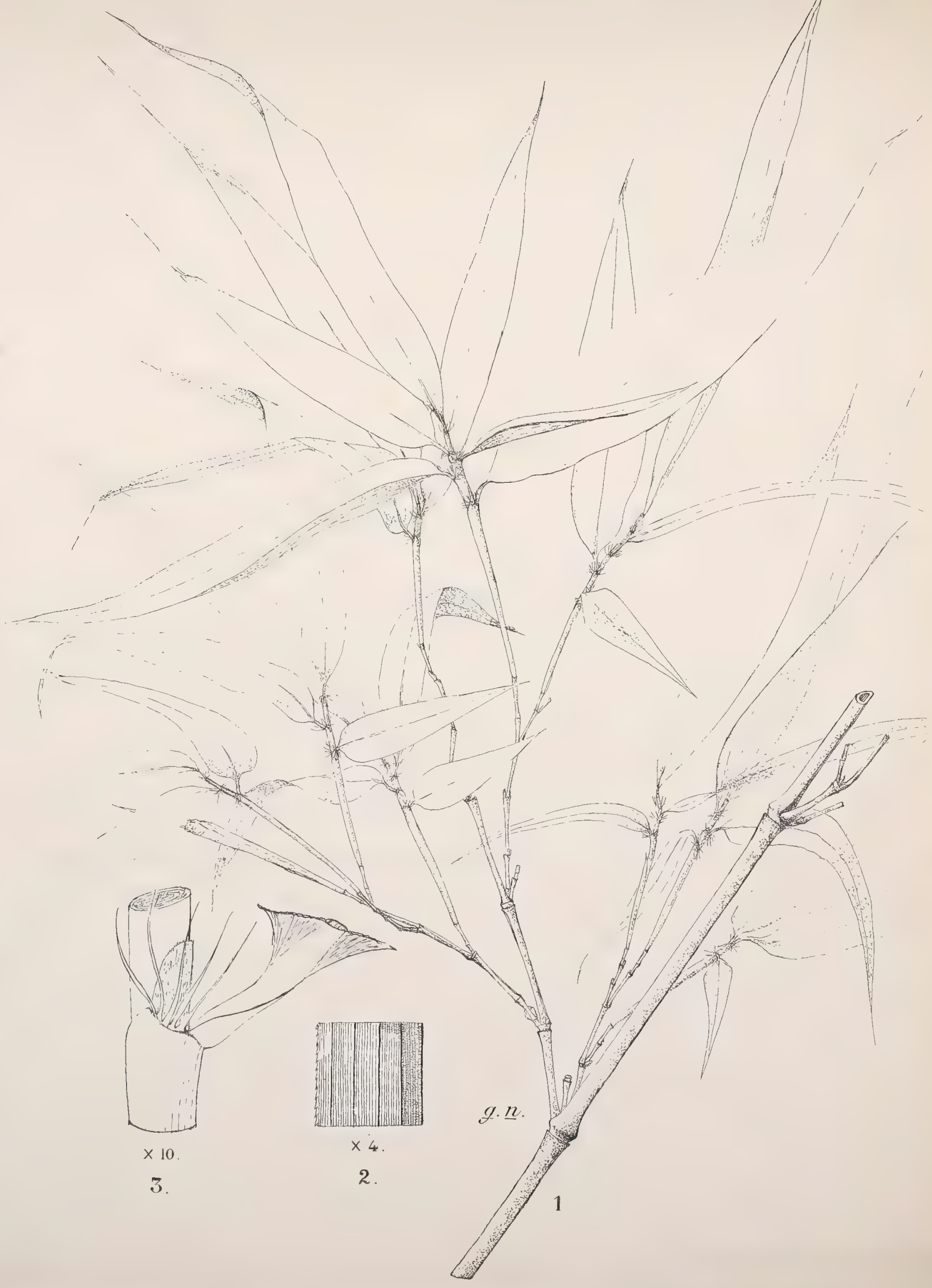





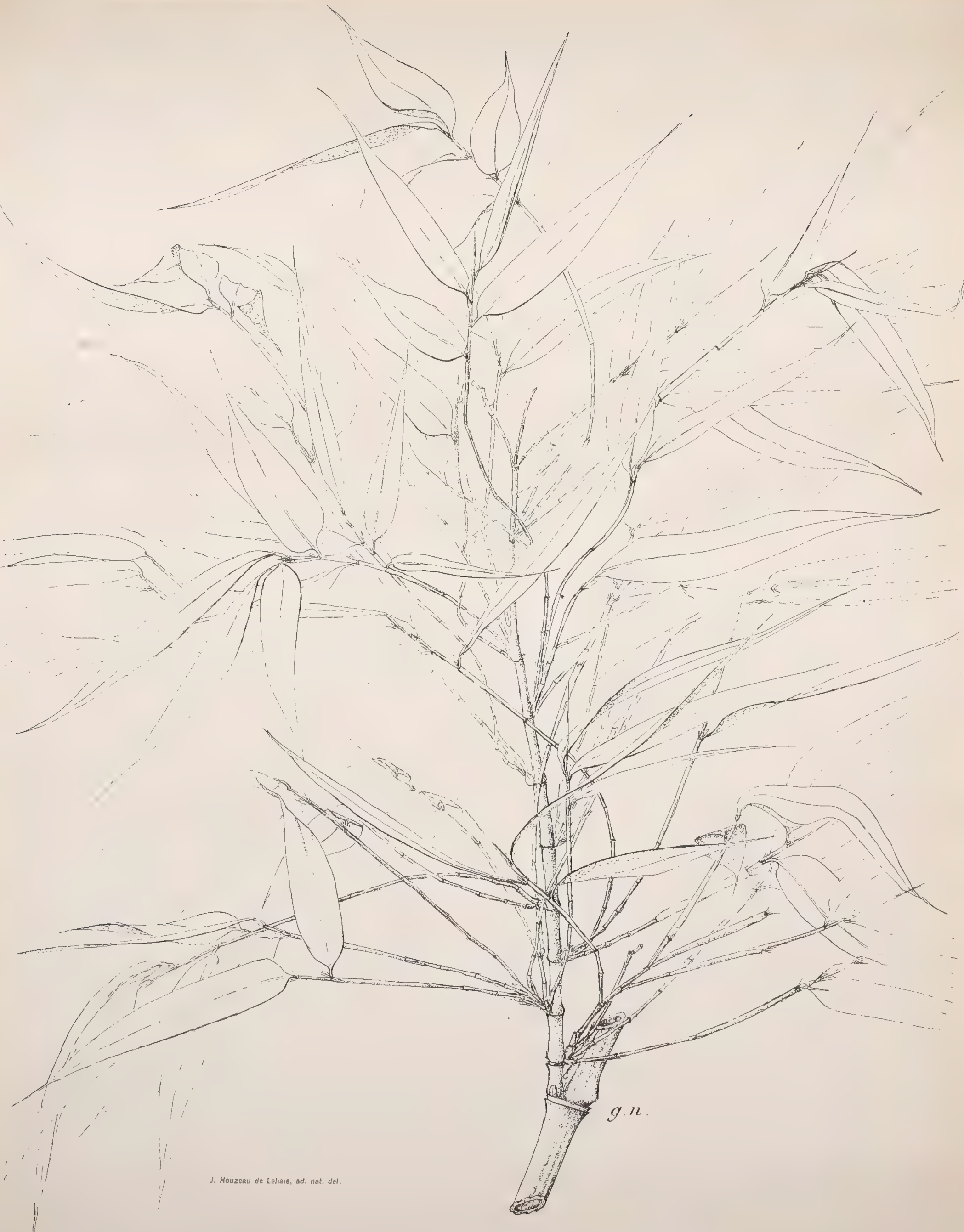

PHYLLOSTACHYS BAMBUSOIDES var. MARLIACEA, Hort, Kew, 


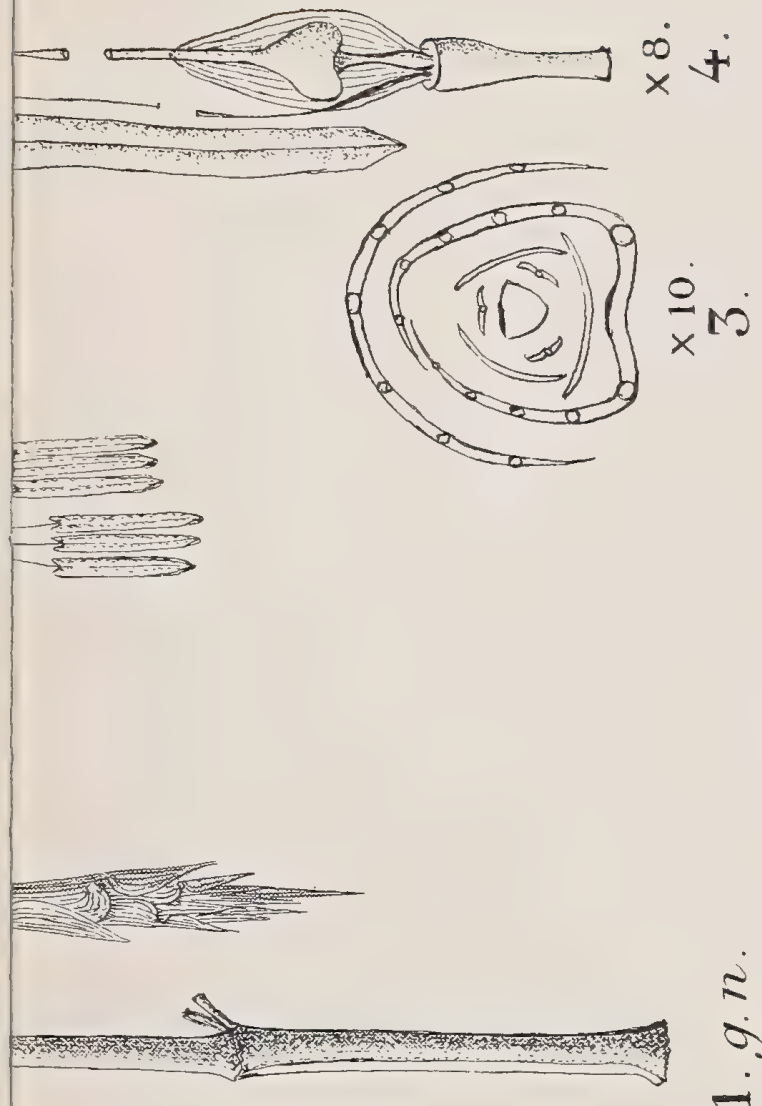

0

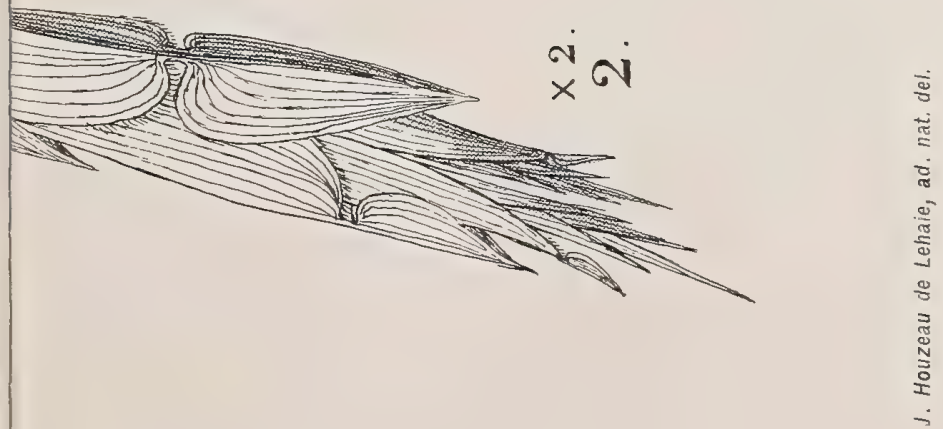





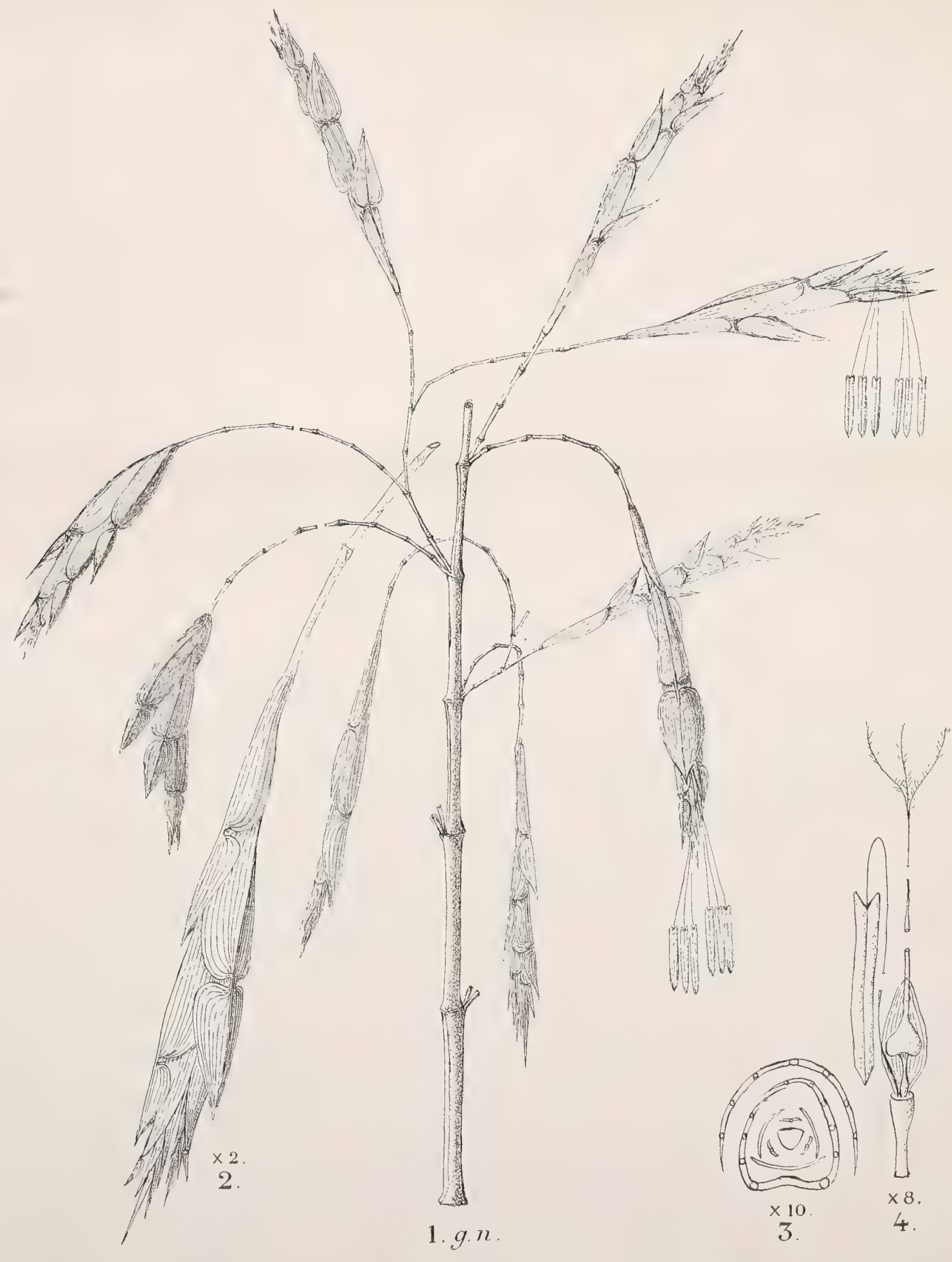





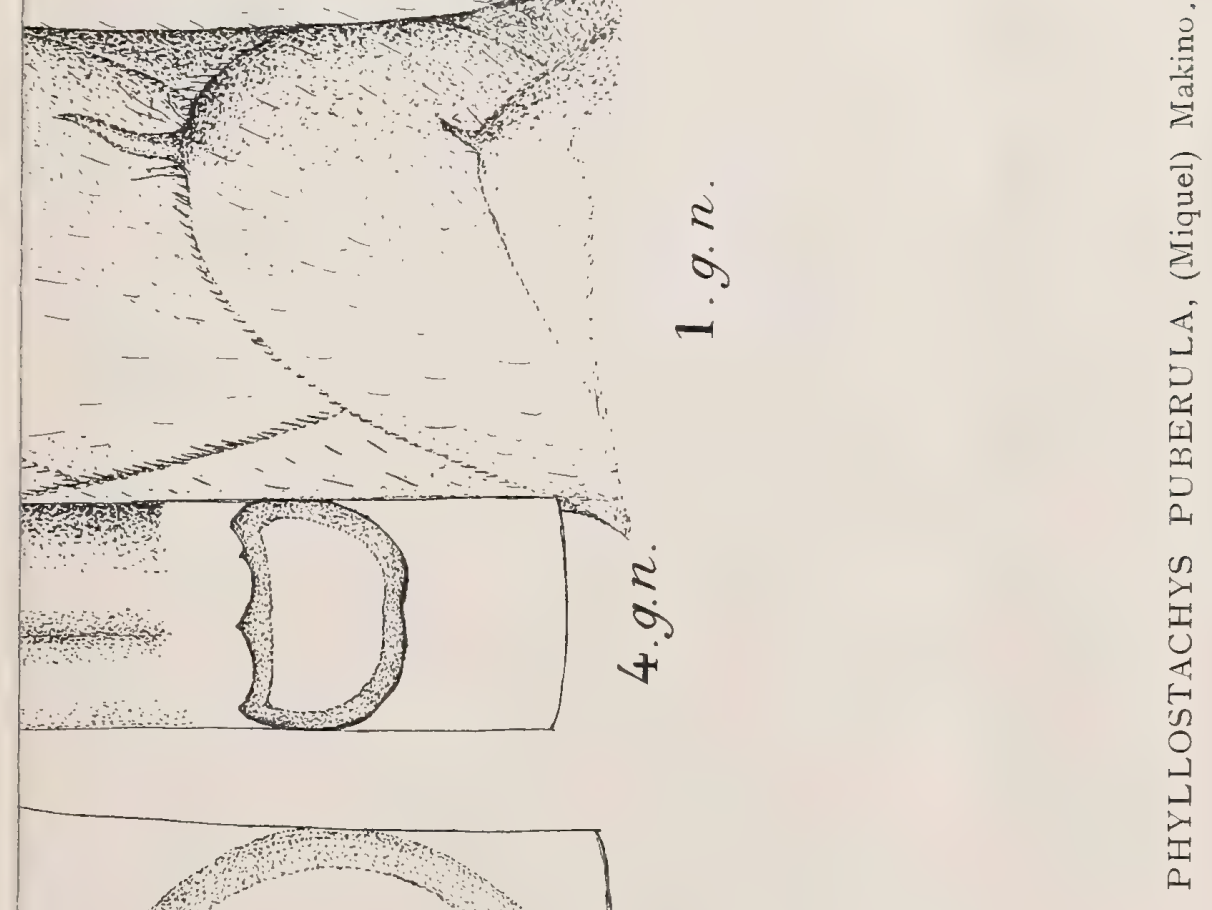





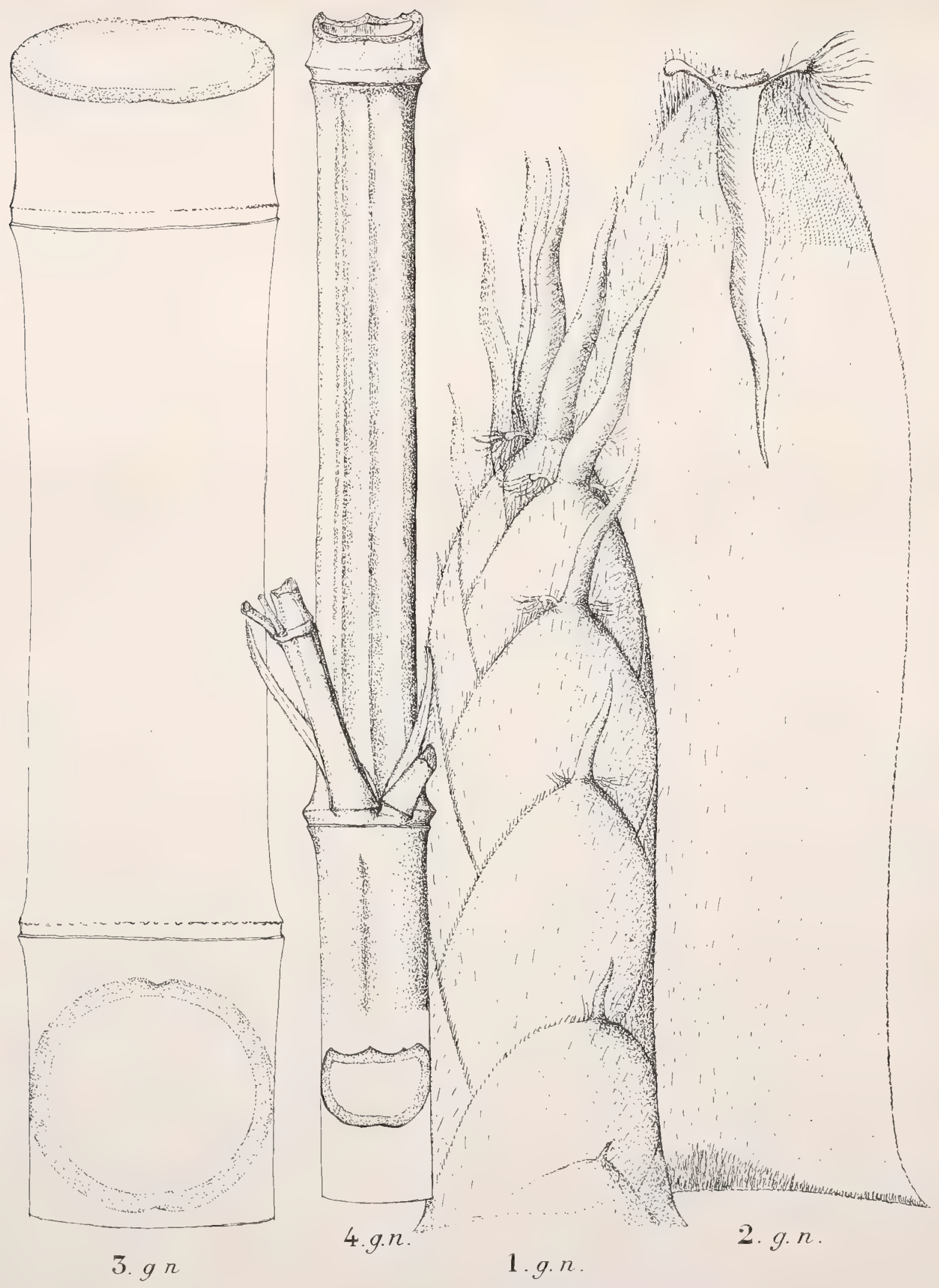




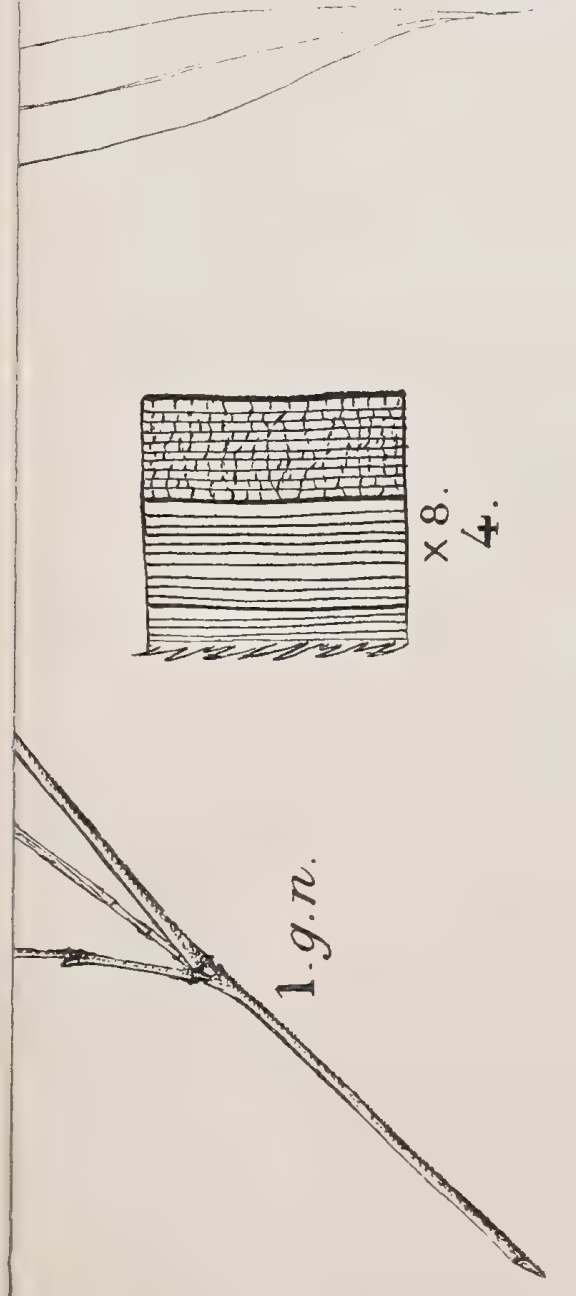



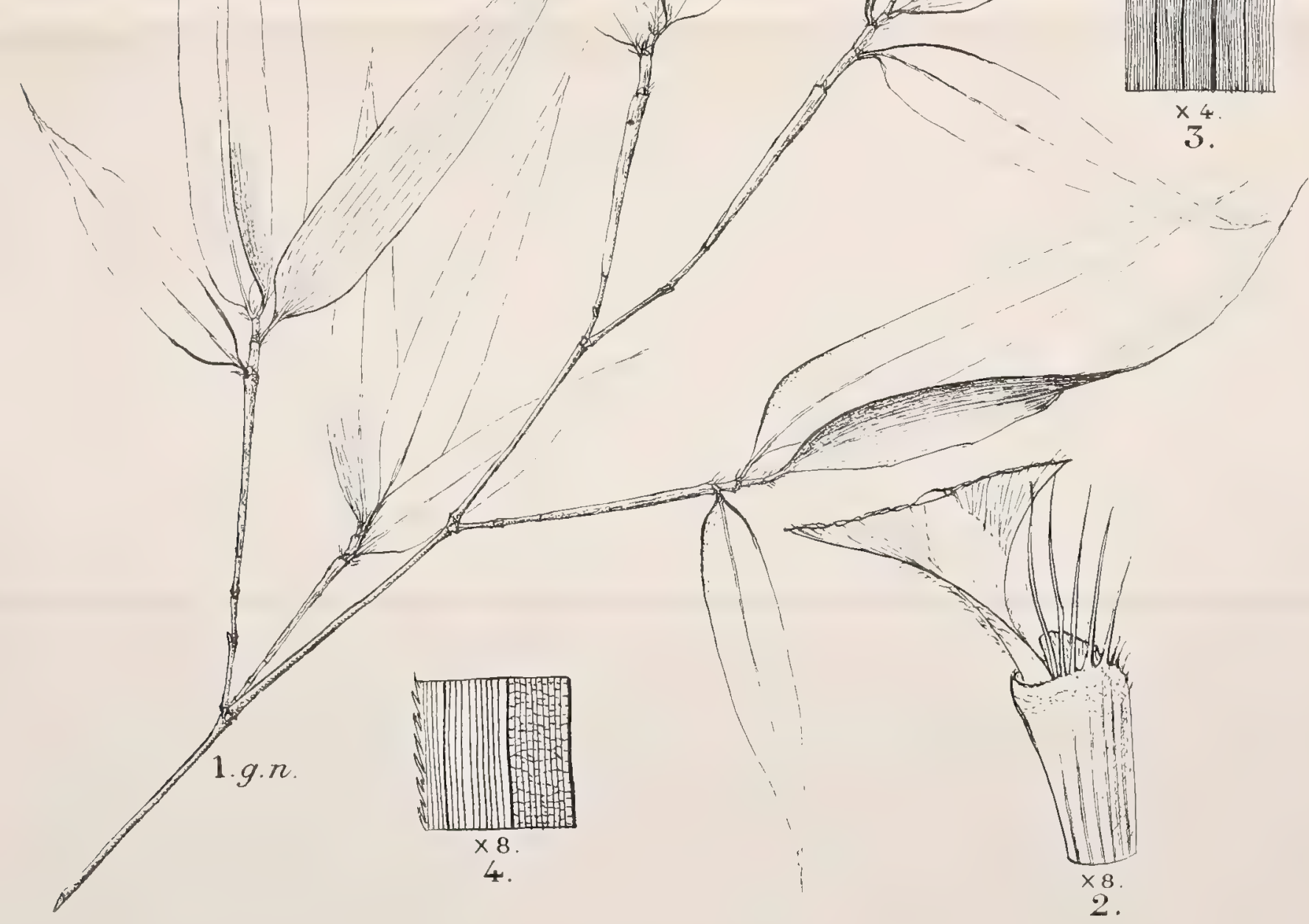




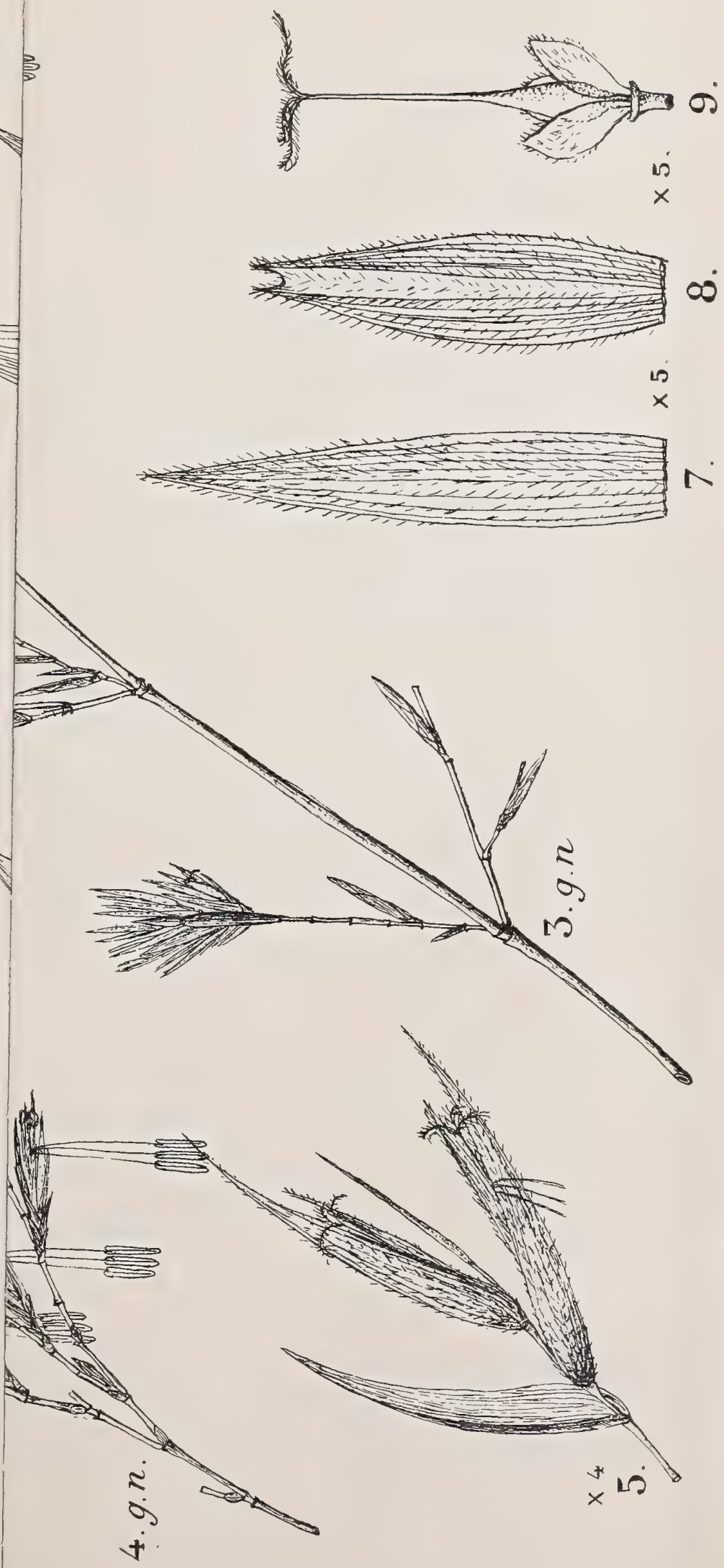



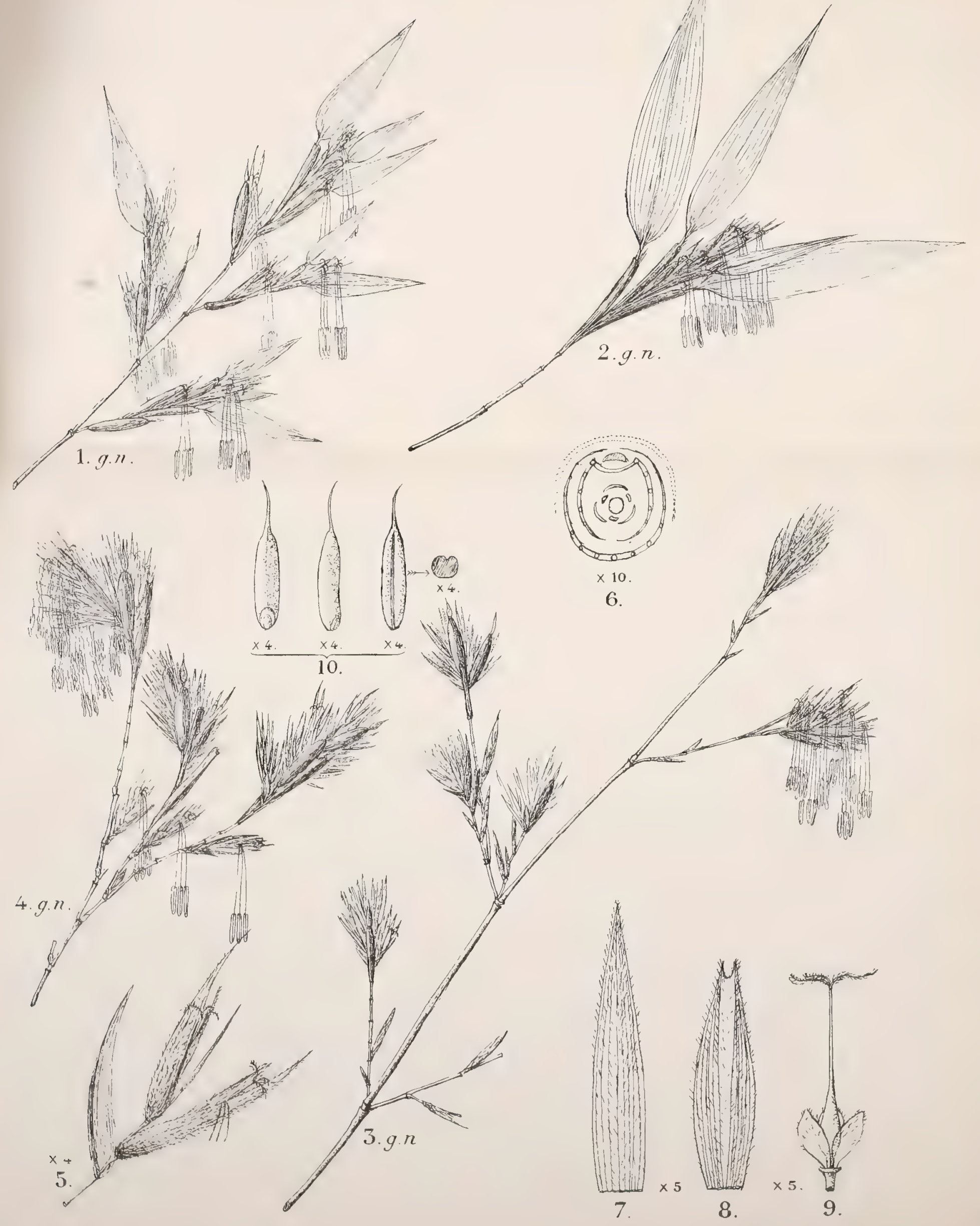





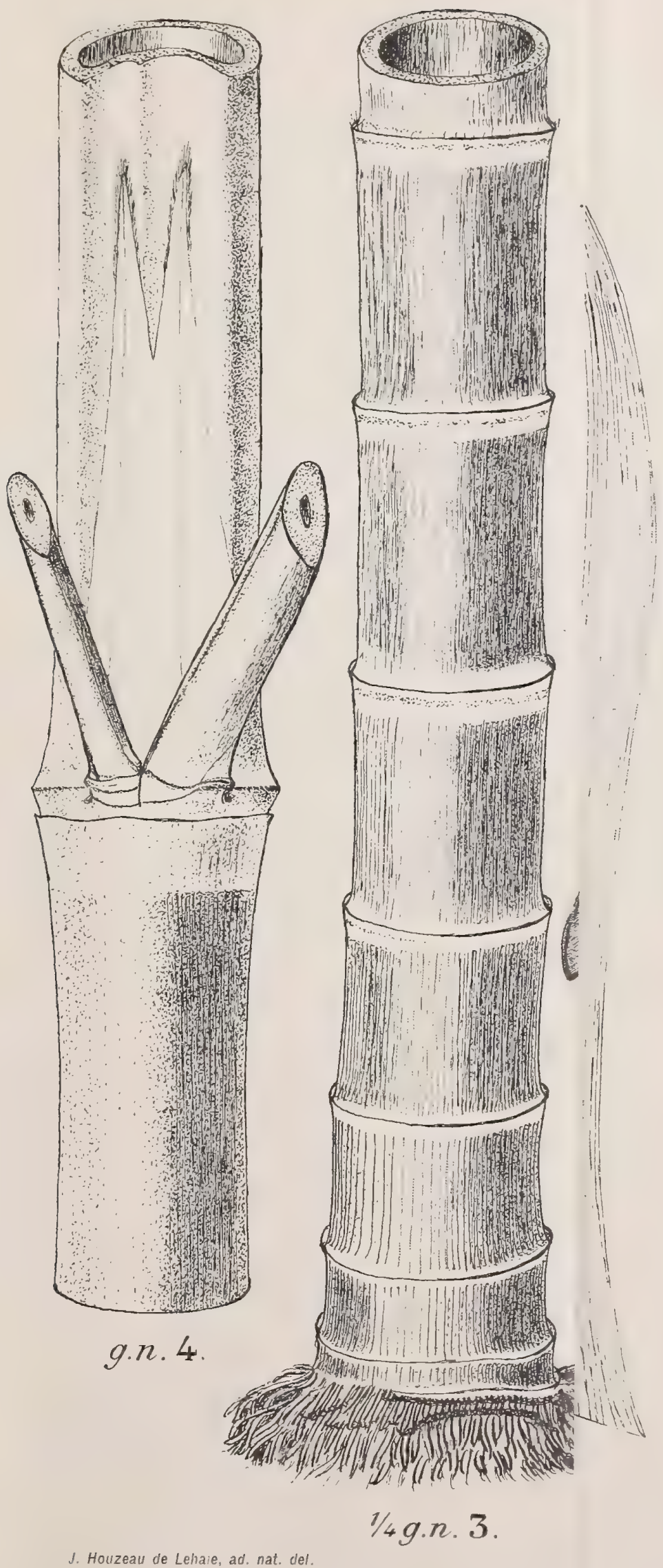





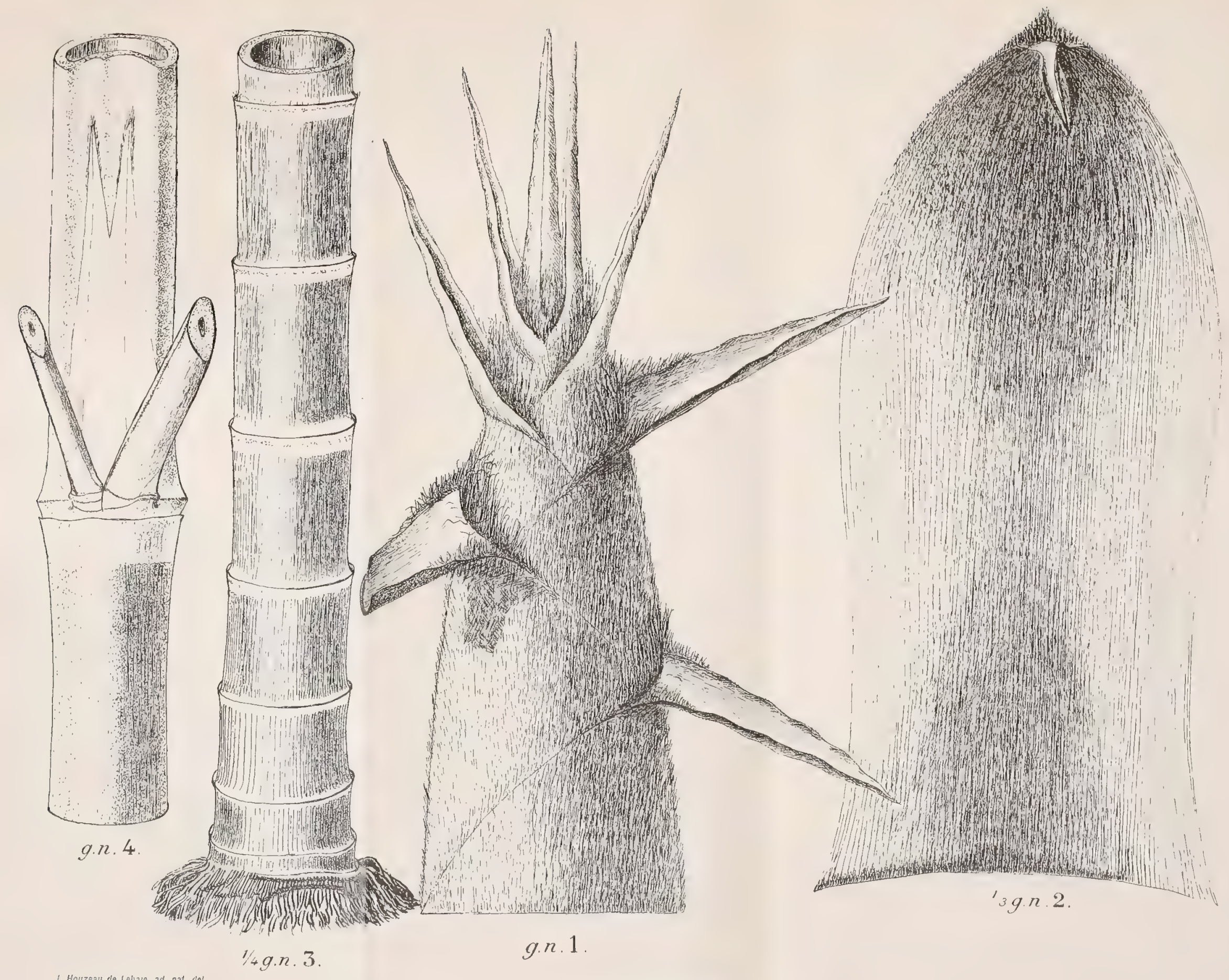

PHYLLOSTACHYS PUBESCENS, Houz. de Lehaie 



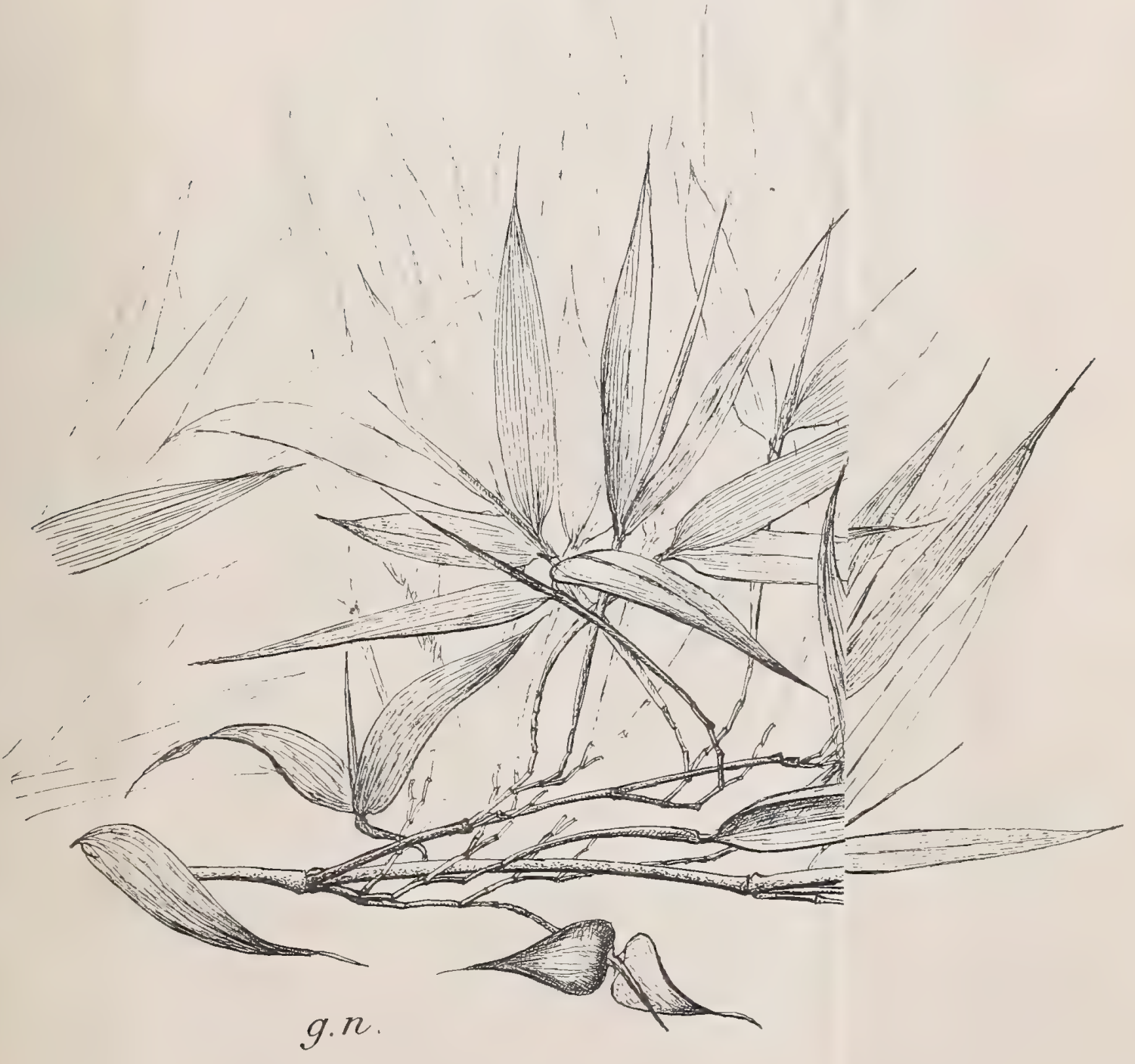

1. Houzeau de Lehaie, ad. nat. del. 



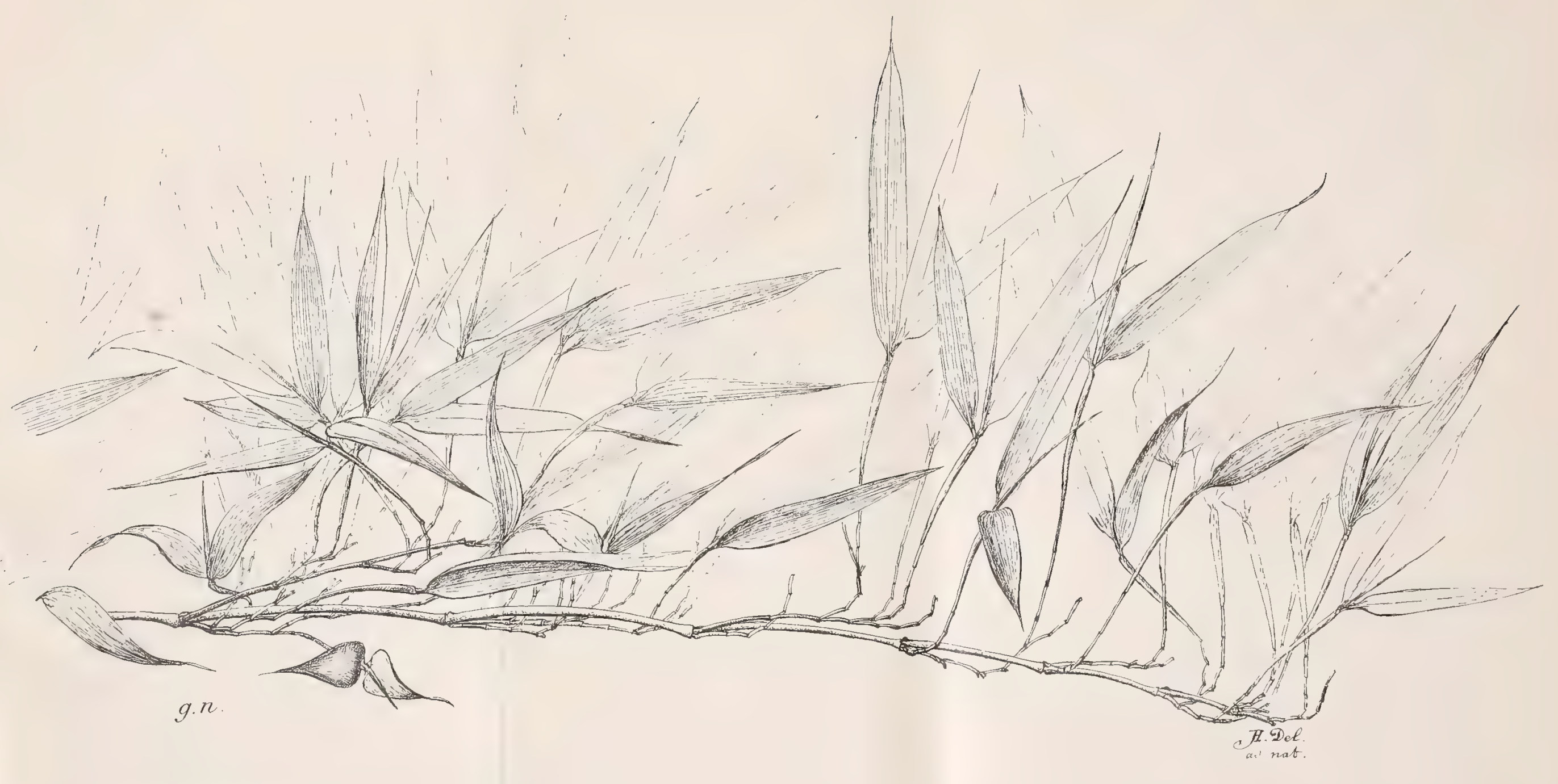




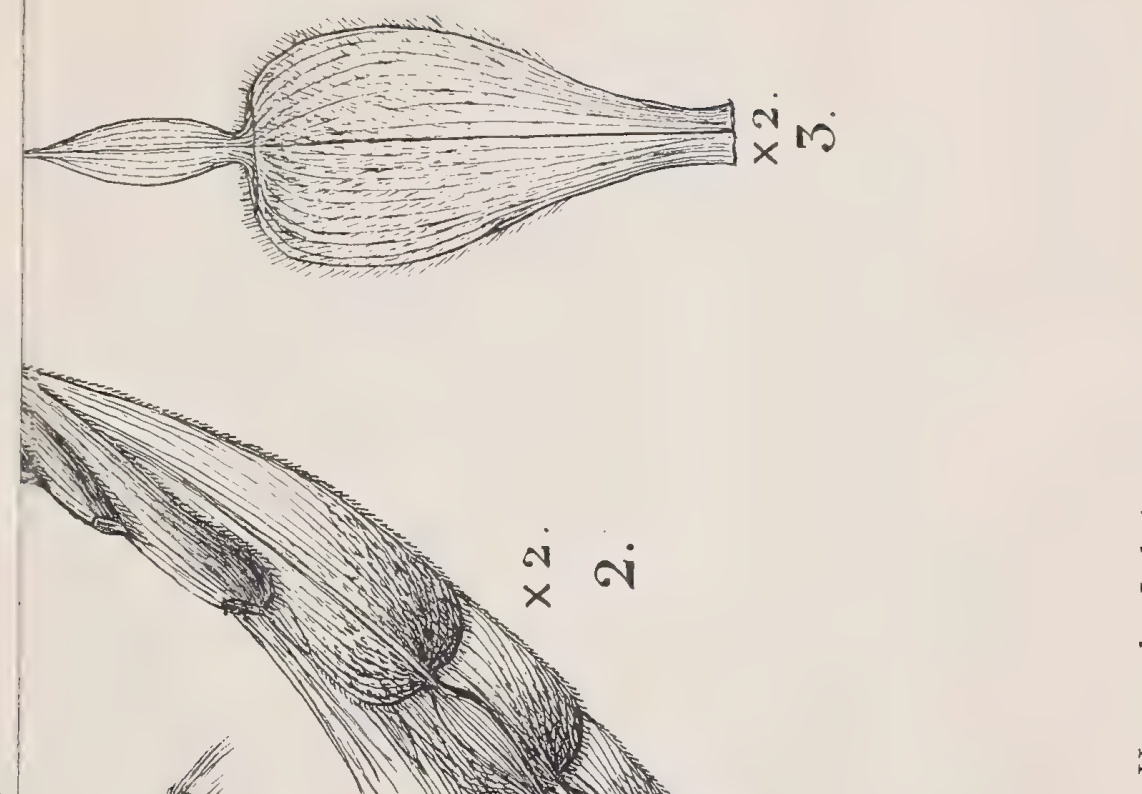

음

峁
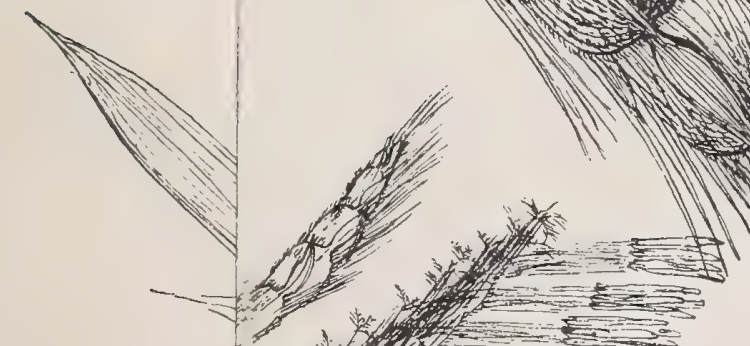

mowe

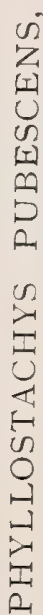





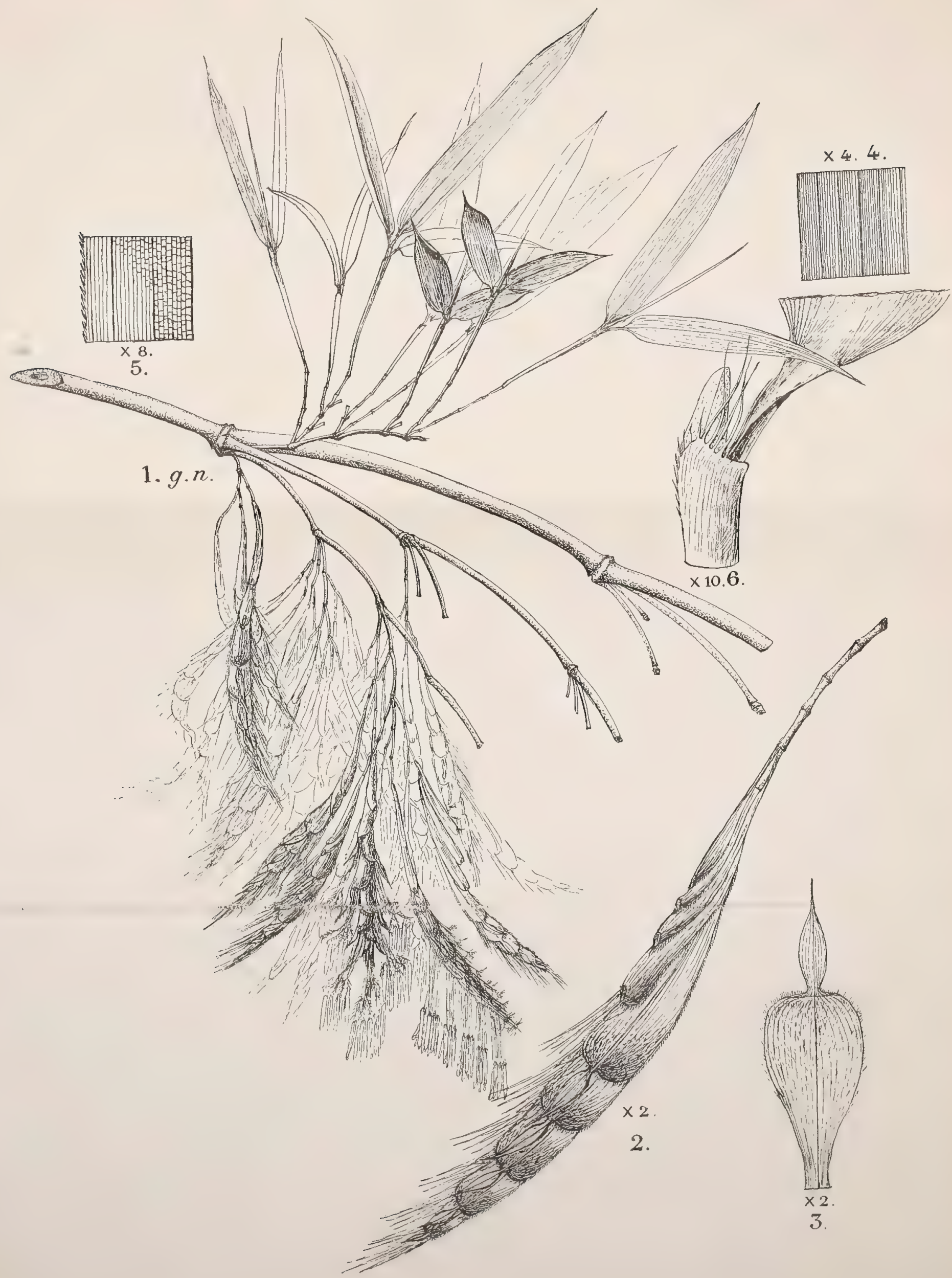





\section{Errata relatifs au travail de $M$. ULBRICH}

\section{Druckfehlerverzeichnis :}

S. 45 Zeile 2 und 3 von unten sind beim Umbruch vertauscht worden

»5 35 > 3 lies etwa statt etwas

\46 15 von unten lies andern statt audern

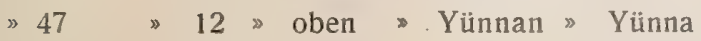

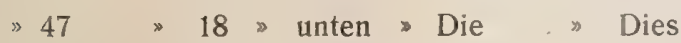

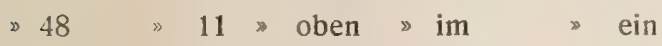

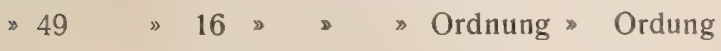

PI. IX im Kopf der Tabelle oben rechts lies den statt der

- IX lies Kaspische statt Karpische

„IX $»$ Kola Koler

- IX „ bei Pyrenäen im Aufdruck: $\begin{aligned} & \text { Europa } \\ & \text { Medit. }\end{aligned}$

》IX A $》$ bis statt dis

» IX A D Dsungarei statt Drungarei

"IX A " Burejagebirge statt Büreiagebirge

„IX A " Kirgisensteppe statt Kirgischsteppe

\IX A * Nordwestlicher statt Nordwestliches

" IX B " Ceylon statt Ceylan

"IX B " Bhuotan statt Bhuohan

"IX B " Aru statt Asu

" IX C $»$ bis statt zu

»IX C lies Centralafrikan. Seengebiet statt Centralafrika, Suezgebiet.

»IX C » C. Kongo statt Kongo.

" IX C " (exkl) statt (erkl.).

"IX D " im Aufdruck Arkt. N. Am. statt Art. N. Am.

» IX E unten lies : Lord Howe, statt Lord Hove.

„IX E unten lies: Samoa statt Sauroa.

»X Mitte lies Alëuten statt Aleuter.

"X " \# Arktisches statt Arktischer.

» $\mathrm{X}$ unten lies Blekinge statt Bleckinge.

\ » » Nördliches statt Nordlisches. 
X A oben lies Europäischen statt Europäisches.

X A » Nördl. Karpathen-Vorland statt Nördl. Karpathen-Vorland.

X A unten lies Griechenland statt Grieckenland.

X B unten D lies Makaronesisches statt Makaronesiches.

X $\mathrm{X} \gg \mathrm{E} \gg$ Unteritalien statt Untertialien.

》 X B Mitte lies Südgriecheniand statt Südgrieckenland.

X B unter F " Han-Hai statt Han-Zai.

"X E oben $»$ Karroo statt Karoo.

X E Mitte × Der statt Des.

X D bei Zentralafrikan. Seenzone lies im Aufdruck C. Afr. statt O. Afr

- X F unter G lies Chatham-Inseln statt Catham-Inseln.

X F $\gg G$. Lord-Howe, Kermadec-Inseln statt Lord Hove, Kermandec-I.

" X F " G $\gg$ im Aufdruck bei Philippinen. Phil. statt. Malesia.

» X G » A 》 Xerophyten-Gebiet statt Herophyten Gebiet.

" X G „ B » Santo Domiugo statt San Domingo.

Dahlem, im Juli 1911.

Dr E. ULBRICH. 



\section{EXTRAIT DU CATALOGUE}

DE WILDEMAN (É.), Docteur en sciences naturelles, Directeur du Jardin botanique de l'Etat, à Bruxelles, chargé de cours à l'Université de Gand.

\section{- Les plantes tropicales de grande culture.}

Tome I. - Caféier. - Cacaoyer. - Colatier. - Vanillier. - Bananier.

Un volume in-80 $(28 \times 19 \mathrm{~cm}$.) de 398 pages, illustré de 64 clichés photographiques dans le texte et 22 grandes planches hors texte, inprimé sur beau papier glacé . fr. 10.00

- Flore des Algues de Belgique.

Un volume in-8u de 528 pages, broché. . . . . . . . . . fr. 12.60 Memoire couronne par la Soclété royale de Botanique de Belgique (Prix Crepin).

- Catalogue de la Flore algologique de la Suisse.

Bruxelles (1895), un volume in-80, 180 pages, broché. . . . . . . . fr. 2.50

- Sciences biologiques et Colonisation.

Une brochure in-80 de 48 pages . . . . . . . . . . . . . fr. 2.00

DE WILDEMAN (É.), Directeur du Jardin botanique de Bruxelles, et DURAND (TH.), de l'Académie des Sciences de Belgique.

- Prodrome de la Flore belge.

Prix de l'ouvrage complet, broché en 3 tomes . : . $\therefore . \quad . \quad . \quad$ fr. 37.60

Tome 1 - Considérations générales. Thallophýtes. 544 pages.

Tome II. - Thallophytes (fin). Bryophytes et Ptéridophytes. 532 pages,

Tome III. - Phanérogames. III2 pages.

Oavrage couronné par la Soclété royale de Botanique de Belgique (Prix Crepin 1894-1897).

DURAND (TH.), de l'Académie royale des Sciences de Belgique, et DURAND (HÉLÈnE), membre de la Société royale de Botanique de Belgique.

- Sylloge Flore Congolance (Phanerognma).

Un volume in-80 de 732 pages. .................... 15.00 Oavrage comronné par l'Académie royale de Belgique (Prix Emíe Laurent).

Petit Atlas du Congo belge.

In-80 $(20 \times 14 \mathrm{~cm}$.) comportant 16 cartes en couleur et 26 cartes et diagrammos en noir, relié. . . . . . . . . . . . . . . . . . . . . fr. 2.50

BERTRAND (j.), Professeur de géographie.

- Le Congo belge. Initiation à la colonisation nationale.

Un volume in-80 $(23 \times 15 \mathrm{I} / 2 \mathrm{~cm}$.), de 160 pages, illustré de 71 vues photographiques et de 32 cartes, cartogrammes et diagrammes dans le texte, comportant deux cartes en couleurs hors texte, à l'échelle de I à 10,000,000 $(24 \times 27 \mathrm{~cm}$.) : PI. I. Le Congo physique - le relief, les rivières et le tapis végétal. - Pl. II. Le Congo politique, économique et administratif . . . . ........ fr. 2.60

Notre Colonie. Le Congo belge.

Un volume in- $4^{\circ}\left(25 \times 33 \mathrm{~cm}\right.$.), de $1_{4} 8$ pages, illustré de plus de 257 vues photographiques, couverture artistique en couleurs. ........ fr. 3.60 




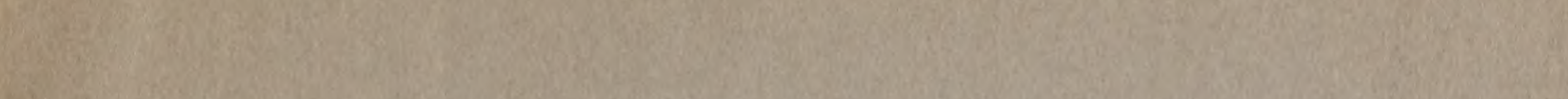


